\title{
Iteração de Transformações Racionais Aplicada ao \\ Método de Newton no Plano Complexo
}

\section{Elizabeth Wegner Karas}

\author{
DISSERTAÇÃO APRESENTADA \\ $\mathrm{AO}$ \\ INSTITUTO DE MATEMÁTICA E ESTATÍSTICA \\ DA \\ UNIVERSIDADE DE SÃO PAULO \\ PARA OBTENÇÃO DO GRAU DE \\ MESTRE EM \\ MATEMÁTICA APLICADA \\ Área de Concentração: Matemática Aplicada \\ Orientador: Prof. Dr. Edson de Faria
}

São Paulo, setembro de 1994. 


\section{Iteração de Transformações Racionais \\ Aplicada ao \\ Método de Newton no Plano Complexo}

Este exemplar corresponde à redação final da Dissertação devidamente corrigida e apresentada por Elizabeth Wegner Karas, e aprovada pela Comissão Julgadora.

São Paulo, 9 de setembro de 1994

Banca Examinadora

- Prof. Dr. Edson de Faria (orientador)

IME-USP

- Prof. Dr. Waldyr Muniz Oliva

IME-USP

- Prof. Dr. Marco Antônio Teixeira

IMECC-UNICAMP 
Ao Ronald,

meu pai. 


\section{Agradecimentos}

Agradeço a todos ( e são tantos!) que direta ou indiretamente contribuiram para a realização deste trabalho. Em especial, aos professores: Edson de Faria, que sempre se mostrou preocupado em transmitir uma visão mais ampla da Matemática, pela orientação nesta dissertação sem podar minhas iniciativas; Waldyr Muniz Oliva pela orientação de meu programa de Mestrado; Manuel Valentim de Pera Garcia pelas motivantes conversas e incentivo; Celso Penteado Serra, a quem devo a materialização deste trabalho, pela extraordinária colaboração e estímulo.

Registro, também, meu agradecimento ao IME-USP, onde foi desenvolvido este trabalho, pelo suporte técnico; à UFPR, especialmente ao Departamento de Matemática, pela licença concedida; à CAPES, pelo apoio financeiro, para a realização do curso de Mestrado.

Não posso deixar de exprimir que neste trabalho tem muito do Edilton, que tem me despertado para a vida, mesmo nos momentos em que tivemos que vencer as barreiras de espaço e tempo para estarmos juntos. 


\section{Resumo}

A presente dissertação tem como objetivo essencial discutir o comportamento do método de Newton quando aplicado a polinômios no plano complexo, com ênfase especial no prognóstico do conjunto de valores iniciais para os quais o método falha.

O fundamento teórico da discussão reside no estudo de iteração de transformações racionais de grau maior ou igual a 2. Esse estudo foi desenvolvido independentemente por Pierre Fatou e Gaston Julia no início do século XX, ganhando, nos últimos anos, contribuições substanciais de vários matemáticos. Uma introdução a esta teoria é apresentada no capítulo 1 .

A dissertação foi desenvolvida com o auxílio de recursos computacionais, tanto para a identificação dos valores iniciais em que o método de Newton falha quando aplicado a polinômios de grau 3 e 4, como também na visualização gráfica de órbitas, conjuntos de Julia e bacias de atração. 


\section{Abstract}

The main purpose of this dissertation is to discuss the behavior of Newton's method applied to polinomials in the complex plane, with special emphasis in predicting the set of initial values for which the method fails

The theoretical basis of the discussion lies in the study of the iteration of rational transformations of degree equal or greater than 2. Such study was developed independently by Pierre Fatou and Gaston Julia in the beginning of the 20th century, receiving in recent times valuable contributions from a number of mathematicians. A brief survey of the theory is presented in chapter 1 .

The dissertation was developed with the aid of computer resources for identifying the initial values that cause Newton's method to fail when applied to $3 \mathrm{rd}$ and 4 th degree polinomials, as well as for providing graphical visualization of orbits, Julia sets and basins of attraction. 


\section{Conteúdo}

Introdução

Capitulo 1 - Iteração de transformações racionais _ . . . . . . . . . . . . 3

1.1 - Considerações iniciais . . . . . . . . . . . . . . . . 3

1.2 - Conjuntos de Fatou e Julia $\quad . \quad$. . . . . . . . . . . . . . . 8

1.3 - Pontos Periódicos _. . . . . . . . . . 11

1.4 - Pontos críticos e ciclos (super) atratores . . . . . . . . . . 23

1.5 - Um algoritmo para o conjunto de Julia _ . . . . . . . . . 26

1.6 - Teorema fundamental da decomposição Fatou/Julia . . . . . . 29

1.7 - Domínios de Sullivan . . . . . . . . . . . . . . 34

Capítulo 2 - Aplicação ao Método de Newton no Plano Complexo _ . . . . . 36

2.1 - Considerações iniciais . . . . . . . . . . . . . 36

2.2 - Método de Newton para polinômio quadrático . . . . . . 40

2.3 - Método de Newton para polinômio de grau $3 \ldots 42$

2.3.1 - Morfologia no plano do parâmetro $a$. . . . . . . . . 45

2.3.2 - Valores iniciais para os quais o método de Newton falha . . . 52

2.4 - Método de Newton para polinômio de grau 4 . . . . . . . . . 61

2.4.1 - Morfologia no plano do parâmetro b . . . . . . . . . . . . 62

2.4.2 - Valores iniciais para os quais o método de Newton falha . . . 65

Apêndice . . . . . . . . . . . . . . . . . 72

Relação do material ilustrativo . . . . . . . . . . . . . . . . . 100

Bibliografia . . . . . . . . . . . . . . . . . . . . . . . . . . 


\section{Introdução}

Durante a Primeira Guerra Mundial, os matemáticos franceses Pierre Fatou e Gaston Julia iniciaram, independentemente, estudos sobre iteração de transformações no plano complexo. Esses estudos motivaram a bela teoria da iteração de transformações ou dos conjuntos de Julia. Esta teoria baseia-se no conceito de famílias normais, que foi estabelecido em 1917 por P. Montel.

Os estudos de iteração de transformações no plano complexo, que prosperaram na década de 20 nas mãos de Julia e Fatou, ficaram de certa maneira dormentes até os anos 70, quando então tornaram-se alvo de grande interesse dos matemáticos. Esse interesse foi despertado principalmente pelas fascinantes figuras obtidas por Mandelbrot no computador e pelos trabalhos de Douady, Hubbard e Sullivan.

O presente trabalho introduz, no primeiro capitulo, a teoria de iteração de transformações racionais de grau maior ou igual a 2 e aplica-a, no capítulo seguinte, ao estudo do comportamento da transformação do método de Newton utilizado para determinar os zeros de polinômios de grau 2, 3 e 4, no plano complexo.

A proposta de estender o método de Newton a polinômios no plano complexo é devida a E. Schröder, em 1870/71 e a A. Cayley, em 1879.

Apesar do primeiro capitulo apresentar mais informações que as estritamente necessárias ao desenvolvimento do trabalho, podemos considerá-lo apenas como uma introdução ao assunto, que é vasto e belo. Para um estudo mais abrangente da matéria, podem ser consultados, por exemplo, os trabalhos [3] e [10]. 
Nas três primeiras seções do capítulo 1, apresentamos considerações, definições e propriedades básicas dos conjuntos de Julia. As duas seções subsequentes são fundamentais para o desenvolvimento do capitulo 2: a quarta seção contém o teorema crucial para a identificação da existência de ciclos atratores e a quinta seção estabelece um algoritmo para a visualização do conjunto de Julia. O conteúdo da sexta seção não é fundamental para o entendimento do capítulo 2, porém é essencial para quem se propõe a desenvolver o assunto, pois representa uma forma dinâmica de definir o conjunto de Julia. A sétima seção diz respeito à classificação dos domínios de Sullivan, uma das contribuições mais importantes à teoria, nos últimos anos. É possivel provar resultados análogos ao teorema da quarta seção para os domínios de Sullivan. Tais demonstrações são apresentadas, por exemplo, em [2].

O segundo capítulo é motivado pelo trabalho [4] e discute o comportamento da transformação do método de Newton quando aplicado a polinômios de graus 2,3 e 4 . No caso de polinômios quadráticos, a discussão é bastante simples e é apresentada de forma a introduzir o tema. No caso de polinômios de graus 3 e 4, consideramos uma família a um parâmetro complexo, tal que a transformação associada ao método de Newton possui um único ponto crítico não fixo. Analisamos a órbita desse ponto crítico quando o parâmetro é variado. Com base nessa análise, descrevemos, para um determinado valor do parâmetro, o conjunto dos valores iniciais para os quais o método de Newton falha, ou seja, a união disjunta do conjunto de Julia e das bacias de atração do ciclo evidenciado pela órbita do ponto crítico não fixo. Quando é de interesse, podemos visualizar, também, as bacias de atração dos zeros do polinômio.

Apresentamos no apêndice, no final do trabalho, as listagens dos programas computacionais elaborados para a análise do capítulo 2 . 


\section{Capítulo 1}

\section{Iteração de transformações racionais}

\section{1 - Considerações iniciais}

A teoria dos conjuntos de Julia será abreviadamente introduzida, neste capítulo, para uma transformação racional $R: \bar{C} \rightarrow \bar{C}$ de grau $d \geq 2$, onde $\bar{C}=C \cup\{x\}$ e $\mathbb{C}$ representa o conjunto dos números complexos. A transformação $R$ é definida em $\bar{C}$ por $R(z)=p(z) / q(z)$, onde $p$ e $q$ são polinômios sem fatores comuns. No nosso contexto, o grau $d$ de $R$ pode ser determinado de dois modos. Como o número das imagens inversas, contado com suas multiplicidades, de qualquer ponto de $\bar{C}$, ou como,

$$
d=\operatorname{grau}(R)=\max \{\operatorname{grau}(p), \operatorname{grau}(q)\} .
$$

Definição 1.1.1. Dado um ponto $z_{0} \in \bar{C}$, a órbita progressiva de $z_{0}$, representada por $\mathrm{O}^{+}\left(z_{0}\right)$, é definida como:

$$
O\left(z_{0}\right)=\left\{R^{n}\left(z_{0}\right): n \in \lambda\right\},
$$


onde $R^{n}$ denota a n-ésima iterada de $R$.

A órbita regressiva de $z_{0} \in \overline{\mathbb{C}}$, representada por $\mathbb{O}^{-}\left(z_{0}\right)$, é definida como

$$
\circlearrowleft\left(z_{0}\right)=\left\{z \in \bar{C}: \exists n \geq 0 \mid R^{n}(z)=z_{0}\right\}=\bigcup_{n \geq 0} R^{-n}\left(z_{0}\right)
$$

onde $R^{n}\left(z_{0}\right)=\left(R^{n}\right)^{-1}\left(z_{0}\right)$ e $R^{0}\left(z_{0}\right)=z_{0}$.

Definição 1.1.2. Se $R^{n}\left(z_{0}\right)=z_{0}$ para algum $n>0$, então $z_{0}$ é dito um ponto periódico e $\mathrm{O}^{+}\left(z_{0}\right)$ é uma órbita periódica ou ciclo. O menor natural não nulo $n$ tal que $R^{n}\left(z_{0}\right)=z_{0}$ é chamado periodo minimo da órbita $\mathrm{O}^{\dagger}\left(z_{0}\right)$.

Se o período mínimo é 1 , ou seja $R\left(z_{0}\right)=z_{0}$, dizemos, usualmente, que o ponto $z_{0}$ é um ponto fixo.

Quando não houver possibilidade de confusão, usaremos simplesmente o termo periodo com o sentido de período mínimo, e órbita com o de órbita progressiva.

Definição 1.1.3. Seja $U$ um conjunto aberto de $\bar{C}$ e $\neg=\{f: U \rightarrow \bar{C}\}$ uma família de funções analíticas. A familia $\square$ é normal se toda sequência $\left\{f_{n}\right\}$ contem uma subsequência $\left\{f_{n_{3}}\right\}$, que converge uniformemente nas partes compactas de $U$.

Definição 1.1.4. A familia $\exists$ de funções analíticas em $U \subset \bar{C}$ é localmente limitada se para todo $a \in U$, existem constantes $M$ e $r>0$ tais que para toda função $f$ em $\neg$. $|f(z)| \leq M$. sempre que $|z-a|<r$. 
Teorema 1.1.5. A familia 7 de funções analiticas em $U \subset \bar{C}$ é normal se, e somente se, 7 é localmente limitada.

Prova: Suponhamos que $\square$ seja normal mas que não seja localmente limitada. Existe, desse modo, um compacto $K \subset U$ tal que $\sup \{|f(z)|, z \in K, f \in \mathcal{7}\}=\infty$. Ou seja, existe uma sequência $\left\{f_{n}\right\}$ em $\exists$ tal que $\sup \left\{\left|f_{n}(z)\right|, z \in K\right\} \geq n$. Como $\exists$ é normal, $\left\{f_{n}\right\}$ contém uma subsequência $\left\{f_{n_{k}}\right\}$ que converge uniformemente para uma função $f$ em $K$; isto é, $\sup \left\{\left|f_{n_{k}}(z)-f(z)\right|, z \in K\right\}$ converge para zero quando $n_{k} \rightarrow x$. Se $|f(z)| \leq M$ para $z$ em $K$, temos

$$
n_{k} \leq \sup \left\{\left|f_{n_{k}}(z)\right|, z \in K\right\} \leq \sup \left\{\left|f_{n_{k}}(z)-f(z)\right|, z \in K\right\}+M
$$

O que contradiz o fato de que $\sup \left\{\left|f_{n_{k}}(z)-f(z)\right|, z \in K\right\}+M$ converge para $M$ quando $n_{k} \rightarrow \propto$.

Reciprocamente, suponhamos que $\neg$ é localmente limitada. Pelo teorema de Arzelá-Ascoli, basta provarmos que 7 é equicontínua em cada ponto $a \in U$. Como $U$ é aberto e $\nabla$ é localmente limitada, para cada $a \in U$ fixado, existem $M>0$ e $r>0$ tais que $\bar{D}_{r}(a) \subset U$ e $|f(z)| \leq M$ para todo $z \in \bar{D}_{r}(a)$ e $f \in \exists$. Sejam $f \in \exists$ e $z$ tal que $|z-a|<\frac{r}{2}$; aplicando a fórmula de Cauchy à curva $\gamma=a+r e^{t t}, \quad 0 \leq t \leq 2 \pi$, temos

$$
|f(z)-f(a)| \leq \frac{1}{2 \pi} \int_{y}\left|\frac{f(w)(z-a)}{(w-z)(w-a)} d w\right| \leq \frac{2 M}{r}|z-a| .
$$

Portanto, dado $\varepsilon>0$, existe $\delta=\min \left\{\frac{r}{2}, \frac{r \varepsilon}{2 M}\right\}$, tal que se $|z-a|<\delta$ entâo para toda $f$ em $\exists$, temos $|f(z)-f(a)|<\varepsilon$ 
Observação 1.1.6. Mencionamos, aqui, alguns conceitos e resultados que usaremos neste trabalho. Para mais detalhes o leitor pode consultar a bibliografia citada.

(1) Dizemos que a família $\exists$ omite o ponto $p$ se $p \notin \bigcup_{f \in !} f(U)$.

(2) Sejam $\left(X, d_{1}\right)$ e $\left(Y, d_{2}\right)$ espaços métricos. Dizemos que $f: X \rightarrow Y$ é uma contração fraca se $d_{2}(f(x), f(y)) \leq d_{1}(x, y)$, para todo $x$ e $y$ em $X$.

(3) A métrica hiperbólica no disco unitário $D_{1}=\{z \in C:|z|<1\}$, na sua forma infinitesimal, é dada por

$$
d s=\frac{2|d z|}{1-|z|^{2}}
$$

Integrando esta métrica ao longo dos possíveis caminhos entre dois pontos $z$ e wo disco e tomando o ínfimo dos comprimentos desses caminhos, obtemos a distância hiperbólica

$$
\rho(z, w)=\log \frac{\left|w-z_{\alpha}\right|\left|w_{\alpha}-z\right|}{\left|z-z_{\alpha}\right|\left|w_{\alpha}-w\right|},
$$

onde $z_{\sigma}$ e $w_{\alpha}$ são as intersecções do círculo unitário com o círculo que contém $z, w$ e é ortogonal ao círculo unitário. ${ }^{1}$

(4) As isometrias que preservam orientação na métrica hiperbólica são os automorfísmos complexos de $I_{1}$, ou seja, as transformações da forma

$$
T(z)=e^{i \theta} \frac{z-\alpha}{1-\bar{\alpha} z}
$$

onde $\alpha \in D_{1}$ e $\theta \in \mathbb{R}$. ${ }^{\prime}$

(5) Lema de Schwarz: " Toda função $f: D_{1} \rightarrow D_{1}$ holomorfa contrai a métrica hiperbólica. E ainda, se $f$ for isometria num ponto, então $f$ é isometria global ". [10, pág. 1-4]

1 Beardon. A. F., The Geometry of Discrete Groups, Springer-Verlag. (1983). 
(6) Teorema da uniformização: " Toda superficie de Riemann $S$ possui como recobrimento universal $\bar{C}, C$ ou $D_{1}$. Se $S=\bar{C}$, então o seu recobrimento universal é $\overline{\mathrm{C}}$. Se $S$ é conformemente equivalente a $\mathrm{C}, \mathcal{C} \backslash\{0\}$ ou a um toro, então seu recobrimento universal é o plano $C$. Nos demais casos, o recobrimento universal é o disco $D_{1}$ ". [7, pág. 180]

(7) Seja $\pi: D_{1} \rightarrow S$ uma transformação de recobrimento. A métrica hiperbólica $\rho$ em $D_{1}$ induz uma métrica $\rho_{S}$ em $S$, tal que $\pi$ é uma isometria. De fato, dado $w_{1} \in S$, existe uma vizinhança $V$ de $w_{1}$ tal que, $\pi^{-1}(V)=\bigcup^{0} V_{1}$, onde $\pi_{V_{i}}$ é homeomorfismo. Seja $w_{2} \in V$ e $\delta$ uma curva de $w_{1}$ a $w_{2}$ contida em $V$. Se $z_{1} \in D_{1}$ tal que $\pi\left(z_{1}\right)=w_{1}$, temos que existe uma única vizinhança $V_{1} \operatorname{com} z_{1} \in V_{1}$ e uma única curva $\delta_{1}$ contida em $V_{1}$, tal que $\pi \circ \delta_{1}=\delta$. Definimos o comprimento de $\delta$ como o comprimento de $\delta_{1}$. Esta definição de distância local não depende da escolha de $V_{1}$, pois pela propriedade de grupo de recobrimento, existe uma isometria $T$ que leva $r_{i}$, em qualquer $V_{,}$.

Teorema 1.1.7. (Montel) Se a familia $\exists$ omite pelo menos três pontos em $\bar{C}$, então ela é normal.

Prova: Como para cada $f \in \mathcal{G}$ existe uma transformação de Möbius $g_{f}$ tal que $g_{f}(a)=0, g_{f}(b)=1, g_{f}(c)=\infty$, quaisquer que sejam $a, b$ e $c$, podemos considerar sem perda de generalidade que os pontos omitidos pela família $\square$ são 0,1 e $\infty$ Seja $\Omega=\bar{C} \backslash\{0,1, \infty\}$. Como a normalidade é uma propriedade local, basta provarmos que para todo $z \in U, \nabla$ é normal em algum disco centrado em $z$ e contido em $U$. Podemos assumir, então, que $\neg$ é uma família de funções analíticas de $D_{1}$ em $\Omega$. Pelo teorema de uniformização, o recobrimento universal de $\Omega$ é $D_{1}$, ou seja, existe uma transformação de recobrimento $\pi: D_{1} \rightarrow \Omega$. A métrica hiperbólica $\rho$ em $D_{1}$, induz uma métrica $\rho_{\Omega}$ em $\Omega$, tal que $\pi$ é uma isometria. Como $\pi$ é um homeomorfismo local analítico, existe numa vizinhança $V$ de $f(0), \pi^{-1}: V \rightarrow V$, que também é um homeomorfismo analítico. Isto determina uma região $R \subseteq D_{1}$ tal que $0 \in R=f^{-1}(V)$. Definimos $F: R \rightarrow D_{1}$ por $F=\pi^{-1} \circ f$ que é analitica em $R$. Mas $F$ pode ser prolongada 
analiticamente ao longo de qualquer curva que parte da origem, e assim, como $D_{1}$ é simplesmente conexo, pelo teorema da monodromia, $F$ pode ser estendida analiticamente a todo $D_{1}$ de forma univalente. Pelo lema de Schwarz, $F: D_{1} \rightarrow D_{1}$ contrai a métrica hiperbólica. Como $\pi$ preserva as distâncias e $\pi \circ F=f$, temos que $f: D_{1} \rightarrow \Omega$ é uma contração fraca.

Seja $K \subseteq D_{1}$ um compacto com diâmetro $d$. Como qualquer ponto do interior de $D_{1}$ está a uma distância hiperbólica infinita de um ponto da fronteira $\partial D_{1}$, a distância de qualquer ponto de $\Omega$ a 0,1 ou $\infty$ é infinita, e existem vizinhanças $N_{0}, N_{1}$ e $N_{\infty}$ de 0,1 e $\infty$ respectivamente tais que a distância entre quaisquer uma delas excede $d$. Para toda $f \in \mathcal{G}, \operatorname{diam} f(K) \leq d$ e $f(K)$ intercepta no máximo uma das vizinhanças $N_{0}, N_{1}$ ou $N_{\infty}$. Assim, existe uma sequência $\left\{f_{n}\right\}$ de $\exists$ e uma vizinhança $N_{1}$ $(j=0,1$ ou $\infty)$ tal que para todo $n, f_{n}(K) \cap N_{j}=\varnothing$. Seja $g: \bar{C} \rightarrow \bar{C}$ uma transformação de Möbius que transforma $N_{t}$ no exterior de $D_{1}$, isto é, em $\bar{C} \backslash \bar{D}_{1}$. Como $f_{n}(K) \cap N_{1}=\varnothing \quad$ e $g$ é uma bijeção, temos $g\left(f_{n}(K)\right) \cap g\left(N_{1}\right)=\varnothing$, ou seja, $g \circ f_{n}(K) \subseteq \bar{D}_{1}, \quad$ e $\left\{g \circ f_{n}\right\}$ é uniformemente limitada em qualquer aberto contido em $K$. Pelo teorema 1.1.5, $\left\{g \circ f_{n}\right\}$ é normal em $K$. Finalmente, como $f_{n}=g^{1} \circ g \circ f_{n}$ e $g^{-1}$ é lipschitziana sobre a esfera de Riemann, temos que $\neg$ é normal.

\section{2 - Conjuntos de Fatou e Julia}

Seja $R$ uma transformação racional de grau $d \geq 2$.

Definição 1.2.1. Um ponto $z \in \bar{C}$ é um elemento do conjunto de Fatou $\mathcal{F}(R)$ de $R$ se existe uma vizinhança $U$ de $z$ em $\bar{C}$, tal que a família de iteradas $\left\{R^{n}\right\}_{n=0}$ restrita a U é uma familia normal. O conjunto de Julia $J(R)$ é o complementar em $\bar{C}$ do conjunto de Fatou.

Quando não houver possibilidade de confusão, representaremos o conjunto de Fatou $\mathcal{F}(R)$, e o conjunto de Julia $J(R)$, simplesmemnte por $\mathcal{F}$ e $J$, respectivamente. 
O exemplo, possivelmente o mais simples que pode ser considerado, é o da transformação $R(z)=z^{2}$ definida em $\bar{C}$. Neste caso, temos $R^{k}(z)=z^{2^{k}}$ para todo $k \in \mathbb{N}$. Assim, para todo $z_{0}$ no disco unitário $D_{1}=\{z \in \mathrm{C}:|z|<1\}$, existe uma vizinhança $U$, por exemplo $U=D_{1}$, em que a sequência de iteradas $\left.R^{n}\right|_{l}$. restrita a $U$ converge uniformemente em cada compacto de $U$ para a função constante identicamente nula. Logo, o disco unitário $D_{1}$ está contido no conjunto de Fatou $\mathcal{F}$. Analogamente, o exterior $\bar{C} \backslash \bar{D}_{1}$ do disco $D_{1}$ está no conjunto de Fatou $\mathcal{F}$, pois a sequência de iteradas de $R$ converge para a função constante $z \mapsto \infty$ no exterior de $D_{1}$. No entanto, se $z_{0}$ estiver no círculo unitário $S^{1}=\{z \in \mathrm{C}:|z|=1\}$, então, em qualquer vizinhança $U$ de $z_{0}$, existe alguma sequência de iteradas de $R$ tal que toda subsequência não converge uniformemente nas partes compactas de $U$. De fato, seja $K \subset U$, compacto, tal que $K \cap D_{1} \neq \varnothing$ e $K \cap\left(\bar{C} \backslash \bar{D}_{1}\right) \neq \varnothing$. Se toda sequencia de iteradas de $R$ restritas a $U$ possuísse uma subsequência uniformemente convergente para uma função $f$ em $K$, então $f(z)=0$ se $z \in K \cap D_{1}, f(z)=\infty$ se $z \in K \cap\left(\bar{C} \backslash \overline{D_{1}}\right), f(z) \in S^{1}$ se $z \in K \cap D_{1}$, o que contradiria a continuidade de $f$. O conjunto de Julia $J$ é, portanto, o círculo unitário $S^{1}$. Neste exemplo, o conjunto de Julia é muito simples, mas na quase totalidade dos casos é bastante intricado. O capitulo 2 dará uma mostra deste fato

As proposições seguintes referem-se a algumas propriedades básicas do conjunto de Julia, úteis ao desenvolvimento deste trabalho.

Proposição 1.2.2. ( conjunto de Julia é não vazio.

Prova: Suponhamos que o conjunto de Julia $J(R)$ seja vazio. Neste caso, o conjunto de Fatou $\mathcal{F}(R)=\bar{C}$, ou seja, a família $\exists=\left\{R^{n}: \overline{\mathrm{C}} \rightarrow \overline{\mathrm{C}}, n \in \mathbb{N}\right\}$ das iteradas de $R$ é normal em $\bar{C}$. Assim, existe uma subsequência $\left\{R^{n_{j}}\right\}$ que converge uniformemente para uma função $S$, que pelo teorema de Weierstrass, é meromorfa. O grau de $R^{n_{3}}$ é igual ao grau de $S$, para $j$ suficientemente grande. Mas o grau de $R^{n_{j}}, d^{n_{j}}$, tende para infinito quando $n_{1} \rightarrow \infty$, o que contradiz o fato de que o grau de $S$ é finito. 
Proposição 1.2.3. () conjunto de Julia é completamente invariante, ou seja,

$$
R(J)=J=R^{-1}(J)
$$

Prova: É equivalente mostrar que o conjunto de Fatou, complementar do conjunto de Julia, é completamente invariante. Seja $U$ um conjunto aberto de $\mathcal{F}$. A familia $\exists=\left\{R^{n}: U \rightarrow \bar{C}, n \in \mathbb{N}\right\}$ é normal em $U$, ou seja, em cada compacto de $U$, toda sequência $\left\{R^{k-1}\right\}$ possui alguma subsequência $\left\{R^{k_{i}-1}\right\}$ uniformemente convergente. Como $R$ é meromorfa, $R(U)$ é aberto. Seja $K$ um subconjunto compacto de $R(U)$. Como $\left\{R^{k_{i}-1}\right\}$ é uniformemente convergente em $R^{-1}(K),\left\{R^{k_{i}}\right\}$ é uniformemente convergente em $K$. Desse modo, $\exists$ é normal em $R(U)$ e $\mathcal{F} \subset R(\mathcal{F})$. De maneira análoga, provam-se as demais inclusões.

Proposição 1.2.4. Para todo inteiro $n$, o conjunto de Julia $J\left(R^{n}\right)$ da n-ésima iterada coincide com o conjunto de Julia $J(R)$.

Prova: Equivalentemente, provamos para o complementar, o conjunto de Fatou $\mathcal{F}(R)$. Para verificar que $\mathcal{F}(R) \subset \mathcal{F}\left(R^{n}\right)$, basta observarmos que se toda sequência $\left\{R^{k}\right\}$ tem uma subsequência uniformemente convergente num dado conjunto, o mesmo é verdadeiro para a sequência $\left\{R^{n k}\right\}$, qualquer que seja o inteiro positivo $n$. Reciprocamente, seja $n$ um inteiro positivo qualquer e $U$ um aberto de $\bar{C}$. Todo natural $k$ pode ser escrito como: $n k_{i}+r$, com $k_{i} \in N$ e $r=0,1, \ldots, n-1$. Para cada $0 \leq r \leq n-1$, considere a família:

$$
\mathcal{F}_{n, r}=\left\{R^{n k_{i}+r}: U \rightarrow \overline{\mathrm{C}}, k_{i} \in \boldsymbol{N}\right\}
$$

Como $R^{n k_{i}+r}=R^{r}\left(R^{n k_{i}}\right), R^{r}$ é contínua e $\left\{R^{n k_{i}}\right\}$ tem uma subsequência uniformemente convergente nas partes compactas de $U$, segue que $\exists_{n, r}$ é normal em $U$. Mas

$$
\exists=\left\{R^{k}: U \rightarrow \overline{\mathbf{C}}, k \in \mathbb{N}\right\}=\bigcup_{r=0}^{n-1} \mathcal{F}_{n, r}
$$

e a união finita de famílias normais é normal. Portanto, $\neg$ é normal e $\mathcal{F}\left(R^{n}\right) \subset \mathcal{F}(R)$. 


\section{3 - Pontos Periódicos}

Discutimos nesta seção o comportamento dinâmico de uma transformação racional numa vizinhança de um ponto periódico, como também a relação entre os conjuntos de Fatou e Julia, e os pontos periódicos.

Definição 1.3.1. Seja $z_{0}$ um ponto periódico de período $n$. O número

$$
\lambda=\left\{\begin{array}{lll}
\left(R^{n}\right)^{\prime}\left(z_{0}\right) & \text { se } & z_{0} \neq x \\
\frac{1}{\left(R^{n}\right)^{\prime}\left(z_{0}\right)} & \text { se } & z_{0}=\infty
\end{array}\right.
$$

é chamado autovalor da órbita periódica.

Pela regra da cadeia,

$$
\left(R^{n}\right)^{\prime}\left(z_{0}\right)=\prod_{i=1}^{n} R^{\prime}\left(R^{i}\left(z_{0}\right)\right)
$$

e o autovalor $\lambda$ é, desse modo, o mesmo para cada ponto $R^{i}\left(z_{0}\right)$ do ciclo. Podemos dizer, assim, que o autovalor $\lambda$ é um invariante para a órbita periódica $\mathbb{O}^{+}\left(z_{0}\right)$

Definição 1.3.2. Uma órbita periódica $\mathrm{O}^{+}\left(z_{0}\right)$ é dita:

(1) atratora, se $0<|\lambda|<1$,

(2) repulsora, se $|\lambda|>1$,

(3) superatratora, se $\lambda=0$,

(4) indiferente, se $|\lambda|=1$.

Se o autovalor $\lambda$ tem módulo unitário, então podemos escrever $\lambda=e^{2 m \alpha}$, com $\alpha$ real. Se $\alpha \in \mathbb{R} \backslash Q$. dizemos que o ciclo correspondente é irracionalmente indiferente; e se $\alpha \in \mathbb{Q}$, que o ciclo é racionalmente indiferente. 
Teorema 1.3.3. Seja $z_{0}$ um ponto de um ciclo atrator de periodo $n$. Existe uma vizinhança Ul de $z_{0}$ e um único homeomorfismo analitico $\phi: U \rightarrow D_{r} \quad$ (para algum $r$ ) tal que $\phi\left(z_{0}\right)=0, \phi^{\prime}\left(z_{0}\right)=1$ e o diagrama

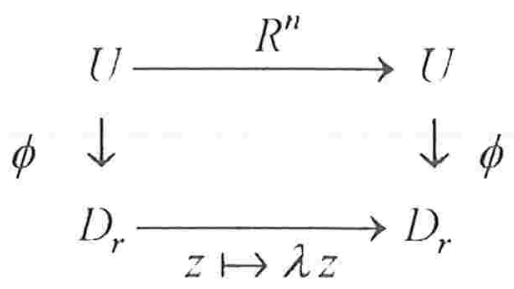

comuta.

Prova: Sem perda de generalidade, podemos supor que $z_{0}=0$ é um ponto fixo atrator, com autovalor $\lambda$. Como $0<|\lambda|<1$, podemos escolher uma constante $c<1$ tal que $c^{2}<|\lambda|<c$, e uma vizinhança $V \subseteq D$, da origem de modo que $|R(z)| \leq c|z|$ para todo $z$ em $V$. Consequentemente $\left|R^{m}(z)\right| \leq c^{m}|z| \leq c^{m} s$. Pelo teorema de Taylor, $|R(z)-\lambda z| \leq K|z|^{2} \quad$ para algum $K>0$ e todo $z \in V^{\prime}$. Logo,

$$
\left|R^{m+1}(z)-\lambda R^{m}(z)\right| \leq K\left|R^{m}(z)\right|^{2} \leq K c^{2 m} s^{2}
$$

Fixado $z^{\prime} \in V^{\prime}$, os números $w_{k}=R^{k}\left(z^{\prime}\right) / \lambda^{k}$ satisfazem

$$
\left|w_{m}-w_{n}\right| \leq \sum_{i=n}^{m-1}\left|w_{i+1}-w_{i}\right| \leq \sum_{i=1}^{m-1} \frac{1}{|\lambda|} K s^{2}\left(\frac{c^{2}}{|\lambda|}\right)^{\prime} \leq \frac{1}{|\lambda|} K s^{2} \sum_{i=n}\left(\frac{c^{2}}{|\lambda|}\right)^{\prime}
$$

sempre que $m>n$. Como $c^{2}<|\lambda|$, a sequência $\left\{w_{m}^{\prime}\right\}_{m>0}$ é uniformemente de Cauchy. Desse modo, a sequência $\left\{\phi_{m}\right\}_{m>0}$ de funções holomorfas definidas por

$$
\phi_{m}(z)=\frac{R^{m}(z)}{\lambda^{m}}
$$


converge uniformemente para uma função $\phi$, que pelo teorema de Weierstrass é holomorfa em $V$. Como $\phi_{m}^{\prime}(0)=1, \phi^{\prime}(0)=1$ e por continuidade existe $V_{1} \subset V$ tal que $\phi^{\prime}(z) \neq 0$, para todo $z$ em $r_{1}$. Tomemos $D, \subset \phi\left(r_{1}^{r}\right)$ e $U=\phi^{-1}\left(D_{r}\right)$. A função $\phi(U \rightarrow D$, é o homeomorfismo analítico procurado.

Para provarmos a unicidade, consideremos homeomorfismos analíticos $\phi: U \rightarrow D_{r}$ e $\psi: U \rightarrow D_{1}$ como definidos acima. Assim, $\psi \circ \phi^{-1}: D_{r} \rightarrow D_{t}$ é uma função analítica que satisfaz $\psi \circ \phi^{\prime}(0)=0$ e $\left(\psi \circ \phi^{-1}\right)^{\prime}(0)=1$. Pelo teorema da aplicação aberta, $\psi \circ \phi^{-1}\left(D_{r}\right)$ é aberto. Seja $q$ o maior raio tal que $\psi \circ \phi^{-1}\left(D_{q}\right) \subseteq D_{q}$. Aplicando o lema de Schwarz a $\psi \circ \phi^{-1}: D_{q} \rightarrow D_{q}$ temos que $\phi$ coincide com $\psi$ em $D_{q}$. Pelo princípio do prolongamento analítico, $\phi$ e $\psi$ coincidem em $U$.

Observação 1.3.4. O teorema anterior também é válido no caso em que $z_{0}$ é um ponto de um ciclo repulsor de periodo $n$ de uma transformação racional $R$. De fato, como o autovalor $\lambda$ do ciclo não é nulo $(|\lambda|>1)$, a transformação inversa $R^{-1}$ é localmente, bem definida, holomorfa e ainda, a órbita de $z_{0}$ por $R^{-1}$ é atratora com autovalor $\lambda^{-1}$.

Teorema 1.3.5. Sejam $R$ uma transformação racional, $O^{\prime}\left(z_{0}\right)$ um ciclo superatrator de periodo $n,\left(R^{n}\right)^{(k)}\left(z_{0}\right) \neq 0$ para algum $k \geq 2$ e

$$
\lambda=\left(R^{n}\right)^{\prime}\left(z_{0}\right)=\left(R^{n}\right)^{(2)}\left(z_{0}\right)=\ldots=\left(R^{n}\right)^{(k \cdot 1)}\left(z_{0}\right)=0 .
$$

Então, existe uma vizinhança (U de $z_{0}$ e um homeomorfismo analitico $\phi:\left(U \rightarrow D_{r}\right.$ ( para algum $r$ ) tal que $\phi\left(z_{0}\right)=0, \phi^{\prime}\left(z_{0}\right)=1$, e o diagrama:

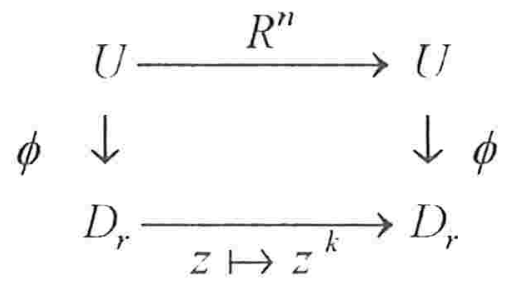

comuta. 
Prova: Podemos supor, sem perda de generalidade, que $z_{0}=0$ é um ponto fixo superatrator. Como $R^{\prime}(0)=R^{(2)}(0)=\ldots=R^{(k \quad 1)}(0)=0$, a expansão em série de potências de $R$ é $a_{k} z^{k}+a_{k+1} z^{k+1}+\ldots$ Mas, $R$ é conjugada pela transformação $z \mapsto b z$, onde $b^{k-1}=\left(a_{k}\right)^{1}$, a

$$
S(z)=z^{k}+b_{k+1} z^{k-1}+\ldots+b_{k+1} z^{k-1}+\ldots
$$

onde $b_{k+1}=\frac{a_{k \cdot 1}}{b^{k+1-1}}$. Seja $D_{r}$ um disco tal que $S\left(D_{r}\right) \subset \operatorname{int}\left(D_{r}\right)$ e $\lim _{n \rightarrow \infty} S^{n}(z)=0$ para todo $z \in D_{r}$. Consideremos a sequência $\left\{\phi_{m}\right\}_{m \geq 0}$ de funções holomorfas definidas em alguma vizinhança $U$ da origem por

$$
\phi_{m}(z)=\left[S^{m}(z)\right]^{\frac{1}{k^{m}}}
$$

Notemos que $\phi_{m}^{\prime}(0)=1$. Seja

$$
H(z)=\left\{\begin{array}{ccc}
\phi_{1}(z) / z & \text { se } & z \neq 0 \\
1 & \text { se } & z=0
\end{array}\right. \text {. }
$$

Observamos que

$$
\frac{\phi_{m \cdot 1}(z)}{\phi_{m}(z)}=\left[\frac{\phi_{1}\left(S^{m}(z)\right)}{S^{m}(z)}\right]^{\frac{1}{k^{m}}}=\left[H\left(S^{m}(z)\right)\right]^{k^{m}}
$$

Assim, usando a notação $\phi_{0}(z)=z$ podemos escrever

$$
\phi_{m+1}(z)=z \prod_{i=0}^{m}\left[H\left(S^{\prime}(z)\right)\right]^{\frac{1}{k}}
$$


Tomemos o ramo principal do logaritmo do produto infinito

$$
\log \prod_{m=0}\left[H\left(S^{m}(z)\right)\right]^{\frac{1}{k^{m}}}=\sum_{m \geq 0} \frac{1}{k^{m}} \log \left(H\left(S^{m}(z)\right)\right) .
$$

Pelas propriedades dinâmicas de $S$ em $D_{r}$, sabemos que

$$
\left|H\left(S^{m}(z)\right)-1\right|<\frac{1}{2} \quad \text { e } \quad\left|H\left(S^{m}(z)\right)-1\right| \leq c\left|S^{m}(z)\right|
$$

para algum $c>0$. Assim,

$$
\left|\log \left(H\left(S^{m}(z)\right)\right)\right| \leq 2\left|H\left(S^{m}(z)\right)-1\right| \leq 2 c\left|S^{m}(z)\right|
$$

e

$$
\left|\sum_{m \geq 0} \frac{1}{k^{m}} \log \left(H\left(S^{m}(z)\right)\right)\right| \leq 2 c \sum_{m \geq 0} \frac{\left|S^{m}(z)\right|}{k^{m}} \leq 2 c r \sum_{m=0} \frac{1}{k^{m}} .
$$

Portanto a sequência $\left\{\phi_{m}\right\}_{m>0}$ converge uniformemente para uma transformação $\phi: U \rightarrow D)_{r}$. Temos, então, a conjugação desejada, pois $\phi(0)=0, \phi^{\prime}(0)=1$ e

$$
\phi \circ S(z)=\lim _{n \rightarrow \infty}\left[S^{n+1}(z)\right]^{\frac{1}{k^{n}}}=\lim _{n \rightarrow \infty}\left[\left(S^{n-1}(z)\right)^{\frac{1}{k^{n-1}}}\right]^{k}=(\phi(z))^{k}
$$

Definição 1.3.6. A bacia de (super) atração de um ciclo (super) atrator de período $n$ de uma transformação $R$ é o conjunto aberto $\Omega \subset \bar{C}$ de todos os pontos $z$ para os quais a sequência de iteradas, $\left\{R^{k n}(z)\right\}_{k=0}$, converge para algum ponto do ciclo. 
A bacia imediata de um ponto $p_{1} \quad(1 \leq i \leq n)$ da órbita periódica, de periodo $n$, é a componente conexa da bacia de atração $\Omega$, que contém $p_{1}$, e será denotada por $A\left(p_{1}, R^{n}\right)$. A bacia imediata da órbita, representada por $A$, é dada pela união $\bigcup_{i=1}^{n} A\left(p_{i}, R^{n}\right)$.

Teorema 1.3.7. Toda órbita periódica (super) atratora está contida no conjunto de Fatou, bem como sua bacia de atração $\Omega$. Entretanto, a fronteira $\partial \Omega$ está no conjunto de .Julia, como também toda órbita periódica repulsora.

Prova: Tendo em vista a proposição 1.2.4 podemos supor, sem perda de generalidade, que $z_{0}$ é um ponto fixo. Se $z_{0}$ é (super) atrator, $0 \leq|\lambda|=\left|R^{\prime}\left(z_{0}\right)\right|<1$. Pela fórmula de Taylor

$$
R^{n}(z)=z_{0}+\lambda^{n}\left(z-z_{0}\right)+o\left(\left(z-z_{0}\right)^{2}\right)
$$

para todo $z$ em uma vizinhança $U$ de $z_{0}$. Assim, a sequência de iteradas de $R$, restritas a $U$ converge uniformemente para a função constante $z \mapsto z_{0}$. Assim, a família $\exists=\left\{R^{n}: U \rightarrow \overline{\mathrm{C}}, n \in \mathbb{N}, n>0\right\}$ é normal em $U$. O mesmo argumento vale para a bacia de atração $\Omega$

Por outro lado, se $z$ é um ponto arbitrário na fronteira $\partial \Omega$ da bacia de atração, então em qualquer vizinhança $V$ de $z$, existe alguma sequência de iteradas de $R$ tal que nenhuma subsequência converge uniformemente nas partes compactas de $V$. De fato, seja $K \subset V$, compacto, tal que $K \cap \Omega \neq \varnothing$ e $K \cap(\bar{C} \backslash \bar{\Omega}) \neq \varnothing$. Se toda sequência de iteradas de $R$ restritas a $U$ possuísse uma subsequência uniformemente convergente para uma função $f$ em $K$, então $f$ seria descontínua, o que contradiz o fato de que as iteradas de $R$ são contínuas. Neste caso, $z$ está no conjunto de Julia.

Se $z_{0}$ é repulsor, $|\lambda|>1$. Como $\left(R^{k}\right)^{\prime}\left(z_{0}\right)=\lambda^{k}$, toda subsequência de derivada das iteradas no ponto $z_{0},\left\{\lambda^{n}\right\}_{n>0}$, é divergente. Pelo teorema de Weierstrass, nenhuma subsequência $\left\{R^{n}\right\}$ de iteradas de $R$ convergirá uniformemente numa vizinhança de $z_{0}$. 
Observação 1.3.8. A discussão sobre a dinâmica da transformação numa vizinhança de um ponto periódico indiferente é bastante extensa. Na verdade, ainda restam questões que não foram esclarecidas. Como esta discussão extrapola os objetivos desta dissertação, alguns resultados serão apenas mencionados. Para mais detalhes, o leitor pode consultar [2] e [10].

Inicialmente, seja $z_{0}$ um ponto fixo indiferente, com autovalor $\lambda$ de módulo unitário, $U$ uma vizinhança de $z_{0}$ e $D_{r}=\{z:|z|<r\}$. Ao tentarmos conjugar $\left.R^{n}\right|_{l:}$ à transformação $z \mapsto \lambda z$, o diagrama:

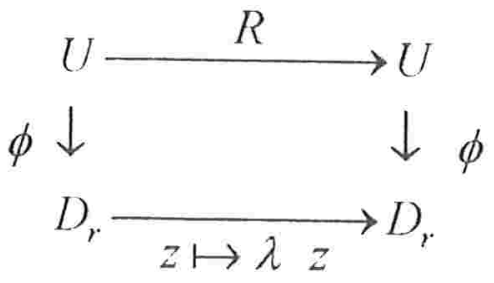

produz uma equação funcional,

$$
\phi \circ R(z)=\lambda \phi(z)
$$

denominada Fquação Funcional de Schröder (EFS).

Teorema 1.3.9. Im ponto fixo indiferente $z_{0}$ pertence ao conjunto de Fatou $\mathcal{F}$ se, $e^{\prime}$ somente se, (EFS) tem uma solução analitica em alguma vizinhança de $z_{0}$.

Prova: Suponhamos que $z_{0}$ pertença ao conjunto de Fatou e seja $U$ a maior componente conexa de $\mathcal{F}(R)$ que contém $z_{0}$. Pelo teorema da uniformização, o disco unitário $D_{1}$ é o recobrimento universal de $U$. Como o grupo de recobrimento é transitivo, podemos escolher um recobrimento $\pi: D_{1} \rightarrow U$ tal que $\pi(0)=z_{0}$ e um levantamento $\tilde{R}$ de $\left.R^{n}\right|_{i}$ tal que $\tilde{R}(0)=0$. Assim, $\tilde{R}: D_{1} \rightarrow D_{1}$ e $\left|\tilde{R}^{\prime}(0)\right|=|\lambda|=1$. Pelo lema de Schwarz, temos $\tilde{R}(z)=\lambda z$, para todo $z$ em $D_{1}$. Portanto, a inversa $\pi: D_{1} \rightarrow U$ do 
recobrimento é a solução $\phi$ de (EFS). Reciprocamente, se existe um homeomorfismo analítico $\phi$ definido em alguma vizinhança $U$ de $z_{0}$ tal que

$$
\phi \circ R(z)=\lambda \phi(z)
$$

então

$$
R^{n}(z)=\phi^{-1} \circ \lambda^{n} \phi(z)
$$

Como $|\lambda|=1$, a família $\exists=\left\{R^{n}: U \rightarrow \bar{C}, n \in N\right\}$ das iteradas restritas a $U$ é localmente limitada. Do teorema 1.1.5, segue que a familia 7 é normal em $U$. Portanto, $z_{0}$ está no conjunto de Fatou.

Corolário 1.3.10. Todo ciclo racionalmente indiferente está contido no conjunto de Julia.

Prova: Sem perda de generalidade, seja $z_{0}$ um ponto fixo racionalmente indiferente, com autovalor $\lambda$. Assim existe um inteiro positivo $t$ tal que $\lambda^{\prime}=1$. Suponhamos que $z_{0}$ pertença ao conjunto de Fatou. Pelo teorema anterior existe um homeomorfismo analítico $\phi$ definido em alguma vizinhança $U$ de $z_{0}$ tal que

$$
\phi \circ R^{t} \circ \phi^{-1}=I d
$$

Logo $R^{\prime}=I d$ em $U$. Pelo princípio do prolongamento analítico, temos que $R^{\prime}=I d$ em $\bar{C}$, o que contradiz a hipótese do grau de $R$ ser maior que 1 .

Pelo corolário anterior, numa vizinhança de um ponto periódico racionalmente indiferente, com autovalor $\lambda$, a transformação não é conjugada à rotação $z \mapsto \lambda z$. Os dois próximos teoremas estabelecem o comportamento dinâmico da transformação numa vizinhança de um ponto irracionalmente indiferente. 
Teorema 1.3.11. Seja $f(z)=\lambda z+a_{2} z^{2}+\ldots$ uma transformaçâo analitica muma vizinhança da origem e suponha que $\lambda^{n}=1 e \lambda^{m} \neq 1$ para $1<m<n$. Então, ou $f^{n}=I d$, ou existe um homeomorfismo local $h$ e um inteiro $k>1$ tal que $h(0)=0$ e $h \circ f \circ h^{-1}(z)=\lambda z\left(1+z^{k n}\right)$.

A condição $z^{k n} \in \mathbb{R}$ descreve um conjunto de $2 n$ retas que passam pela origem, e que formam um ângulo de $\pi / k n$ entre si. Essas retas são invariantes pela transformação $g(z)=z\left(1+z^{k n}\right)$. Então $z \mapsto \lambda z\left(1+z^{k n}\right)$ é a composição de $g$ com a rotação periódica $z \mapsto \lambda z$. A figura 1 ilustra o caso em que $k=3$ e $n=1$.

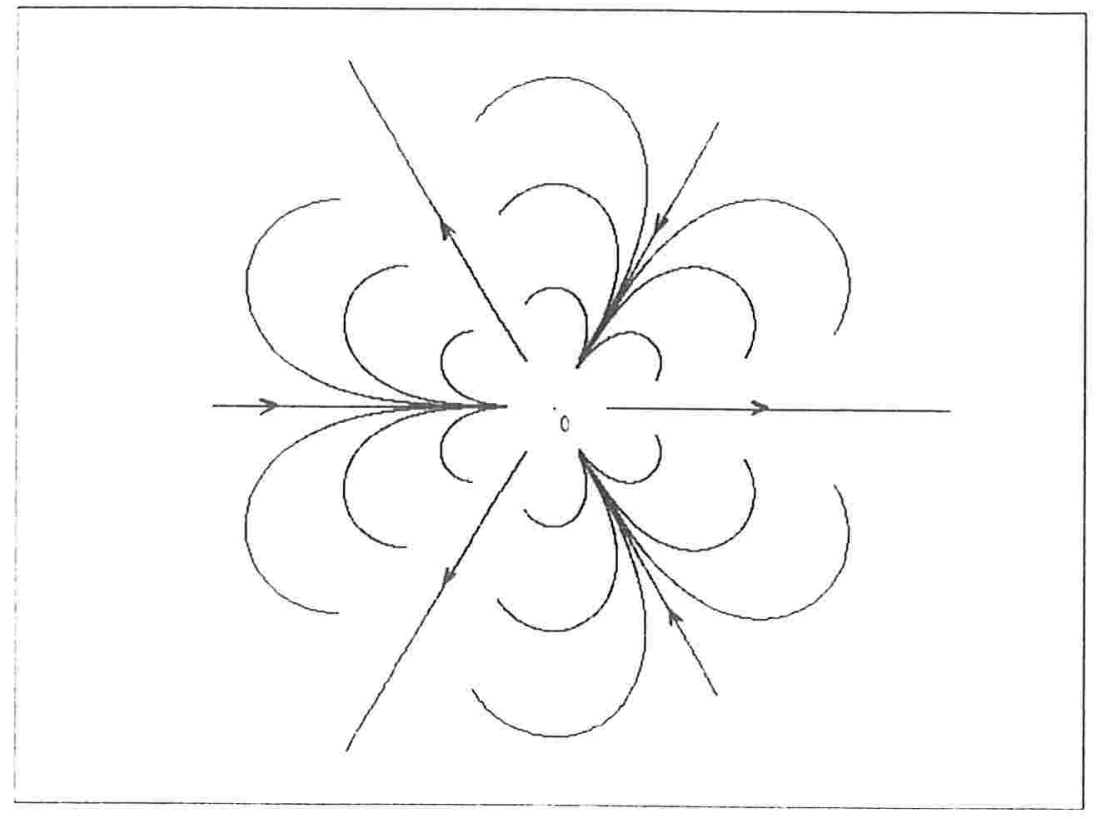

Figura 1 - Órbitas parciais da transformação $z \mapsto z\left(1+z^{3}\right)$.

O próximo teorema é conhecido como teorema das flores. 
Teorema 1.3.12. Seja $f(z)=\lambda z+a_{2} z^{2}+\ldots$ uma transformação analitica numa vizinhança da origem e suponha que $\lambda^{n}=1$ e $\lambda^{n} \neq 1$ para $1<m<n$. Se $f^{n} \neq I d$, existe um inteiro $k$ e $n k$ curvas analiticas que são tangentes aos pares na origem e que limitam pétalas. A união dessas pétalas é invariante pela órbita progressiva, e a órbita de qualquer ponto no interior de uma pétala é assintótica à origem.

Pelo corolário 1.3.10, se um ciclo indiferente está no conjunto de Fatou, então seu autovalor $\lambda$ pode ser escrito na forma $e^{2 \pi i \alpha}$, com $\alpha$ irracional. No entanto, a recíproca não é verdadeira, como mostra o exemplo de Cremer, que descrevemos a seguir. Seja $P(z)=z^{d}+\ldots+\lambda z$ onde $\lambda=e^{2 \pi i \alpha}$, com $\alpha$ irracional, satisfazendo

$$
\left|\lambda^{n}-1\right| \leq\left(\frac{1}{n}\right)^{d^{n}-1}
$$

para uma infinidade de números naturais $n$. Para determinarmos os pontos periódicos, devemos resolver a equação

$$
P^{n}(z)-z=0
$$

que assume a forma

$$
z^{d^{n}}+\ldots+\left(\lambda^{n}-1\right) z=0
$$

Uma das raízes é a nula e as demais serão denotadas por $\mu_{1}, \mu_{2}, \ldots, \mu_{d^{n}-1}$. Podemos escrever

$$
\left|\mu_{1}\right|\left|\mu_{2}\right| \ldots\left|\mu_{d^{n}-1}\right|=\left|\lambda^{n}-1\right| .
$$

Seja $m=\min \left\{\left|\mu_{t}\right|: i=1,2, \ldots, d^{n}-1\right\}$. Então

$$
m^{d^{n}-1} \leq\left|\lambda^{n}-1\right| \leq\left(\frac{1}{n}\right)^{d^{n}-1}
$$


para uma infinidade de números naturais. Logo, $P$ tem uma infinidade de pontos periódicos convergindo para a origem, que é um ponto fixo irracionalmente indiferente com autovalor $\lambda$. Suponhamos que a origem pertença ao conjunto de Fatou. Pelo teorema 1.3.9, (EFS) tem solução: numa vizinhança da origem, o polinômio $P$ é conjugado à rotação irracional $z \mapsto \lambda z$. Isso induz uma contradição, pois rotações irracionais não possuem pontos periódicos, além do centro. Portanto, a origem é um ponto fixo irracionalmente indiferente que está no conjunto de Julia.

Uma pergunta natural que surge é se existem valores $\lambda=e^{2 \pi t a}$, com $\alpha$ irracional, satisfazendo (1.3.1) para uma infinidade de números naturais. A resposta é afirmativa. De fato, observamos inicialmente que

$$
\left|\lambda^{n}-1\right|=\left|e^{2 \pi i n \alpha}-1\right|=\left|e^{\pi i n \alpha}-e^{-\pi i n \alpha}\right|=2|\sin \pi n \alpha| .
$$

Para cada $n$, seja $m_{n}$ o inteiro que satisfaz $\left|n \alpha-m_{n}\right| \leq \frac{1}{2}$. Usando as desigualdades

$$
2 x \leq \sin \pi x \leq \pi x \leq \frac{7}{2} x,
$$

válidas para $|x| \leq \frac{1}{2}$, temos

$$
\left|\lambda^{n}-1\right|=2|\sin \pi n \alpha|=2 \sin \left(\pi\left|n \alpha-m_{n}\right|\right)
$$

$\mathrm{e}$

$$
4\left|n \alpha-m_{n}\right| \leq\left|\lambda^{n}-1\right| \leq 7\left|n \alpha-m_{n}\right|
$$

Para construirmos valores de $\lambda=e^{2 \pi i \alpha}$ de modo a satisfazer (1.3.1), usaremos expansão em frações contínuas. Seja $\left\{a_{n}\right\}_{n \geq 0}$ uma sequência de inteiros positivos, e consideremos o racional

$$
\frac{p_{n}}{q_{n}}=a_{0}+\frac{1}{a_{1}+\frac{1}{a_{2}+\frac{1}{\ddots \frac{1}{a_{n}}}}}
$$


na forma irredutivel. A sequência $\left\{p_{n} / q_{n}\right\}$ converge para um número irracional $\alpha$. Escolhendo os $k$ primeiros valores de $\left\{a_{n}\right\}$, sabemos que $a_{k \cdot 1}$ deverá satisfazer

$$
\left|q_{k} \alpha-p_{n}\right|<\frac{1}{q_{k+1}}=\frac{1}{a_{k+1} q_{k}+q_{k-1}}<\frac{1}{a_{k+1} q_{k}} .
$$

Assim prosseguimos indutivamente tomando

$$
a_{k+1}>7 q_{k}^{d^{q_{k-2}}}
$$

Logo, por (1.3.2), (1.3.3) e (1.3.4), teremos

$$
\left|\lambda^{q_{k}}-1\right| \leq 7\left|q_{k} \alpha-p_{k}\right|<\frac{7}{a_{k+1} q_{k}}<\left(\frac{1}{q_{k}}\right)^{d^{q_{k-1}}}
$$

o que mostra que $\alpha$ satisfaz (1.3.1) para $n=q_{0}, q_{1}, \ldots . \Gamma$

Cabe observar que os exemplos acima exigem que $\alpha$ seja " bem aproximado por racionais ". Esta é uma condiçào necessária para a construção de tais exemplos. De fato, se $\alpha$ for " mal aproximado por racionais ", então $f$ é localmente conjugada à rotação irracional correspondente, em virtude do seguinte teorema de C. Siegel. ${ }^{2}$

Teorema 1.3.13. Seja $\lambda=e^{2 \pi u}$, com $\alpha \in \mathbb{R} \backslash \mathbb{Q}$. Suponhamos que existam constantes positivas $a$ e $b$ tais que

$$
\left|\alpha-\frac{p}{q}\right|>\frac{a}{q^{b}} \quad \text { paratodo } p, q \in \mathbb{Z}, q \geq 1 .
$$

Então a equação funcional de Schröder tem solução.

\footnotetext{
${ }^{2}$ Siegel, C. L. . Iteration of analytic functions, Ann. of Math. . 43. 607 - 616, (1942).
} 
Seja $z_{0}$ um ponto periódico indiferente com autovalor $\lambda$ satisfazendo as hipóteses do teorema acima. A vizinhança $U$ de $z_{0}$ em que a transformação $R$ é conjugada à rotação irracional $z \mapsto \lambda z$ é chamada disco de Siegel ( ver seção 1.7 ). Neste caso, pelo teorema 1.3 .9 , o ponto $z_{0}$ pertence ao conjunto de Fatou.

\section{4 - Pontos críticos e ciclos (super) atratores}

Esta seção fundamental para o desenvolvimento do capitulo 2, expõe a possibilidade de identificarmos a existência de ciclos (super) atratores analisando a órbita dos pontos críticos da transformação racional $R$.

Definição 1.4.1. Se a equação $R(z)=v$ tem uma solução $c$, cuja multiplicidade é maior que 1 , dizemos que $v$ é um valor critico de $R$. A solução $c$ é chamada ponto critico.

Topologicamente, os pontos críticos são aqueles em que a transformação $R$ não é localmente injetora. Em coordenadas locais, o ponto crítico $c$ satisfaz a condição $R^{\prime}(c)=0$.

Teorema 1.4.2. Toda transformação racional $R$ de grau $d \geq 2$ tem no máximo $(2 d-2)$ pontos criticos.

Prova: Podemos escrever a transformação racional $R$ sob a forma

$$
R(z)=\frac{p(z)}{q(z)}
$$

onde $p$ e $q$ são polinômios em $z$ com grau no máximo $d$, sem fatores comuns. A derivada de $R$ é dada por 


$$
R^{\prime}(z)=\frac{p^{\prime}(z) q(z)-p(z) q^{\prime}(z)}{(q(z))^{2}}
$$

Assim, para determinarmos os pontos críticos de $R$, devemos resolver

$$
p^{\prime}(z) q(z)-p(z) q^{\prime}(z)=0
$$

que é uma equação polinomial de grau no máximo $(2 d-2)$ e consequentemente tem no máximo $(2 d-2)$ soluções, que são os pontos críticos de $R$.

Corolário 1.4.3. Toda transformação racional de grau $d \geq 2$ tem no máximo $(2 d-2)$ valores criticos.

Para provarmos a próxima proposição, precisamos do seguinte lema.

Lema 1.4.4. Se $a \in J(R)$, então existe $b \in J(R)$ tal que $a \in \mathbb{O}^{+}(b)$ mas $b \notin O^{+}(a)$.

Prova: Se $a$ não é periódico, então $b$ pode ser uma pré-imagem de $a$; visto que o conjunto de Julia é completamente invariante. Se $a$ é periódico de período $n$, consideremos a transformação $S=R^{n}$ e a equação

$$
S(z)=a
$$

Se $a$ é a única solução de (1.4.1), então $S$ pode ser conjugada a um polinômio por uma transformação de Möbius que leva $\infty$ em $a$. Como $\infty$ é um ponto fíxo superatrator, está no conjunto de Fatou do polinômio. Segue que $a \in \mathcal{F}(S)$, o que contradiz a hipótese. Existe, portanto, outra solução $b$ de (1.4.1), com $b \notin \mathbb{O}^{+}(a)$, pois $a$ é periódico de período $n$. 
Proposição 1.4.5. O conjunto de Julia $J(R)$ é perfeito.

Prova: Pela própria definição, o conjunto de Julia $J(R)$ é fechado. Para provarmos que não tem pontos isolados, consideremos $a \in J$ e $U$ uma vizinhança de $a$. Pelo lema anterior, existe $b \in J$ tal que $a \in \mathbb{O}^{+}(b)$ mas $b \notin \mathbb{O}^{+}(a)$. Como $b \in J$, pelo teorema de Montel existe um inteiro positivo $k$ tal que $b \in R^{k}(U)$. Assim, existe $c \in U$ tal que $R^{k}(c)=b$. Como $b \notin \mathbb{O}^{+}(a)$, segue que $c \neq a$. Pela invariância do conjunto de Julia, temos que $c \in J$. Portanto, para toda vizinhança $U$ de um ponto $a \in J$, existe $c \in J \cap U$.

Teorema 1.4.6. Seja $R$ uma transformação racional de grau $d \geq 2$. Então a bacia imediata de todo ciclo (super)atrator contém pelo menos um ponto critico de $R$.

Prova: No caso de um ciclo superatrator não há nada a provar, pois como o autovalor do ciclo é nulo, pelo menos um dos pontos periódicos é crítico.

Sejam $\left\{z_{1}, z_{2}, \ldots, z_{n}\right\}$ um ciclo atrator e $A\left(z_{i}, R^{n}\right), 1 \leq i \leq n$, a bacia imediata de cada ponto $z_{1}$ do ciclo. Assumindo que o teorema vale para o caso de um ponto fixo, temos que cada $A\left(z_{i}, R^{n}\right)$ contém um ponto crítico de $R$. Assim, no caso de um ciclo atrator, é suficiente provar o resultado para um ponto fixo. Seja $p$ um ponto fixo atrator e $A=A(p, R)$ sua bacia imediata. Pelo teorema da uniformização, o disco unitário $D_{1}$ é o recobrimento universal de $A$. Como o grupo de recobrimento é transitivo, podemos escolher um recobrimento $\Pi: D_{1} \rightarrow A$ tal que $\Pi(0)=p$ e um levantamento $\tilde{R}$ de $\left.R\right|_{A}$ tal que $\tilde{R}(0)=0$. Ou seja, o diagrama

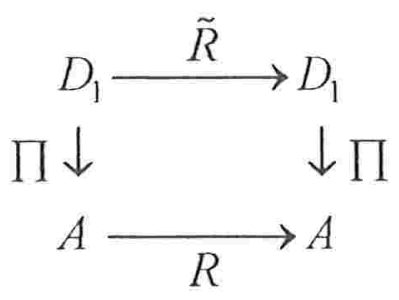

comuta. Suponhamos que $R$ não tenha pontos críticos em $A$. Então o ramo da inversa $R^{-1}$, que fixa $p$, pode ser prolongado analiticamente ao longo de toda curva em $A$. Assim, dada uma curva $\gamma$ em $D_{1}$, existe uma curva $\Gamma$, a saber $\Pi^{-1} \circ R^{-1} \circ \Pi(\gamma)$, que trans- 
forma-se pela $\tilde{R}$ em $\gamma$. Em particular $\tilde{R}\left(D_{1}\right)=D_{1}$. Ainda, como $R$ não tem pontos críti$\cos$ em $A, \tilde{R}$ não tem pontos críticos em $D_{1}$. Desse modo, $\tilde{R}$ é uma transformação de recobrimento analítico de $D_{1}$ em $D_{1}$, sendo assim um homeomorfismo e consequentemente, uma transformação de Möbius. Como, no entanto, $\Pi \circ \tilde{R}=R \circ \Pi$, temos

$$
\left|\tilde{R}^{\prime}(0)\right|=\left|R^{\prime}(p)\right|<1
$$

o que contradiz o fato de que a transformação de Möbius $\tilde{R}$ é uma isometria hiperbólica.

Corolário 1.4.7. O número de ciclos (super)atratores de toda transformação racional $R$ de grau $d \geq 2$ é no máximo $(2 d-2)$.

\section{5 - Um algoritmo para o Conjunto de Julia}

Teorema 1.5.1. Seja $U \subset \bar{C}$ uma vizinhança de um ponto $z \in J(R)$. Então, o conjunto

$$
W=\bigcup_{n \geq 0} R^{n}(U)
$$

omite no máximo dois pontos e estes pontos, denominados excepcionais, estão no conjunto de Fatou.

Prova: Se $W$ omitisse pelo menos três pontos, a família de iteradas $\left\{R^{n}\right\}_{n \geq 0}$ restrita a $U$, pelo teorema de Montel, seria normal. Isto contradiz a hipótese de que $z \in J(R)$. Portanto $W$ omite no máximo dois pontos. Vamos provar, agora, que esses pontos estão no conjunto de Fatou. Por definição, o conjunto $W$ é completamente invariante, e assim os pontos omitidos, $z_{1}$ e $z_{2}$, são fixos ou definem um ciclo de período 2 . No primeiro caso, $R^{-1}\left(z_{i}\right)=z_{i} \quad(i=1,2)$, com $z_{1}$ e $z_{2}$ distintos ou não. No segundo, $R^{-1}\left(z_{1}\right)=z_{2}$ e $R^{-1}\left(z_{2}\right)=z_{1}$. Em todos os casos, a multiplicidade da solução é $d$, onde $d$ 
é o grau da transformação $R$. Portanto, $z_{1}$ e $z_{2}$ são pontos críticos, consequentemente superatratores. Pelo teorema 1.3.2, $z_{1}$ e $z_{2}$ estão no conjunto de Fatou.

Corolário 1.5.2. Seja $z_{0} \in J(R)$, então a órbita regressiva $O^{-}\left(z_{0}\right)$ é densa em $J(R)$.

Prova: Seja $z$ um ponto arbitrário em $J(R)$ e $U$ vizinhança de $z$. Pelo teorema anterior, o conjunto

$$
W=\bigcup_{n \geq 0} R^{n}(U)
$$

não omite, em particular, o ponto $z_{0} \in J$. Assim, existe $w \in U$ tal que $R^{n}(w)=z_{0}$, ou seja, $w \in\left(\mathbb{O}^{-}\left(z_{0}\right) \cap U\right)$.

Este corolário sugere um método computacional para o traçado do conjunto de Julia. O algoritmo consiste em calcular a órbita regressiva de um ponto $z_{0}$ do conjunto de Julia. Tomam-se todos os valores possíveis de $R^{-k}\left(z_{0}\right)$, com $k$ variando de 1 até um certo nível máximo de recorrência, nvmax. Cabe ressaltar que, se a transformação racional $R$ é de grau $d$, então em cada nível $k>0$ são calculados e plotados na tela gráfica $d^{k}$ pontos, correspondentes a $R^{-k}\left(z_{0}\right)$, para um dado ponto inicial $z_{0}$ do conjunto de Julia. O método é bastante rápido mas favorece as partes externas do conjunto, raramente gerando pontos nas partes mais internas, que mal aparecem no traçado. Imaginando um campo eletrostático produzido por uma carga elétrica no conjunto de Julia, este método enfatizará somente as regiões nas quais as linhas de força tendem a chegar.

O algoritmo básico do programa computacional é apresentado no fluxograma da figura 2, na página seguinte. O algoritmo foi implementado para o traçado do conjunto de Julia da transformação associada ao método de Newton para uma classe de polinômios de graus 3 e 4, como veremos no capítulo 2 . 


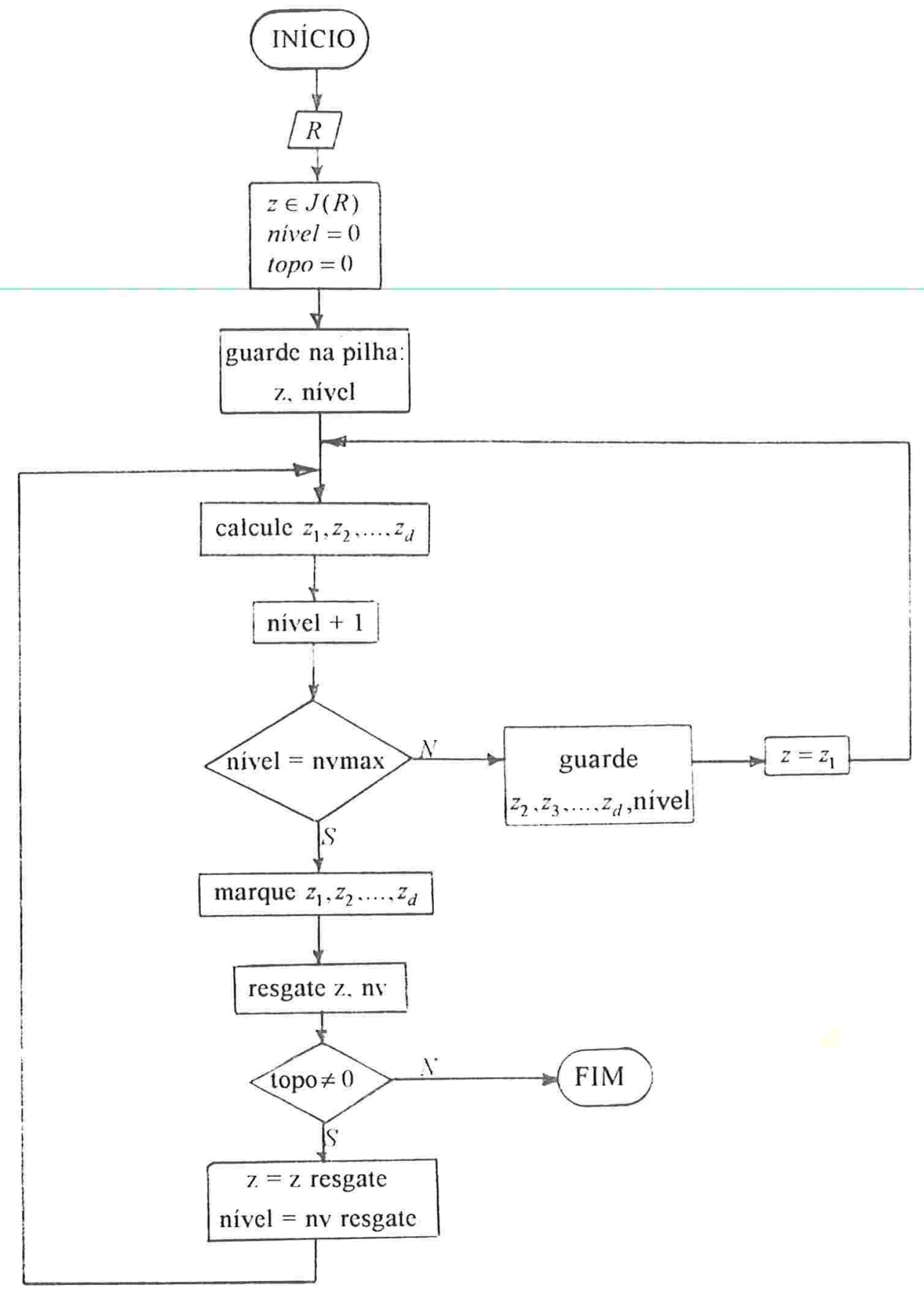

Figura 2: Algoritmo do traçado do conjunto de Julia de uma transformação $R$. 


\section{6 - Teorema fundamental da decomposição Fatou/Julia}

Lema 1.6.1. Toda tranșformação racional $R$ de grau $d \geq 2$ tem exatamente $(d+1)$ pontos fixos, contados com sua multiplicidade.

Prova: Conjugando $R$ por um automorfismo linear fracionário, caso isso seja necessário, podemos assumir que $\infty$ não é ponto fixo para $R$. Assim, podemos escrever $R$ como o quociente

$$
R(z)=\frac{p(z)}{q(z)}
$$

onde $p$ é um polinômio de grau no máximo igual a $d$, e $q$ um polinômio de grau exatamente igual a $d$. A equação $R(z)=z$ é equivalente a

$$
p(z)=z q(z)
$$

que possui $(d+1)$ soluções, que são os pontos fixos de $R$.

Teorema 1.6.2. O conjunto de Julia de uma transformação racional de grau $d \geq 2$ está contido no fecho do conjunto dos pontos periódicos.

Prova: Pela proposição 1.4.5, o conjunto de Julia não tem pontos isolados. Assim, podemos provar o teorema para o conjunto de Julia, exceto um número finito de pontos. Pelo lema anterior, $R$ tem um número finito de pontos fixos, e pelo corolário 1.4.3, um número finito de ponto críticos. Desse modo, podemos considerar $z_{0}$ um ponto no conjunto de Julia $J(R)$, que não é um ponto fixo nem um valor crítico. Assim, $z_{0}$ tem $d$ pré-imagens: $z_{1}, z_{2}, \ldots, z_{d}$, distintas entre si e de $z_{0}$. Pelo teorema da função inversa, temos $d$ transformações holomorfas $z \mapsto \varphi_{i}(z)$ definidas numa vizinhança $U$ de $z_{0}$, 
tais que $R\left(\varphi_{j}(z)\right)=z$ e $\varphi_{j}\left(z_{0}\right)=z_{,}, 1 \leq j \leq d$. Consideremos a familia $G$ de transformações holomorfas $g_{n}: U \rightarrow \bar{C}$ definidas por

$$
g_{n}(z)=\frac{\left(R^{n}(z)-\varphi_{1}(z)\right)\left(z-\varphi_{2}(z)\right)}{\left(R^{n}(z)-\varphi_{2}(z)\right)\left(z-\varphi_{1}(z)\right)} .
$$

Suponhamos que a familia $G$ omita os valores 0,1 e $\infty$, em $\bar{C}$. Pelo teorema de Montel, $G$ é normal e consequentemente a família $\nabla=\left\{R^{n}: U \rightarrow \overline{\mathrm{C}}, n \in \mathbb{N}\right\}$ das iteradas de $R$ é normal em $U$. Isso contradiz o fato de que $U$ intercepta o conjunto $J(R)$. Logo, a família $G$ não omite $0,1, \infty$. Em outras palavras, para algum $n>0$ e algum $z \in U$, $R^{n}(z)$ assume um dos três valores: $z, \varphi_{1}(z), \varphi_{2}(z)$. No primeiro caso, $z$ é um ponto periódico de período $n$ e nos dois últimos de período $(n+1)$. Há, portanto, um ponto periódico $z$ arbitrariamente próximo do ponto $z_{0} \in J(R)$.

Teorema 1.6.3. Seja $R$ uma transformação racional com $N$ pontos periódicos indiferentes. Existe um $\varepsilon>0$ e uma direção 6 no plano w tal que, se $0<\rho<\varepsilon$, a transformação racional

$$
R_{r}(z)=R(z, w)=R\left(z, \rho e^{2 \pi \theta \theta}\right)=\left(1-\rho e^{2 \pi \theta}\right) R(z)+\rho e^{2 \pi \theta}
$$

tem pelo menos $N / 2$ pontos periódicos atratores (que são pertubações de órbitas indiferentes de $R$ ).

Prova: Sejam $z_{j}, j=1,2, \ldots, N$, os pontos periódicos indiferentes de período $n_{j}$ e autovalor $\lambda, . \mathrm{O}$ par $(z, 0)$ satisfaz a equação

$$
F_{j}(z, w)=R^{n_{j}}(z, w)-z=0
$$

Como $F_{j}(z, w)$ é uma função racional de $z$ e $w$, existe uma equação algébrica

$$
A_{i}\left(z, w^{\prime}\right)=p_{0}\left(w^{\prime}\right) z^{n}+p_{1}(w) z^{n-1}+\ldots+p_{n}(w)=0
$$


onde $n=d n_{j}$ e $p_{i}$ são polinômios, equação essa equivalente a $F_{j}(z, w)=0$. Aplicando a teoria de funções algébricas a cada equação $A_{j}(z, w)=0$, podemos introduzir novas variáveis $\xi_{j}$ e funções analiticas $\phi_{j}\left(\xi_{j}\right)$ tais que

$$
\begin{array}{ll}
w^{\prime}=\xi_{l}^{m_{i}} & \text { onde } m_{l} \text { é um inteiro positivo } \\
z=\phi_{1}\left(\xi_{l}\right) \quad \mathrm{e} \\
A_{l}\left(\phi_{,}\left(\xi_{j}\right), \xi_{j}^{m_{j}}\right)=F_{j}\left(\phi_{j}\left(\xi_{j}\right), \xi_{j}^{m_{l}}\right)=0 .
\end{array}
$$

Podemos definir as funções derivadas por:

$$
\alpha_{j}\left(\xi_{1}\right)=\frac{\partial R^{n_{j}}}{\partial z}\left(\phi_{,}\left(\xi_{1}\right), \xi_{1}^{m_{1}}\right)
$$

Seja $m$ o mínimo múltiplo comum de todos os inteiros $m_{l}$ correspondentes aos $N$ pontos periódicos indiferentes. Consideremos uma nova variável $v$ tal que $v^{m}=w$. Então

$$
v^{\frac{m}{m_{j}}}=w^{\frac{1}{m_{j}}}=\xi_{\jmath} .
$$

O ângulo $\theta$ é obtido calculando-se um ângulo $\theta_{1}$ no plano $v$. Para determinarmos $\theta_{1}$, escrevemos

$$
\alpha_{j}(v)=\lambda,+a_{0,} v^{k_{j}}+a_{1, j} v^{k_{j}+1}+\ldots \quad \text { onde } a_{0_{j}} \neq 0
$$

Um termo $k_{j}$ de ordem superior existe, pois $\alpha_{j}$ não é constante. Seja

$$
\tilde{\alpha}_{j}(v)=\lambda_{j}+a_{j} v^{k_{j}} \quad\left(a_{j}=a_{0_{j}}\right)
$$

Suponhamos que $2^{\ell}$ é a maior potência de 2 que divide qualquer $m_{l}$. Para cada $\lambda$, no círculo unitário, consideremos as direções tangentes e as direções que diferem da tan- 
gente de um ângulo múltiplo de $\pi / 2^{\ell}$. Considerando todos os autovalores $\lambda_{j}$, obtemos um número finito de direções. Escolhemos um ângulo $\theta_{2}$ que não seja uma destas direções. A figura 3 ilustra o caso em que $\ell=1$ e existem três ciclos indiferentes. $\mathrm{O}$ ângulo $\theta_{1}$ desejado será a soma $\left(\theta_{2}+\theta_{3}\right)$ onde $\theta_{3}$ é determinado por um processo indutivo, isto é:

$$
\theta_{3}=\pi\left(b_{0}+\frac{b_{1}}{2}+\ldots+\frac{b_{f}}{2^{l}}\right)
$$

onde $b_{i} \in\{0,1\}$. Determinamos $b_{i-1}$ após o cálculo de $b_{i}, \ldots, b_{\ell}$.

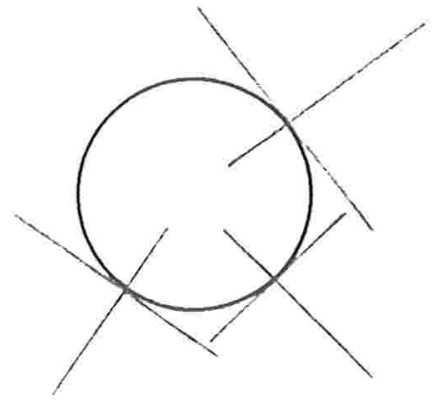

(3a) Direções tangentes e que diferem destas de $\pi / 2$

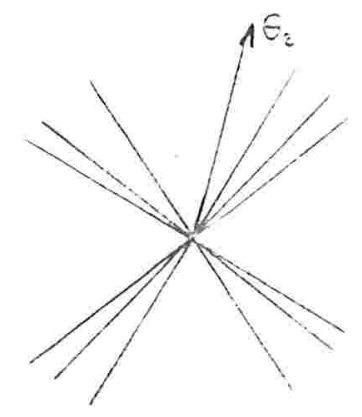

(3b) Direção $\theta_{2}$

Figura 3 - Direções para o caso em que existem três ciclos indiferentes e $\ell=1$.

Consideremos todos os pontos periódicos $z$, cujo período $k$, correspondente é divisível por $2^{\ell}$. Então,

$$
\tilde{\alpha}_{j}\left(\rho e^{2 \pi i \theta_{1}}\right)=\lambda_{j}+a_{j} \rho^{k_{j}} e^{2 \pi i\left(k_{j} \theta_{2}+b_{t} \pi\right)} .
$$

Como a direção $k_{j} \theta_{2}$ não é uma daquelas direções excluídas, escolhemos $b_{\ell}$ tal que pelo menos metade dos $\tilde{\alpha}_{j}$ estejam no interior do círculo unitário. Para determinarmos $b_{\ell-1}$, repetimos o cálculo em todos os pontos $z_{j}$ para os quais $k_{j}$ é divisível por $2^{\ell-1}$ mas não por $2^{\ell}$. Então, 


$$
\tilde{\alpha}_{j}\left(\rho e^{2 \pi i \theta_{1}}\right)=\lambda,+a_{j} \rho^{k_{j}} e^{2 \pi i\left(k_{j} \theta_{2}+\frac{q}{2} b_{t} \pi+b_{t-1} \pi\right)}
$$

onde $q$ é um número impar. Como

$$
k_{j} \theta_{2}+\frac{q}{2} b_{r} \pi
$$

não é tangente ao circulo unitário, escolhemos $b_{t-1}$ tal que pelo menos metade dos $\tilde{\alpha}_{\text {, }}$ estejam no interior do disco. Continuamos o processo até que o ângulo $\theta_{1}$ seja determinado.

Corolário 1.6.4. Seja $R$ uma transformação racional de grau $d \geq 2$. O múmero de ciclos atratores somado à metade do número de ciclos indiferentes é no máximo $(2 d-2)$.

Prova: Basta combinarmos o teorema 1.6 .3 com o corolário 1.4.7.

Observação 1.6.5. Usando métodos de cirurgia quase-conforme, Shishikura ${ }^{3}$ mostrou que a melhor estimativa para o número de ciclos atratores e indiferentes é $(2 d-2)$. Embora o corolário 1.6.4 não apresente essa estimativa, é suficiente para provar o próximo teorema, dito teorema fundamental da decomposição Fatou/Julia.

Teorema 1.6.6. O conjunto de Julia é o fecho do conjunto dos pontos periódicos repulsores.

Prova: Basta combinarmos o teorema 1.6.2 com o corolário 1.6.4.

\footnotetext{
${ }^{3}$ M. Shishikura. On the quasiconformal surgery of rational functions. Ann. Sci. É Norm. Sup.. 20, 1-29. (1987)
} 


\section{7 - Domínios de Sullivan}

Definição 1.7.1. Seja $D$ uma componente do conjunto de Fatou. Se existir um inteiro positivo $n$ tal que $R^{n}(D)=D$, então $D$ é uma componente periódica. Por outro lado, $D$ é uma componente finalmente periódica se existir $n$ tal que $R^{n}(D)$ seja periódica. A componente $D$ é pré-periódica se for finalmente periódica, mas não periódica.

Definição 1.7.2. Um dominio de Sullivan de $R: \bar{C} \rightarrow \overline{\mathrm{C}}$ é uma componente periódica do conjunto de Fatou.

Definição 1.7.3. Seja $D$ um domínio de Sullivan de periodo $n$ e seja $S=R^{n}$.

(1) $D$ é um dominio atrator se $D$ contiver um ponto periódico $p$ tal que $0<|S(p)|<1$ e $D=A(p, S)$.

(2) $D$ é um dominio superatrator se $D$ contiver um ponto periódico $p$ tal que $p$ seja um ponto crítico de $S$ e $D=A(p, S)$.

(3) $D$ é um dominio parabólico se existir um ponto periódico $p$ em $\partial D$ cujo período divide $n$ e $S^{k}(z) \rightarrow p$ quando $k \rightarrow \infty$ para todo $z \in D$.

(4) $D$ é um disco de Siegel se $D$ for simplesmente conexo e se $\left.S\right|_{D}$ for analiticamente conjugado a uma rotação. Em outras palavras, existe um homeomorfismo analítico $h: D \rightarrow D_{r}\left(D_{r}=\{z \in \mathbb{C}:|z|<r\} \quad\right.$ para algum $\left.r>0\right)$ tal que o diagrama:

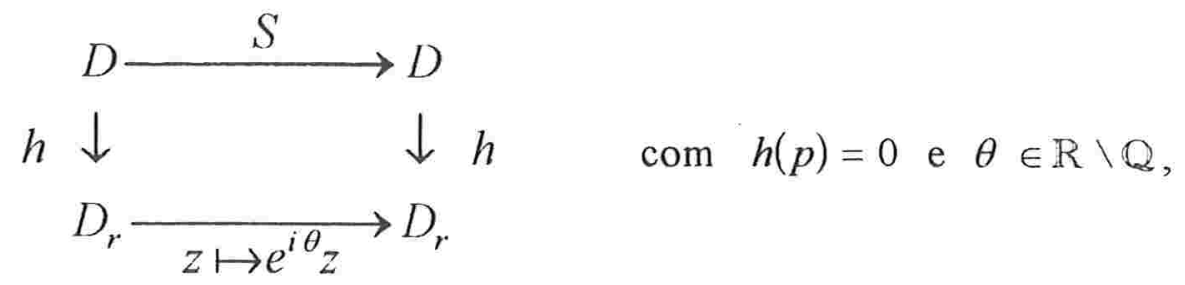

comuta. 
(5) $D$ é um anel de Herman se for conformemente equivalente a um anel $A=\left\{z \in C: r_{1}<|z|<r_{2}\right\} \quad\left(r_{1}, r_{2} \in \mathbb{R}, r_{1} \geq 0 \quad e \quad r_{2}>0\right)$ e se a transformação $\left.S\right|_{D}$ for analiticamente conjugada a uma rotação rígida do anel.

Referimo-nos, frequentemente, aos discos de Siegel e aos anéis de Herman como dominios de rotação.

Observação 1.7.4. Fazendo uma analogia com as seções anteriores, observamos que os domínios (super) atratores relacionam-se com ciclos (super) atratores; os domínios de rotação com ciclos irracionalmente indiferentes; e os parabólicos com ciclos racional e irracionalmente indiferentes. 


\section{Capítulo 2}

\section{Aplicação ao Método de Newton no Plano Complexo}

\section{1 - Considerações iniciais}

Em 1669, Newton discutiu a equação $x^{3}-2 x-5=0$. Tomando $x_{0}=2$ como primeira aproximação da raiz real $\xi$, escreveu $x=y+2$ e obteve a equação $y^{3}+6 y^{2}+10 y-1=0$. Desprezando os termos não lineares, obteve $y=1 / 10$ e tomou $x_{1}=2.1$ como próxima aproximação para $\xi$. O método foi sistematicamente discutido em 1690 , por Joseph Raphson, que obteve o familiar esquema de iterações

$$
x_{n+1}=x_{n}-\frac{f\left(x_{n}\right)}{f^{\prime}\left(x_{n}\right)}
$$

para determinar as soluções da equação $f(x)=0$. Isto significa iterar a transformação

$$
N_{f}(x)=x-\frac{f(x)}{f^{\prime}(x)} .
$$

Em 1879, Cayley propôs este método para encontrar os zeros de funções complexas. Ele perguntou-se sob que condições a sequência $z_{n}$ converge para uma raiz $\xi$ e resol- 
veu o problema para um polinômio quadrático qualquer. No mesmo ano, Cayley comentou numa nota de rodapé: " the case of the cubic equation appears to present considerable difficulty " 1; e onze anos mais tarde, ele ressuscitou a questâo: " J'espère appliquer cette théorie au cas d'une equation cubic, mais les calculs sont beaucoup plus difficiles " 2 . Neste capitulo, retomamos essa questão, discutindo o comportamento do método de Newton aplicado a polinômios no plano complexo, à luz da teoria motivada pelos estudos de Fatou e Julia durante a primeira Guerra Mundial, e apresentada no capítulo precedente.

Seja $p$ uma função polinomial em $\bar{C}$, e $N_{p}$ a transformação associada ao método de Newton, dada por

$$
N_{p}(z)=z-\frac{p(z)}{p^{\prime}(z)}
$$

Proposição 2.1.1. Se $\xi$ é um zero de ordem $m>1$ de $p$, então $\xi$ é um ponto fixo atrator de $N_{p}$. Se $\xi$ é um zero de ordem $m=1$ de $p$, então $\xi$ é um ponto fixo super-atrator de $N_{p}$.

Prova: Se $\xi$ é um zero de ordem $m$ de $p$, então existe uma função $g$ analítica tal que $g(\xi) \neq 0$ e $p(z)=(z-\xi)^{m} g(z)$. Assim

$$
N_{p}(z)=z-\frac{(z-\xi) g(z)}{m g(z)+(z-\xi) g^{\prime}(z)}
$$

Desse modo, $N_{p}(\xi)=\xi$, ou seja $\xi$ é um ponto fixo para $N_{p}$. Como

$$
\left(m g(z)+(z-\xi) g^{\prime}(z)\right)
$$

não se anula em $\xi$, podemos diferenciar (2.1.2), obtendo

$$
N_{p}^{\prime}(\xi)=\frac{m-1}{m}
$$

${ }^{1}$ Cayley, M. A.. The Newton-Fourier imaginary problem. Amer. J. Math.. 2. 97. (1879).

${ }^{2}$ Cayley, M. A.. Sur les racines d'une equation algebrique. Comptes Rendus Acad. Sci. Paris. 110. $215-218$. (1880). 
Como o autovalor do ponto fixo $\xi$ é $\lambda=N_{p}^{\prime}(\xi)$, temos $0 \leq \lambda<1$ e $\xi$ é um ponto fixo atrator para $N_{p}$. Ainda, se $\xi$ é um zero de ordem 1 de $p$, então $\lambda=0$ e $\xi$ é um ponto fixo superatrator de $N_{p}$.

Proposição 2.1.2. A bacia de (super) atração do ponto fixo $\xi$ é o conjunto de valores iniciais $z$ para os quais a sequência de iteradas $N_{p}^{k}(z)$ converge para a solução $\xi$ de $p(z)=0$.

Prova: Consequência da definição 1.3.6.

Se $N_{p}^{k}(z)$ não converge para nenhum dos zeros de $p$, dizemos que $z$ é um valor inicial para o qual o método de Newton falha.

Proposição 2.1.3. () conjunto de valores iniciais para os quais o método de Newton falha é a união do conjunto de Julia de $N_{p}$ e as componentes eventualmente periódicas associadas aos dominios de Sullivan existentes, além das bacias (super) atratoras dos zeros de p.

Prova: Consequência das definições 1.2.1, 1.7.1 e 1.7.2.

O conjunto de Julia $J\left(N_{p}\right)$, pelas proposições 1.2 .2 e 1.4 .5 , é não vazio e fechado, enquanto aquelas componentes, quando existem são conjuntos abertos. A seção 1.5 sugere um algoritmo para determinarmos o conjunto de Julia da transformação $N_{p}$. Para determinarmos a existência de domínios de Sullivan, as órbitas dos pontos críticos desempenham um papel fundamental. Na seção 1.4, provamos que toda bacia imediata de um ciclo (super) atrator ou, equivalentemente, todo domínio de Sullivan (super) atrator possui um ponto critico. É demonstrado em [2] que as órbitas dos pontos críticos evidenciam, também, quando existem, os domínios parabólicos e de rotação contidos no conjunto de Fatou. Tendo em vista que estes domínios estão associados a ciclos com autovalor de módulo unitário, torna-se dificil identificar uma transformação $N_{p}$ que possua tal ciclo. Esta dificuldade é consequência dos fatos de que os coeficientes do polinômio $p$, neste caso, possuem geralmente partes real e imaginária com número infinito de casas decimais, e de que, logicamente, o computador suporta um número finito delas. Assim, não é discutido, neste trabalho, o comportamento das transformações $N_{p}$ que possuem ciclos indiferentes, ou seja, que o conjunto de Fatou $\mathcal{F}\left(N_{p}\right)$ possui domínios parabólicos ou de rotação. 
Proposição 2.1.4. Se p é um polinômio de grau $d \geq 2$, com zeros de multiplicidade 1 , então $N_{p}$ tem no máximo $(d-2)$ pontos criticos, não fixos.

Prova: Neste caso, como a transformação $N_{p}$ associada ao método de Newton é racional de grau $d$, pelo teorema $1.4 .2, N_{p}$ tem no máximo $(2 d-2)$ pontos críticos. Se $p$ tem zeros distintos, então pela prova da proposição 2.1.1, temos que os $d$ zeros de $p$ são pontos críticos de $N_{p}$, e além disso são pontos fixos, donde segue o resultado.

Proposição 2.1.5. Se a transformação $N_{p}$ possui um ciclo atrator, além dos pontos fixos, então a bacia de tal ciclo contém pelo menos um dos $(d-2)$ pontos críticos não fixos.

Prova: Consequência do teorema 1.4 .6 e da proposição anterior.

Tendo em vista a proposição anterior, observamos que se $N_{p}$ tem um ciclo atrator, além dos pontos fixos, então a órbita de algum ponto crítico o evidenciará. Portanto, basta analisarmos as órbitas dos pontos críticos para prognosticar a existência de um conjunto de valores iniciais para os quais o método de Newton falha: a bacia de atração de tal ciclo. Este é o ponto central na discussão das seções 2.3 e 2.4 .

Para facilitar a discussão das próximas seções, consideremos o seguinte lema.

Lema 2.1.6. Sejam a constante $c$, a transformação afim $T(z)=a z+b$, e o polinômio $p$. Então, (a) $N_{c p}=N_{p}$;

(b) $T^{-1} \circ N_{p} \circ T=N_{p \circ T}$

Prova: A parte (a) segue de (2.1.1). Para a parte (b) basta observar que $T^{-1} \circ N_{p} \circ T(z)=\frac{1}{a}\left(T(z)+\frac{p \circ T(z)}{p^{\prime} \circ T(z)}-b\right)=z+\frac{p \circ T(z)}{p^{\prime} \circ T(z)} \frac{1}{a}=z+\frac{p \circ T(z)}{(p \circ T)^{\prime}(z)}=N_{p \circ T}(z)$.

Observação 2.1.7. Se existe uma transformação $T$ tal que $p \circ T=q$, então dizemos que $p$ é equivalente a $q$, pela transformação $T$. 


\section{2 - Método de Newton para polinômio quadrático}

Se $p$ é um polinômio quadrático com raizes distintas, então pela proposição 2.1.4, $N_{p}$ não possui pontos críticos além dos zeros de $p$. Neste caso, pela proposição 2.1.3, o conjunto de valores iniciais para os quais o método de Newton falha, reduz-se ao conjunto de Julia de $N_{p}$. Para identificá-lo, consideremos inicialmente o seguinte lema.

Lema 2.2.1. Seja $q(z)=z^{2}-1$ e $N_{q}$ a transformação associada ao método de Newton. Então o conjunto de Julia $J\left(N_{q}\right)$ é a reta $i R$, mediatriz do segmento que une as duas raizes de q: 1 e - 1 . A bacia de atração de cada uma das duas raizes, indicada por $A(1) e$ $A(-1)$, respectivamente, é o semiplano limitado por $J\left(N_{q}\right)$, que contém a raiz.

Prova: A transformação associada ao método de Newton de $q(z)=z^{2}-1$,

$$
N_{q}(z)=\frac{z^{2}+1}{2 z}
$$

é conjugada a

$$
R(u)=u^{2}
$$

em $\bar{C}$, pela transformação de Möbius:

$$
T(z)=u=\frac{z-1}{z+1}
$$

Como o conjunto de Julia $J(R)$ é $S^{1}=\{z \in \mathbb{C}:|z|=1\}$ e $T(i \mathbb{R})=S^{1}$, temos $J\left(N_{q}\right)=i \mathbb{R}$. E ainda

$$
\begin{array}{lll}
T(A(1))=A(0, R)=D_{1} & \Rightarrow & A(1)=\{z \in \subset: \operatorname{Re}(z)>0\} \\
T(A(-1))=A(x, R)=\bar{C} \backslash \bar{D}_{1} & \Rightarrow & A(-1)=\{z \in \subset: \operatorname{Re}(z)<0\} .
\end{array}
$$


Proposição 2.2.2. Seja $p(z)=\alpha(z-a)(z-b)$, um polinômio quadrático com zeros distintos. O conjunto de Julia de $N_{p}$ é a mediatriz do segmento que une os dois zeros. A bacia de atração de cada um dos zeros é o semiplano que os contém, limitado por $J\left(N_{p}\right)$.

Prova: Consideremos a transformação afim

$$
T(z)=\frac{a-b}{2} z+\frac{a+b}{2} \text {. }
$$

Observamos que

$$
\frac{1}{\alpha}\left(\frac{2}{a-b}\right)^{2} p \circ T(z)=z^{2}-1=q(z) \text {. }
$$

Pelo lema 2.1.6, a transformação $N_{p}$ associada ao método de Newton de $p$ é cconjugada a

$$
N_{q}(z)=\frac{z^{2}+1}{2 z}
$$

Do lema 2.2.1, segue a conclusão.

Observação 2.2.3. Se $p$ é um polinômio de grau 2 com uma raiz dupla em $z \quad a$, ou seja, $p(z)=(z-a)^{2}$; então a transformação associada ao método de Newton de $p$ é

$$
N_{p}(z)=\frac{z+a}{2}
$$

A sequência de iteradas de $N_{p}$ converge uniformemente para $a$, para todo $z$ em C. As$\operatorname{sim}$, o conjunto de Julia $J\left(N_{p}\right)$ de $N_{p}$ é vazio. Cabe ressaltar que este fato não contradiz a proposição 1.2.2. Ela é válida para transformações racionais com grau $d \geq 2$, enquanto, neste caso, $N_{p}$ tem grau 1. 


\section{3 - Método de Newton para polinômio de grau 3}

Mostramos na seção precedente que o conjunto de valores iniciais, para os quais o método de Newton quando aplicado a um polinômio de grau 2 com raizes distintas falha, determina uma reta no plano complexo. Nesta seção, analisaremos o comportamento da transformação associada ao método de Newton de um polinômio complexo de grau 3.

Lema 2.3.1. Todo polinômio cúbico $p(z)=\mu(z-\alpha)(z-\beta)(z-\gamma)$, com pelo menos dois zeros distintos, é equivalente a pelo menos um e a no máximo três polinômios da forma $p_{a}(z)=z^{3}+(a-1) z-a$, por uma transformação afim.

Prova: Para determinarmos $T(z)=A z+B$ tal que $p \circ T=p_{a}$, para algum $a$, obtemos o sistema de equações

$$
\left\{\begin{array}{l}
3 B-(\alpha+\beta+\gamma)=0 \\
3 B^{2}-2 B(\alpha+\beta+\gamma)+\beta \gamma+\alpha \beta+\alpha \gamma=(a-1) A^{2} \\
(B-\alpha)(B-\beta)(B-\gamma)=-a A^{3}
\end{array} .\right.
$$

Resolvendo-o, temos três valores para $A$,

$$
A_{1}=\frac{-\alpha-\beta+2 \gamma}{3}, \quad A_{2}=\frac{-\alpha+2 \beta-\gamma}{3}, \quad A_{3}=\frac{2 \alpha-\beta-\gamma}{3}
$$

e

$$
B=\frac{\alpha+\beta+\gamma}{3}
$$

Se $T_{i}(z)=A_{i}(z)+B$, então $p \circ T_{i}(z)=p_{a_{i}}(z)(i=1,2,3)$ com

$$
a_{1}=\frac{-(\alpha+\beta-2 \gamma)(\alpha-2 \beta+\gamma)(-2 \alpha+\beta+\gamma)}{(-\alpha-\beta+2 \gamma)^{3}}
$$




$$
\begin{aligned}
& a_{2}=\frac{-(\alpha+\beta-2 \gamma)(\alpha-2 \beta+\gamma)(-2 \alpha+\beta+\gamma)}{(-\alpha+2 \beta-\gamma)^{3}} \\
& a_{3}=\frac{-(\alpha+\beta-2 \gamma)(\alpha-2 \beta+\gamma)(-2 \alpha+\beta+\gamma)}{(2 \alpha-\beta-\gamma)^{3}} .
\end{aligned}
$$

Observamos que, se dois zeros de $p$ são coincidentes, então dois valores do parâmetro $a$ são iguais a -2 e o outro valor é $1 / 4$.

A expressão $p_{a}(z)=z^{3}+(a-1) z-a$ representa uma família a um parâmetro $a$, de polinômios mônicos. A soma das raizes é zero e uma delas é igual a 1 .

Observação 2.3.2. Se $p$ é um polinômio cúbico com uma raiz tripla em $z=\alpha$, ou seja, $p(z)=\mu(z-\alpha)^{3}$, então a transformação associada ao método de Newton de $p$ é

$$
N_{p}(z)=\frac{2 z+\alpha}{3}
$$

A sequência de iteradas de $N_{p}$ converge uniformemente para $\alpha$, para todo $z$ em $C$.

Proposição 2.3.3. A transformação associada ao método de Newton de um polinômio $p$ é conjugada a pelo menos uma e a no máximo três transformações da forma

$$
N_{p_{a}}(z)=\frac{2 z^{3}+a}{3 z^{2}+a-1}
$$

onde a é um parâmetro complexo.

Prova: Segue da proposição 2.3.1 e do lema 2.1.6. 
Proposição 2.3.4. O único ponto crítico não fixo da transformação $N_{p_{a}} \dot{e}$ a origem.

Prova: Como a derivada de (2.3.1) é:

$$
N_{p_{a}}^{\prime}(z)=\frac{p_{a}(z) p_{a}^{\prime \prime}(z)}{\left(p^{\prime}(z)_{a}\right)^{2}}=\frac{\left(z^{3}+(a-1) z-a\right) 6 z}{\left(3 z^{2}+a-1\right)^{2}}
$$

os pontos críticos de $N_{p_{a}}$ são os zeros de $p_{a}$ e a origem $z=0$. Pela proposição 2.1.1, os zeros de $p_{a}$ são pontos fixos (super) atratores de $N_{p_{a}}$. Como $N_{p_{a}}(0) \neq 0$, temos o resultado. -

Observação 2.3.5. Tendo em vista a proposição 2.1.5, observamos que, se para um determinado valor do parâmetro $a, N_{p_{a}}$ tem um ciclo atrator, além dos pontos fixos, então a órbita da origem o evidenciará. Portanto, basta analisarmos a órbita da origem para prognosticar a existência de um conjunto de valores iniciais para os quais o método de Newton falha: a bacia de atração do ciclo. Para auxiliar tal análise, que será discutida nas próximas subseções,foram escritos alguns programas computacionais em linguagem $C+$. Essa é uma linguagem orientada para objetos que se vale plenamente dos recursos de superação dos operadores. Graças a isso, as quantidades complexas são tratadas como objetos, com a vantagem de que os operadores e funções usados normalmente com números reais, podem também ser usados com números complexos. Esse fato facilita grandemente a programação. As listagens completas de todos os programas citados neste capítulo encontram-se no apêndice. $\mathrm{Na}$ forma que são apresentados, os programas foram compilados no sistema Borland $\mathrm{C}++$, versão 3.1. Os programas executáveis produzidos com o mencionado compilador podem ser rodados em microcomputadores usuais da linha PC, equipados com DOS versão 5.0 ou posterior, e adaptador gráfico VGA. Entretanto, mesmo que os programas sejam compilados com o emulador do coprocessador matemático ativado, é altamente recomendável executá-los em um computador equipado com tal coprocessador, a fim de que a execução transcorra com velocidade aceitável. A emulação possibilita a execução do programa em um micro não dotado de coprocessador, mas a velocidade de processamento pode ficar inaceitavelmente lenta. 


\subsection{1 - Morfologia no plano do parâmetro $a$}

Como vimos, a órbita da origem, ponto crítico de $N_{p_{a}}$, permite prognosticar a existência de ciclos (super) atratores, além dos pontos fixos. Esses ciclos implicam na existência de um conjunto de valores iniciais para os quais o método de Newton falha que é a bacia de atração do ciclo. Para visualizar os valores de $a$ para os quais $N_{p_{a}}$ possui tal bacia, podemos construir uma figura a qual denominamos morfologia no plano do parâmetro $a$.

Para a construção dessa figura implementamos um programa computacional, cujo algoritmo descrevemos a seguir. Inicialmente, consideramos uma grade de 640 x 480 pontos correspondentes ao parâmetro $a$. Essa divisão da grade é determinada pela resolução da tela gráfica. Cada ponto da grade relaciona-se ao centro de um pixel, que é a menor unidade que pode ser apresentada na tela do computador. Os dados de entrada do programa implementado são os limites de variação da parte real ( pmin e pmax ) e imaginária ( qmin e qmax ) do parâmetro $a$. Assim, a diferença entre duas colunas consecutivas da grade é dada por $($ pmax - pmin $) / 639$, e entre duas linhas consecutivas por $(q \max -q \min ) / 479$. A fim de que a morfologia não seja deformada, é recomendável respeitar o fator de forma $4: 3$ da base para a altura, isto é,

$$
\frac{p \max -p \min }{q \max -q \min }=\frac{640}{480}=\frac{4}{3} .
$$

Para cada um dos 307.200 valores do parâmetro $a$, calculamos as iteradas da respectiva transformação do método de Newton

$$
N_{p_{a}}(z)=z-\frac{p_{a}(z)}{p_{a}^{\prime}(z)}
$$

partindo de $z \quad 0$. Se para algum $k$ entre 1 e um certo número máximo de iterações, nmax,

$$
\left|N_{p_{a}}^{k}(0)-1\right| \leq \delta
$$

para um dado $\delta>0$, então a órbita da origem, pela transformação $N_{p_{a}}$, converge para a raiz unitária de $p_{a}$. Neste caso, o pixel correspondente ao parâmetro $a$ é assinalado, e aparece em cinza na figura. No caso contrário, existem duas possibilidades. Ou a órbita da origem converge para um dos outros dois zeros do polinômio $p_{a}$; ou não ocorre a convergência, dentro do número de iterações considerado, para nenhum dos zeros. Esta última situação é a que desperta interesse no momento, pois está relacionada com os valores do parâmetro a para os quais a órbita da origem evidencia a existência de ciclos não 
repulsores, além dos pontos fixos de $N_{p_{a}}$. Para identificar estes valores, devemos verificar se

$$
\left|N_{p_{a}}^{k}(0)-N_{p_{a}}^{k-1}(0)\right|>\delta
$$

para o dado $\delta>0$ e todo $k$ entre 1 e $n \max$. Se esta condição for satisfeita, então o pixel correspondente ao parâmetro $a$ também é assinalado, e aparece em preto na figura. Se nenhuma das duas condições acima for satisfeita, para um determinado valor de $a$, então o pixel correspondente é desconsiderado, ou seja, permanece em branco na figura.

Neste trabalho, adotamos o valor $10^{-6}$ para $\delta$. Assim, se para o valor inicial $z_{0}$,

$$
\left|N_{p_{a}}^{k}\left(z_{0}\right)-N_{p_{a}}^{k-1}\left(z_{0}\right)\right| \leq 10^{-6}
$$

para algum $k$ entre 1 e $n \max$, e um determinado valor do parâmetro $a$, então consideramos que a órbita de $z_{0}$ converge para um dos pontos fixos da transformação $N_{p_{a}}$, zeros do polinômio $p_{a}$. Adotamos $n \max =200$ para o número máximo de iterações.

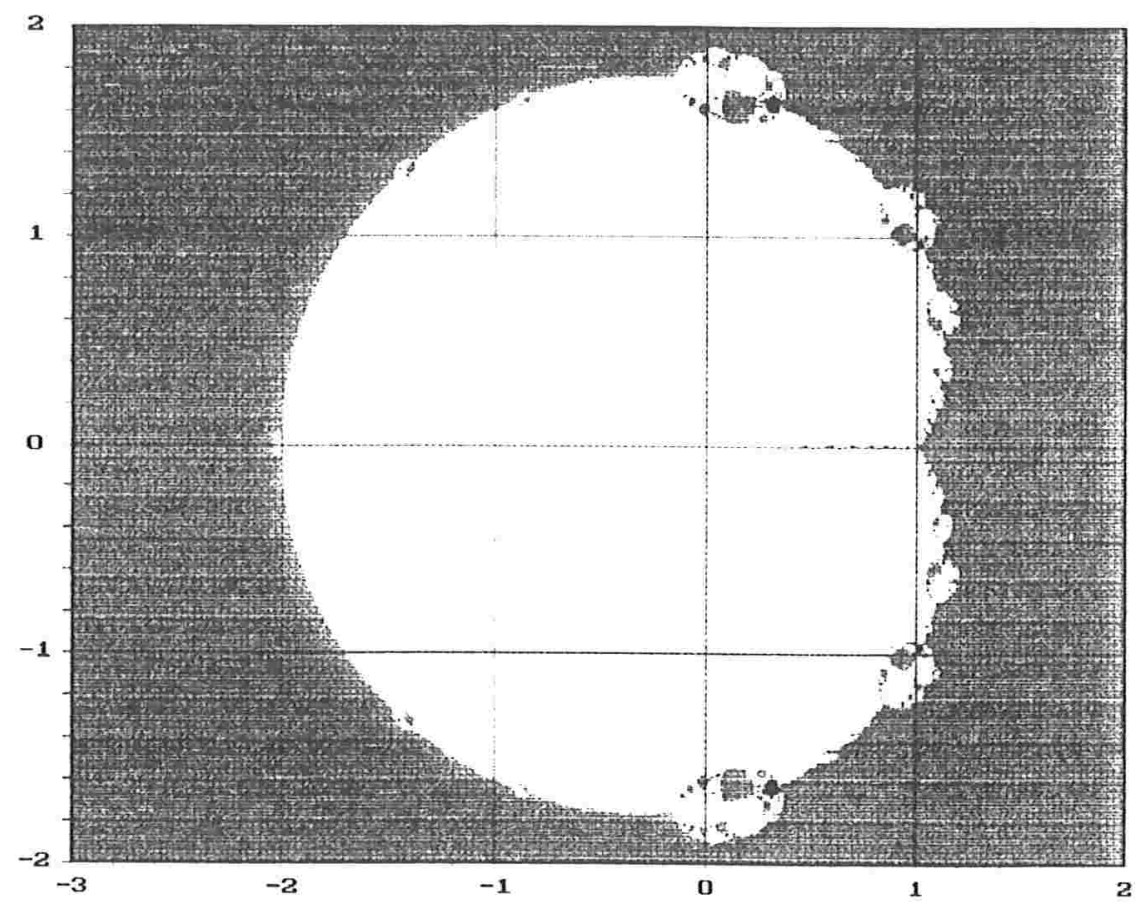

Figura 4 - Morfologia no plano do parâmetro $a$. 
A figura 4 fornece uma visão geral do comportamento da órbita do ponto crítico da transformação do método de Newton $N_{p_{a}}$. Foi obtida considerando

$$
\begin{aligned}
& \text { pmin }=-3.7, \quad \quad p \max =2.7, \\
& q \min =-2.4, \quad q \max =2.4 \text {. }
\end{aligned}
$$

Na região em cinza, as iteradas do ponto crítico convergem para a raiz real unitária. Nas regiões brancas, convergem para algum dos outros dois zeros do polinômio $p_{a}$. Finalmente, nas regiões pretas, em que concentraremos a atenção, a órbita da origem não converge para os pontos fixos da transformação $N_{p_{a}}$, dentro do número máximo de iterações considerado.

Nas figuras deste capítulo, suprimimos as partes mais externas que não acrescentavam informações, a favor da estética e para permitir a construção das graduações nas margens da figura. As graduações horizontal e vertical nas margens das figuras desta subseção indicam, respectivamente, a parte real e imaginária do parâmetro $a$.

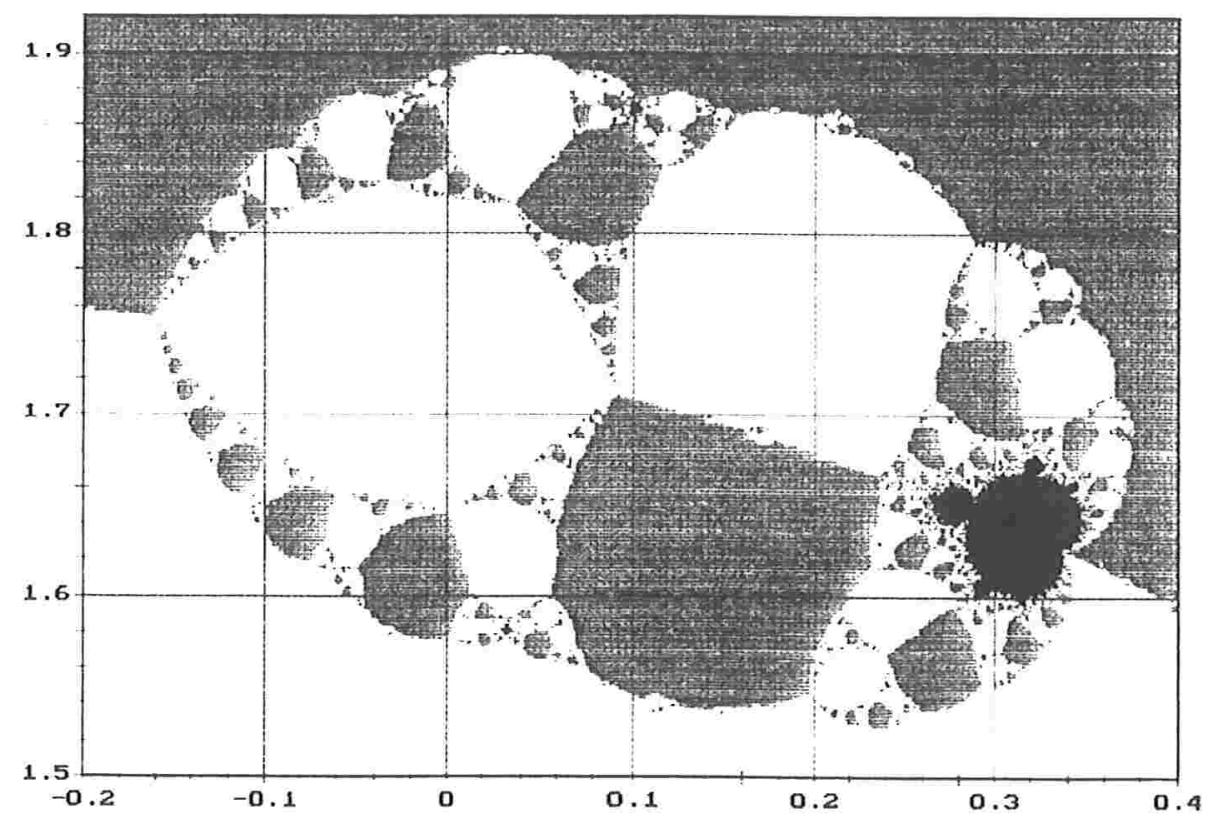

Figura 5 - Ampliação da "ilha" na parte superior da figura 4. 
Para visualizar mais detalhadamente os objetos de maior interesse, podemos ampliálos, restringindo os limites de variação da parte real ( pmin e pmax ) e imaginária ( qmin e qmax ) do parâmetro $a$. Cabe lembrar que esses valores são os dados de entrada no programa computacional implementado para a construção da morfologia e que devemos escolher de modo a manter o fator de forma $4: 3$ da base para a altura.

A " ilha " que aparece na parte superior da figura 4 e outra que está um pouco mais abaixo e à direita podem ser vistas nas figuras 5 e 6 , respectivamente. A figura 5 foi construida atribuindo-se os valores $-0,27$ e 0.47 para os limites de variação da parte real; 1.42 e 1.975 da parte imaginária do parâmetro $a$. Como mencionamos acima, a parte periférica da figura foi suprimida para ceder lugar às graduações das margens, razão pela qual é visível apenas a região compreendida entre -0.2 e 0.4 , na parte real, e entre 1.5 e 1.92 , na parte imaginária. Na figura 6 , fornecemos os valores 0.55 e 1.35 para a parte real; 0.80 e 1.40 para a imaginária. Observamos que essas " ilhas " possuem uma estrutura morfológica semelhante.

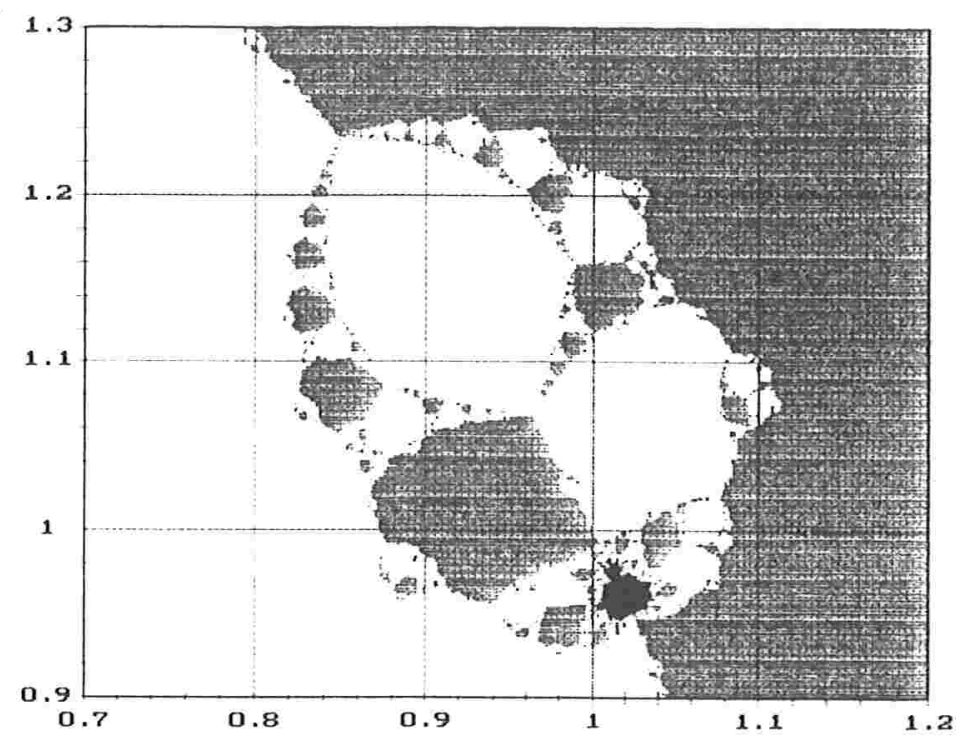

Figura 6 - Ampliação de outra "ilha" da figura 4.

Um fato bastante interessante nas figuras 5 e 6 , e que evidencia a existência de bifurcações da dinâmica nessas regiões, é o aparecimento de imagens similares ao " boneco de gengibre " ( gingerbreadman ) característico da morfologia no plano do parâmetro c 
para a transformação quadrática $p(z)=z^{2}+c$. Essa morfologia foi publicada, pela primeira vez, pelo matemático Benoit Mandelbrot ${ }^{3}$, em 1980, e é obtida por um processo similar ao descrito nesta subseção.

As figuras 7 e 8, ampliações de regiões das figuras 5 e 6 , respectivamente, são exemplos do fato citado acima. Para a construção da figura 7, foram atribuídos os valores: $0.21,0.39,1.57$ e 1.71 para pmin, pmax, qmin, qmax, respectivamente. Para a figura 8: $0.975,1.055,0.935$ e 0.995 , respectivamente. A região em preto indica que a órbita da origem, para os correspondentes valores do parâmetro $a$, não converge para os zeros do polinômio $p_{a}$, dentro do número de iterações considerado. Como a origem é ponto crítico não fixo de $N_{p_{a}}$, isto evidencia que o conjunto de Fatou $\mathcal{F}\left(N_{p_{a}}\right)$ contém domínios eventualmente periódicos de não convergência do método de Newton. Esses domínios de não convergência são devidos à existência de um ciclo não repulsor, além dos pontos fixos.

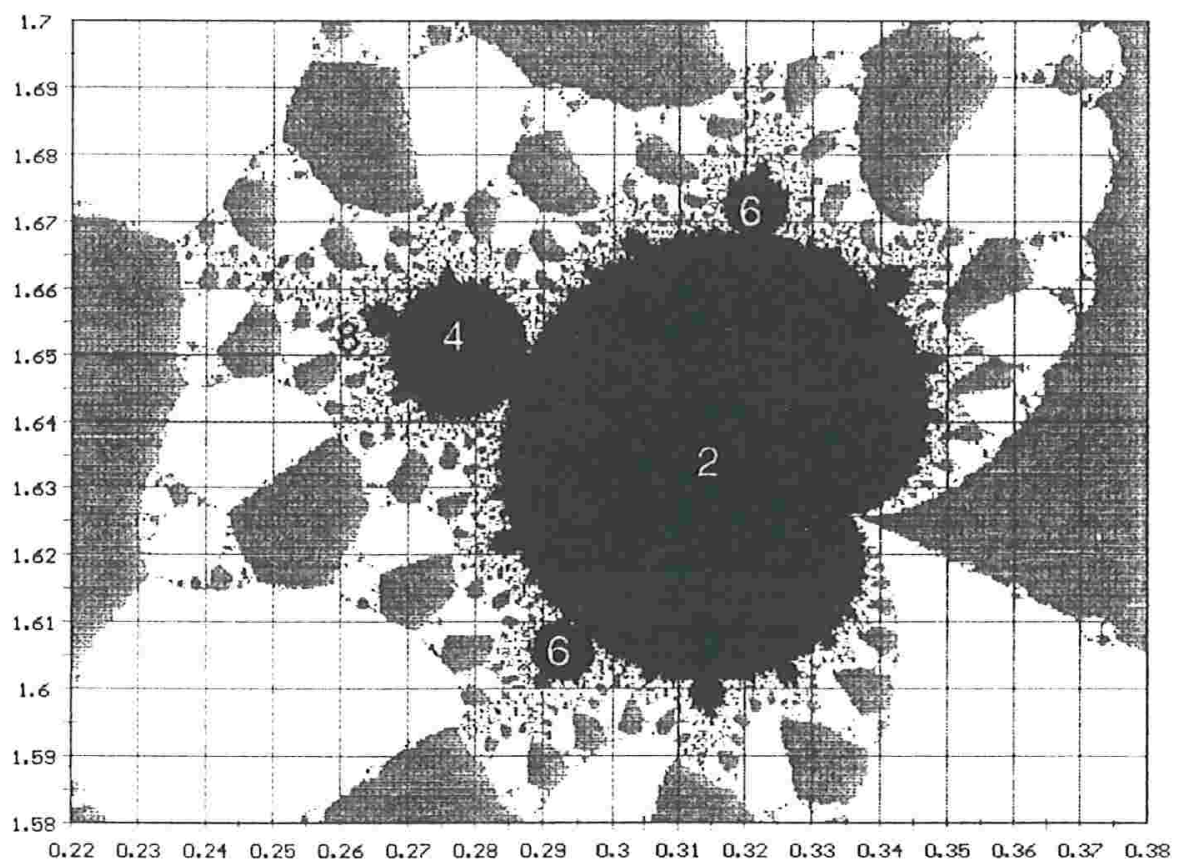

Figura 7 - Uma das regiões onde o método de Newton exibe comportamento periódico.

${ }^{3}$ B. Mandelbrot. Fractal aspects of $z \mapsto \lambda z(1-z)$ for complex $\lambda$ and $z$. Ann. N. I. Acad. Sci. 357. 249-259. (1980). 
Determinamos a órbita da origem, pela transformação $N_{p_{a}}$, com vários valores do parâmetro $a$ extraidos das figuras 7 e 8 . Observamos que os pontos localizados na região preta da figura 7 , delimitada por uma curva em forma de cardióide, correspondem a valores do parâmetro $a$ para os quais a órbita da origem converge para um ciclo de período 2 . Em outras palavras, para estes valores de $a$, as transformações $N_{p_{a}}$ possuem um ciclo atrator de período 2. A seguir analisamos as regiões pretas, com formato de disco, em ordem decrescente de tamanho. Os pontos localizados no interior do disco maior, à esquerda da figura, correspondem a valores do parâmetro para os quais a órbita da origem converge para um ciclo de período 4. Para os valores no disco imediatamente menor, na parte superior da figura preta, e no seu simétrico em relação ao eixo do cardióide, as transformações possuem ciclos atratores de período 6 . Os pontos no disco imediatamente menor, à esquerda do disco de período 4 , correspondem a valores do parâmetro $a$ para os quais as transformações $N_{p_{a}}$ possuem ciclos atratores de período 8. Cabe ressaltar que para todos os valores localizados na região preta desta figura, as correspondentes transformações do método de Newton possuem ciclos atratores de período par. Os números nas regiões pretas das figuras 7 e 8 indicam o valor do período do ciclo atrator para o qual a órbita da origem converge.

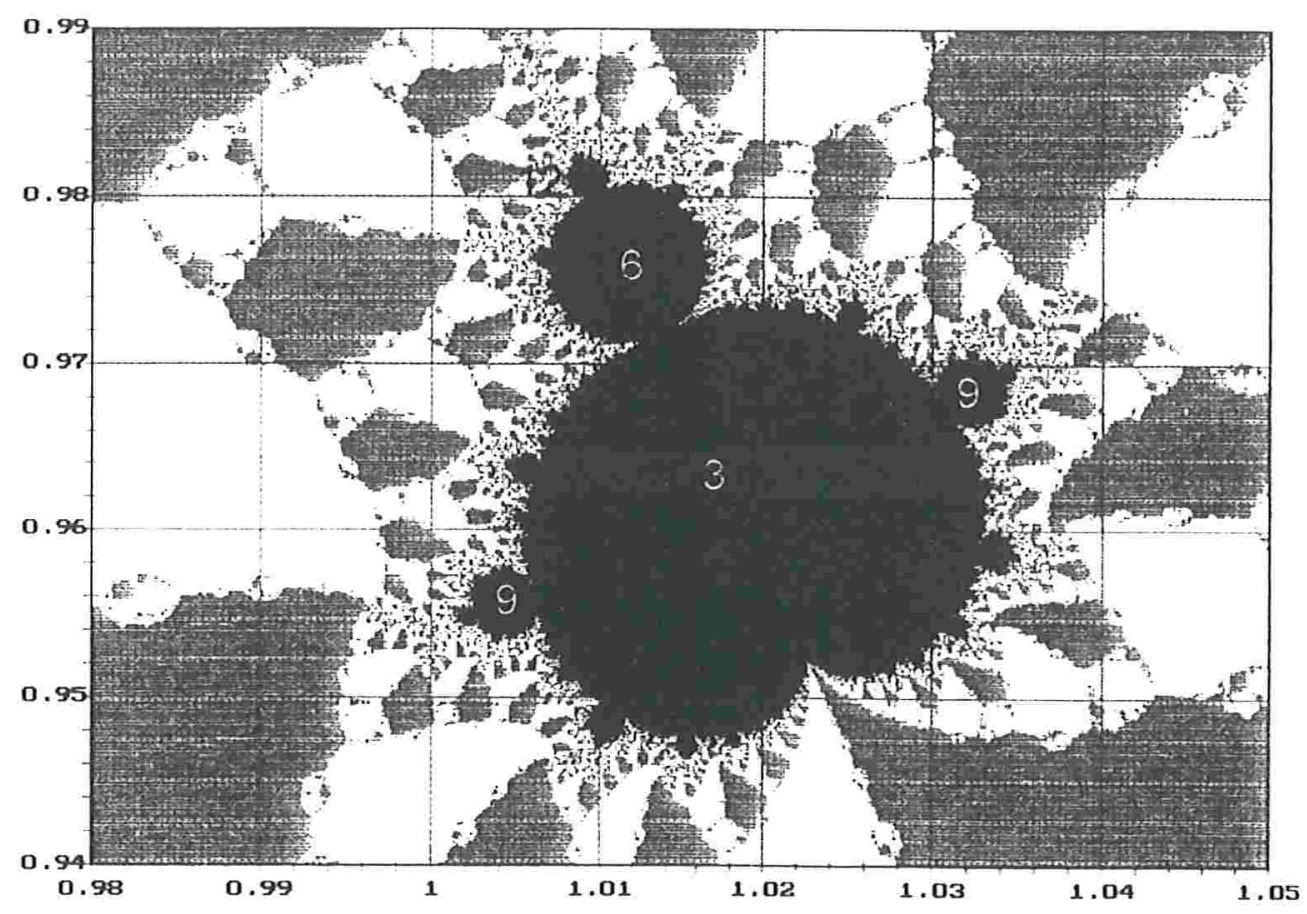

Figura 8 - Outra das regiões onde o método de Newton exibe comportamento periódico 
Para todos os valores localizados na região preta da figura 8 , as correspondentes transformações possuem ciclos atratores de período múltiplo de 3 . Os pontos localizados na região preta delimitada pela curva em forma de cardióide, correspondem a valores do parâmetro $a$ para os quais a órbita da origem converge para um ciclo de periodo 3 . No que concerne às áreas em forma de disco agregadas à " cardióide ", seguindo a análise feita no caso da figura 7, mutatis mutandis, observamos que os ciclos atratores de $N_{p_{a}}$ são de periodo 6 , 9,12 .

Desse modo, podemos dizer que as figuras 7 e 8 , e análogas, constituem um indicador de periodicidade de ciclos atratores para $N_{p_{a}}$.

Na tabela 1, relacionamos alguns valores do parâmetro $a$. Selecionamos os valores de modo que fossem representativos os ciclos evidenciados pela órbita da origem. Para um determinado valor do parâmetro $a$, basta analisar a órbita da origem, pela transformação $N_{p_{a}}$, para identificar o periodo do ciclo (super) atrator. Tendo o valor do parâmetro e o período do ciclo, é imediato calcular o módulo do autovalor.

Na próxima subseção pretemos visualizar o conjunto de valores iniciais para os quais o método de Newton falha, para a transformação $p_{a}$. Concentraremos a atenção em algumas transformações $p_{a}$, cujos valores do parâmetro $a$ estão relacionados na tabela 1 .

Tabela 1

\begin{tabular}{|l|l|c|c|}
\hline \multicolumn{2}{|c|}{ Parâmetro } & \multicolumn{1}{c|}{ Ciclo evidenciado } & pela órbita da origem \\
\hline \multicolumn{1}{|c|}{ Parte real } & Parte imaginária & Periodo & módulo do autovalor \\
\hline 0 & 1.75 & 1 & 0 \\
0.3 & 1.65 & 2 & 0.7531 \\
0.27 & 1.65 & 4 & 0.7542 \\
0.32 & 1.674 & 6 & 0.4858 \\
0.266 & 1.655 & 8 & 0.1264 \\
1.02 & 0.96 & 3 & 0.1623 \\
1.01 & 0.976 & 6 & 0.3768 \\
1.0324 & 0.9688 & 9 & 0.2338 \\
1.009 & 0.981 & 12 & 0.2600 \\
\hline
\end{tabular}




\subsection{2 - Valores iniciais para os quais o método dle Newton falla}

Pela proposição 2.1.3, o conjunto dos valores iniciais para os quais o método de Newton falha, para uma transformação polinomial $p$, é a união do conjunto de Julia $J\left(N_{p}\right)$ com as componentes eventualmente periódicas associadas aos domínios de Sullivan existentes, além das bacias (super) atratoras dos zeros de $p$. Pretendemos, agora, usando o computador, visualizar estes conjuntos para a transformação polinomial $p_{a}(z)=z^{3}+(a-1) z-a$, para um dado valor do parâmetro $a$, com ênfase em alguns valores extraídos da tabela 1 .

Tendo em vista a seção 1.5 , podemos obter uma boa aproximação do conjunto de Julia $J\left(N_{p_{a}}\right)$ para um dado valor de $a$, calculando a órbita regressiva de algum ponto $z_{0}$ do conjunto de Julia.

Proposição 2.3.6. O infinito pertence ao conjunto de Julia $J\left(N_{p_{a}}\right)$.

Prova: A transformação $N_{p_{a}}$ é conjugada, pela transformação

$$
h(z)=\left\{\begin{array}{lll}
\frac{1}{z} & \text { se } & z \neq 0 \\
\infty & \text { se } & z=0
\end{array}\right.
$$

a

$$
\phi(w)=h \circ N_{p_{a}} \circ h^{-1}(w)=\frac{(a-1) w^{3}+3 w}{a w^{3}+2}
$$

A derivada de (2.3.3) é dada por

$$
\phi^{\prime}\left(w^{\prime}\right)=\frac{3\left((a-1) w^{2}+1\right)\left(a w^{3}+2\right)-3 a w^{2}\left((a-1) w^{3}+3 w\right)}{\left(a w^{3}+2\right)^{2}} .
$$


Como $\phi(0)=0$, temos que $N_{p_{a}}(\infty)=\infty$, ou seja, $\infty$ é um ponto fixo de $N_{p_{a}}$. E é repulsor, pois:

$$
\phi^{\prime}(0)=\frac{1}{N_{p_{a}}^{\prime}(\infty)}=\lambda=\frac{3}{2}>1
$$

Portanto, pelo teorema 1.3.7, o infinito pertence ao conjunto de Julia $J\left(N_{p_{a}}\right)$

Além do próprio infinito, suas pré-imagens pela $N_{p_{a}}$ são os pontos críticos de $p_{a}$, $z= \pm \sqrt{(1-a) / 3}$, que também estão em $J\left(N_{p_{a}}\right)$ pois, pela proposição 1.2 .3 , ele é invariante. Assim, para o traçado do conjunto de Julia $J\left(N_{p_{a}}\right)$ podemos determinar a órbita regressiva do ponto $z_{0}=\sqrt{(1-a) / 3}$, por exemplo.

Tendo em vista a definição 1.1.1, para determinarmos a órbita regressiva do ponto $z_{0} \in J\left(N_{p_{a}}\right)$, calculamos primeiro as três pré-imagens de $z_{0}$, depois as três pré-imagens de cada uma das anteriores, e assim sucessivamente. Procedemos assim até um determinado nível máximo de iteração, nvmax. Desse modo, convém encontrar a expressão de cada uma das pré-imagens de um ponto $w \in \mathbb{C}$, ou seja, dos valores de $z$ que satisfazem a igualdade

$$
\frac{2 z^{3}+a}{3 z^{2}+a-1}=w
$$

Através do software Mathematica ( Wolfram Research, Inc. ), versão 2, determinamos as expressões das pré-imagens de um ponto $w \in \mathcal{C}$, que são:

$$
\begin{gathered}
z_{1}=\frac{1}{2}\left(w+r+\frac{w^{2}}{r}\right) \\
z_{2}=\frac{w}{2}+i \frac{\sqrt{3}}{4}\left(r-\frac{w^{2}}{r}\right)-\frac{1}{4}\left(r+\frac{w^{2}}{r}\right) \\
z_{3}=\frac{w}{2}-i \frac{\sqrt{3}}{4}\left(r-\frac{w^{2}}{r}\right)-\frac{1}{4}\left(r+\frac{w^{2}}{r}\right)
\end{gathered}
$$

onde: 


$$
r=\left(-2 a-2(1-a) w+w^{3}+2 \sqrt{a^{2}+2 a(1-a) w+(1-a)^{2} w^{2}-a w^{3}-(1-a) w^{4}}\right)^{1 / 3}
$$

Como o processo de traçado do conjunto de Julia é recorrente e exige um grande volume de cálculo, o computador torna-se fundamental para realizar essa tarefa. Para tanto, implementamos um programa em linguagem $C^{-\cdots}$, com base no algoritmo proposto na seção 1.5 , ( ver figura 2 ). Os dados de entrada do programa são o valor do parâmetro $a$ e os limites da parte real ( $x \min$ e $x \max$ ) e imaginária ( ymin e ymax ) da região selecionada para o traçado do conjunto. Como anteriormente, devemos respeitar o fator de forma $4: 3$ da base para a altura da tela gráfica, ou seja:

$$
\frac{x \max -x \min }{y \max -y \min }=\frac{640}{480}=\frac{4}{3}
$$

A área útil da figura é essa região selecionada subtraindo-se uma área periférica para as margens e graduações. As graduações horizontal e vertical nas bordas da figura indicam a parte real e imaginária, respectivamente, da variável $z$.

Para o traçado do conjunto de Julia das figuras relacionadas nesta subseção, adotamos o nível máximo de recorrência, $n v m a x$, igual a 11. Como em cada nível intermediário $k$ são marcados graficamente $3^{k}$ pontos, ao final do processo são plotados 265.719 pixeis. Os pontos marcados são as pré-imagens

$$
N_{p_{a}}^{-k}\left(\sqrt{\frac{1-a}{3}}\right),
$$

$\operatorname{com} 1 \leq k \leq 11$.

A figura 9 mostra uma aproximação do conjunto de Julia para a transformação $N_{p_{a}}$ correspondente ao valor de $a=1.75 \mathrm{i}$; foi obtida pelo programa citado acima, atribuindose os valores $-2.3,2.1,-1.7,1.6$ para $x \min , x \max , y \min , y \max$, respectivamente. Como a órbita da origem, pela transformação $N_{p_{a}}$, converge para um dos zeros de $p_{a}$ ( o valor do parâmetro $a$ está localizado numa região branca da figura 7 ), $N_{p_{a}}$ não possui domínios de Sullivan além dos superatratores correspondentes aos zeros de $p_{a}$. Dessa maneira, a figura 9 representa o conjunto dos pontos para os quais o método de Newton falha para $p_{a}$.

Nas figuras desta subseção, os zeros do polinômio, quando visiveis na região selecionada, estão marcados com um círculo com um ponto no interior . A origem e o ciclo (super) atrator para o qual a sua órbita converge estão assinalados por cruzetas. As setas 
que aparecem em algumas figuras indicam regiões onde estão assinaladas as cruzetas dificeis de identificar rapidamente.

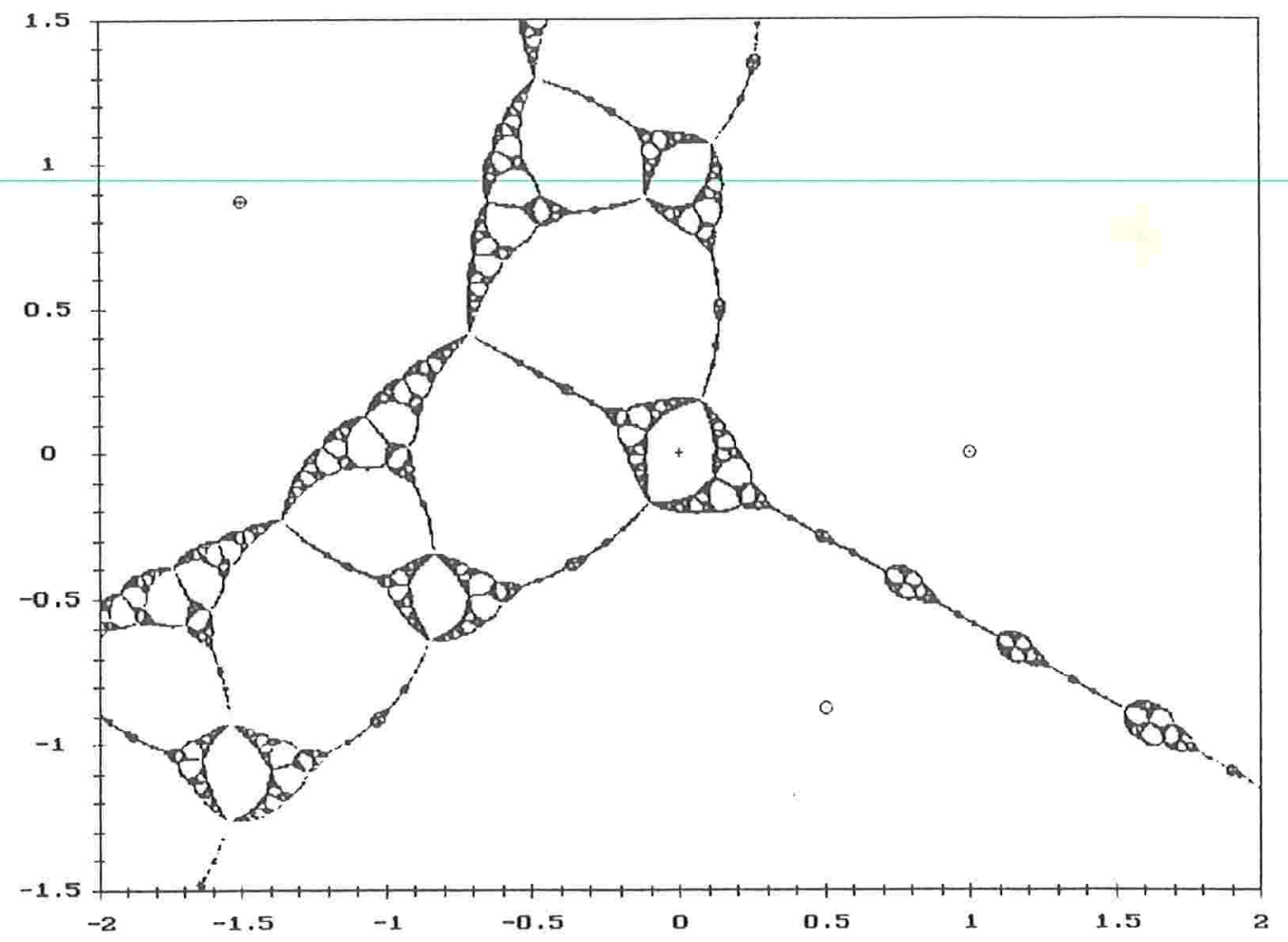

Figura 9- Conjunto de Julia de $N_{p_{a}}$, para $a=1.75 \mathrm{i}$.

Por outro lado, para os valores do parâmetro $a$ contidos nas regiões pretas das figuras 4 a 8 , conjecturamos que as correspondentes transformações do método de Newton, $N_{p_{a}}$, possuem ciclos não repulsores além dos pontos fixos. Esses ciclos implicam na existência de domínios eventualmente periódicos de não convergência do método de Newton. Para visualizá-los, implementamos uma rotina computacional que descrevemos a seguir.

Consideramos, inicialmente, uma grade de $640 \times 480$ pontos, semelhante à descrita na subseção anterior. Entretanto, cada ponto da grade corresponde agora ao valor inicial $z_{0}$ para o qual será aplicado o método de Newton. Para um dado valor fixo do parâmetro $a$, calculamos as iteradas da transformação $N_{p_{a}}$, partindo de cada ponto $z_{0}$ da grade. Se para todo $k$ entre 1 e um certo número máximo de iterações, nmax, 


$$
\left|N_{P_{s}}^{k}\left(z_{0}\right)-N_{P_{s}}^{k-1}\left(z_{0}\right)\right|>\delta
$$

para um dado $\delta>0$, então $z_{0}$ é um valor inicial para o qual sua órbita não converge, dentro do número de iterações considerado, para os zeros do polinômio. Neste caso, o pixel correspondente ao ponto $z_{0}$ é assinalado.

Caso contrário, ou seja, se

$$
\left|N_{P_{s}}^{k}\left(z_{0}\right)-N_{P_{u}}^{k-1}\left(z_{0}\right)\right| \leq \delta
$$

para algum $k$ entre 1 e $n m a x$, então a órbita de $z_{0}$ converge para alguma raiz de $p_{a}$ e o pixel é desconsiderado.

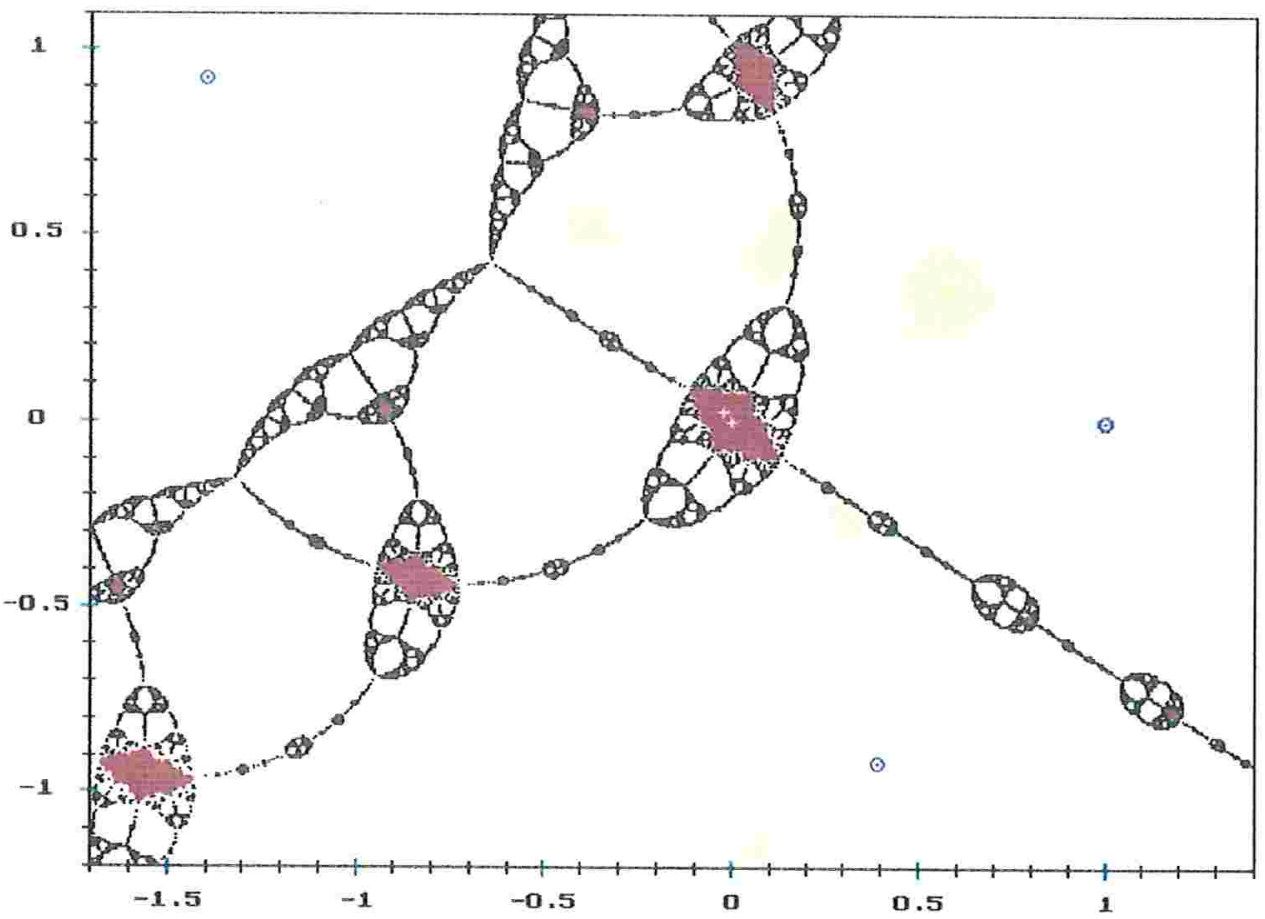

Figura 10 - Valores iniciais para os quais o método de Newton falha para $p_{a}, \operatorname{com} a=0.3+1.65 \mathrm{i}$. 
A figura 10 representa o conjunto dos valores iniciais para os quais o método de Newton falha, para o polinômio $p_{a}$, com $a=0.3+1.65$ i. Fornecemos os valores: -2.0 , $1.6,-1.5$ e 1.2 para $x \min , x \max , y \min$ e $y \max$, respectivamente. Primeiro, o programa percorre as 640 colunas e marca os pixeis correspondentes a $z_{0}$ para os quais a sua órbita não converge para os zeros de $p_{a}$. Estes pontos estão marcados em vermelho. Representam a bacia de atração do ciclo atrator de periodo 2 , evidenciado pela órbita da origem. O ciclo atrator e a origem estão marcados com cruzetas brancas. A seta indica a região onde está localizada umas das cruzetas, dificil de identificar rapidamente. Depois, o programa traça o conjunto de Julia, pelo processo descrito no início desta subseção. O conjunto de Julia foi traçado em preto.

É possivel, quando for de interesse, visualizarmos também as bacias dos pontos fixos (super) atratores de $N_{p_{u}}$, zeros de $p_{a}$. Tendo em vista a rotina computacional descrita acima, basta marcar com cores distintas o pixel que anteriormente era desconsiderado. Ou seja, se

$$
\left|N_{p_{a}}^{k}\left(z_{0}\right)-N_{p_{a}}^{k-1}\left(z_{0}\right)\right| \leq 10^{-6}
$$

para algum $k$ entre 1 e $n m a x$, então o pixel correspondente a $z_{0}$ é assinalado com uma entre três cores selecionadas, dependendo da raiz de $p_{a}$ para a qual a órbita de $z_{0}$ converge. As três cores escolhidas devem ser distintas entre si, uma para cada bacia de atração dos pontos fixos; e distintas, também, das cores que representam os valores iniciais para os quais o método de Newton falha. O processo acima também pode ser aplicado para figuras em preto e branco, utilizando-se tons diferentes de cinza.

Como os zeros do polinômio $p_{a}=z^{3}+(a-1) z-a$ são $1,(-1+\sqrt{1-4 a}) / 2$ e $(-1-\sqrt{1-4 a}) / 2$, não é dificil identificar para qual deles a órbita de $z_{0}$ converge. Basta verificar se converge para um valor unitário, ou com parte real menor ou igual a $-1 / 2$, ou nenhum destes casos. Ainda, se converge para um valor com parte real igual a $-1 / 2$, então devemos analisar o sinal da parte imaginária. Cabe observar que se $a=1 / 4$, então $-1 / 2$ é um zero de ordem 2. Se $a=1$, dois dos zeros de $p_{a}$ possuem parte real igual a $-1 / 2$, no entanto diferem no sinal da parte imaginária. Se $a=-2$, a raiz unitária é dupla.

O valor do parâmetro $a$, na figura 11 , é $0.27+1.65$ i. Os limites da parte real da variável $z$ são -0.5 e 1.1 , e da parte imaginária, -0.8 e 0.5 . O programa percorre cada uma das 640 colunas e verifica se o ponto $z_{0}$ da grade satisfaz a condição (2.3.4) ou (2.3.5). Se a primeira é verdadeira, então o pixel correspondente a $z_{0}$ é assinalado em marrom. Estes pontos representam valores iniciais para os quais o método de Newton falha. A órbita desses pontos converge para um ciclo atrator de periodo 4 , assinalado com cruzetas brancas. 
No outro caso, ou seja, $z_{0}$ satisfaz a condição (2.3.5), o pixel correspondente é marcado em amarelo, vermelho ou azul, dependendo do zero de $p_{a}$ para o qual a órbita de $z_{0}$ converge. Finalizado este processo, é traçado o conjunto de Julia, em preto.

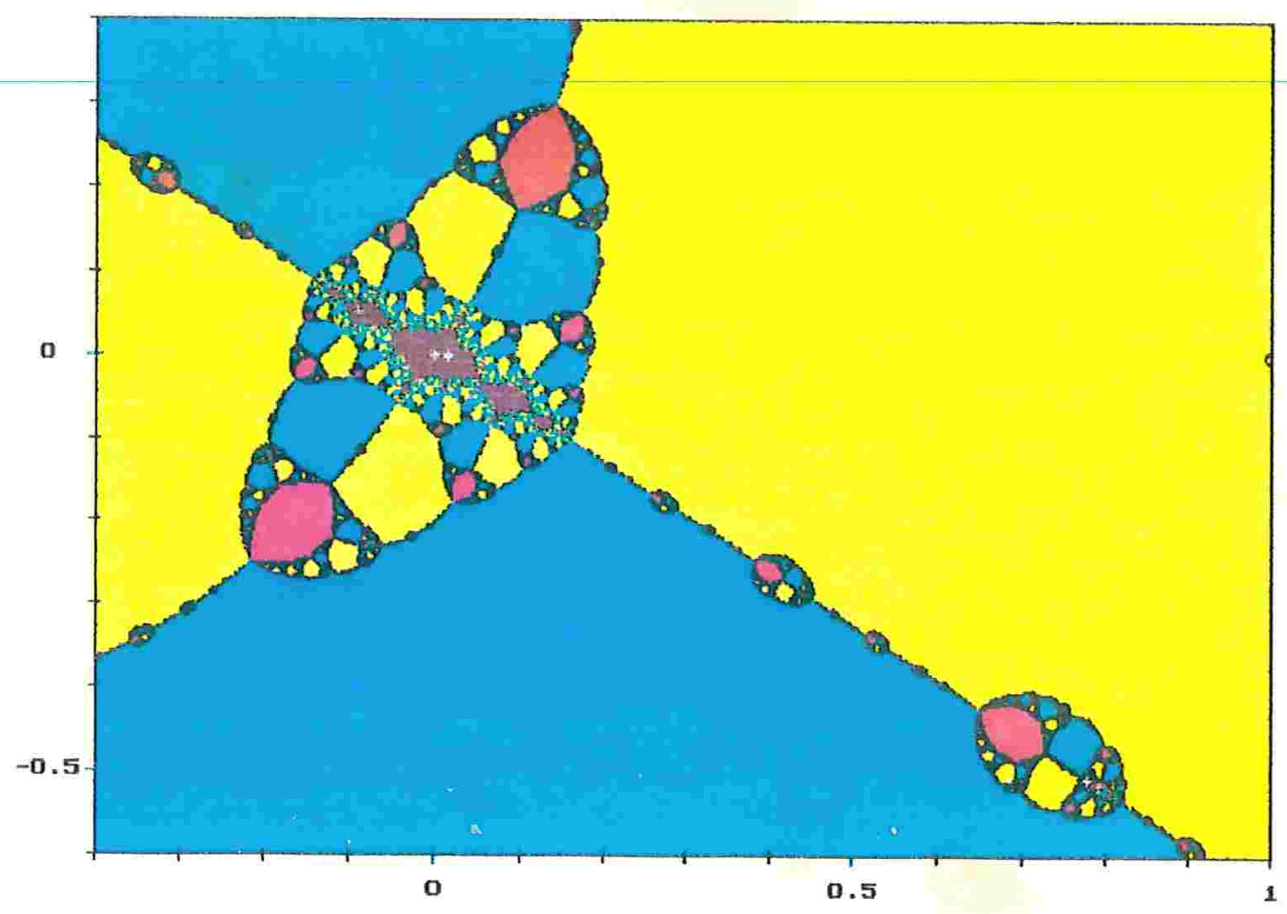

Figura 11 - Bacias de convergência e valores iniciais para os quais o método de Newton falha, para o polinômio $p_{a}$, com $\mathrm{a}=0.27+1.65 \mathrm{i}$.

Pelo teorema 1.3.7, a fronteira das bacias de (super)atração estão contidas no conjunto de Julia. No entanto, notamos na figura 11, por exemplo, que o traçado do conjunto de Julia pelo método descrito no início desta subseção não atinge as partes internas mais detalhadas do conjunto. Isto ilustra a ponderação feita sobre este método no final da seção 1.5 .

Pela definição 1.3.6, as bacias de atração são invariantes. Assim, se um ponto encontra-se numa componente de determinada cor, sua órbita está contida em componentes 
daquela mesma cor. Este fato, pode ser visualizado na figura 12. Com cruzetas cinzas foram assinalados os pontos da órbita do ponto arbitrário $\mathrm{P}$, escolhido numa região amarela no lado esquerdo da figura. Como podemos observar, a órbita deste ponto converge para a raiz real unitária do polinômio. Nessa figura, o valor do parâmetro é 1.02 + $0.96 \mathrm{i}$; e os limites de variação da parte real e imaginária da variável $z$ são -2.0 e 1.6, e -1.5 e 1.2 , respectivamente. A órbita da origem converge para um ciclo de período 3 , marcado com cruzetas brancas. Cabe observar que um dos pontos do ciclo está muito próximo da origem. As bacias de não convergência do método de Newton estão assinaladas em azul escuro, e as de atração dos pontos fixos superatratores em amarelo, vermelho e azul claro.

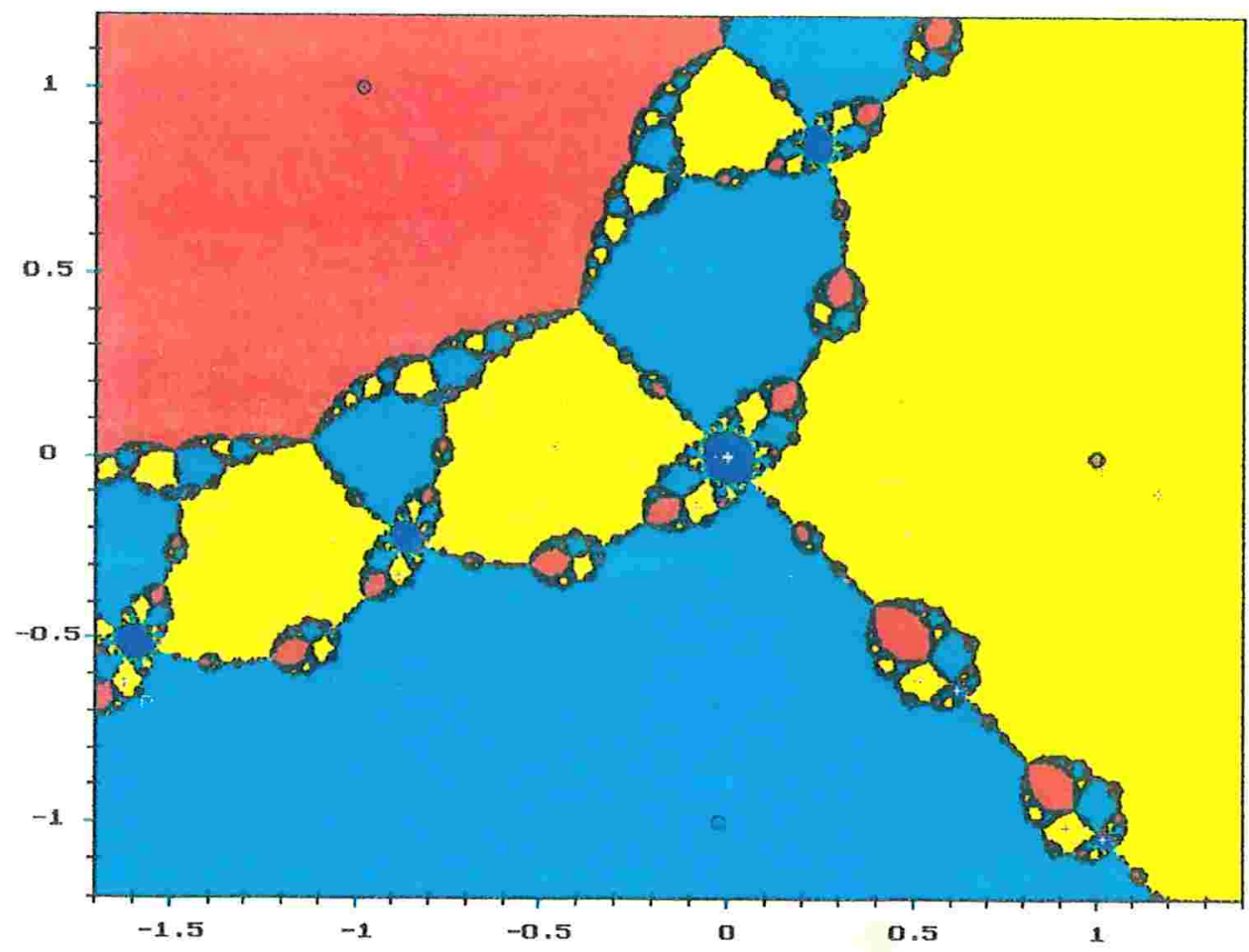

Figura 12 - Bacias de convergência e valores iniciais para os quais o método de Newton falha, para o polinômio $p_{a}$, com $\mathrm{a}=1.02+0.96 \mathrm{i}$ 
As figuras desta subseção foram obtidas pelo mesmo programa. O programa oferece as alternativas de traçar ou não, as bacias dos pontos fixos (super) atratores. Nas figuras 9 e 10 optamos pela não apresentação dessas bacias. Nas demais figuras, as bacias foram assinaladas.

Na figura 13, a órbita da origem, pela transformação $N_{p_{a}}$, com 0 valor do parâmetro $a$ igual a $1.0324+0.9688 \mathrm{i}$, converge para um ciclo atrator de período 9 , assinalado com cruzetas pretas. A figura foi ampliada e enquadrada de modo a favorecer a visualização do ciclo. A parte real de $z_{0}$ variou entre -0.52 e 1.35 ; e a imaginária entre -1.2 e 0.2 . A bacia de atração daquele ciclo foi marcada em magenta, enquanto as bacias dos pontos fixos superatratores em amarelo, vermelho e azul claro. O conjunto de Julia foi traçado em cinza.

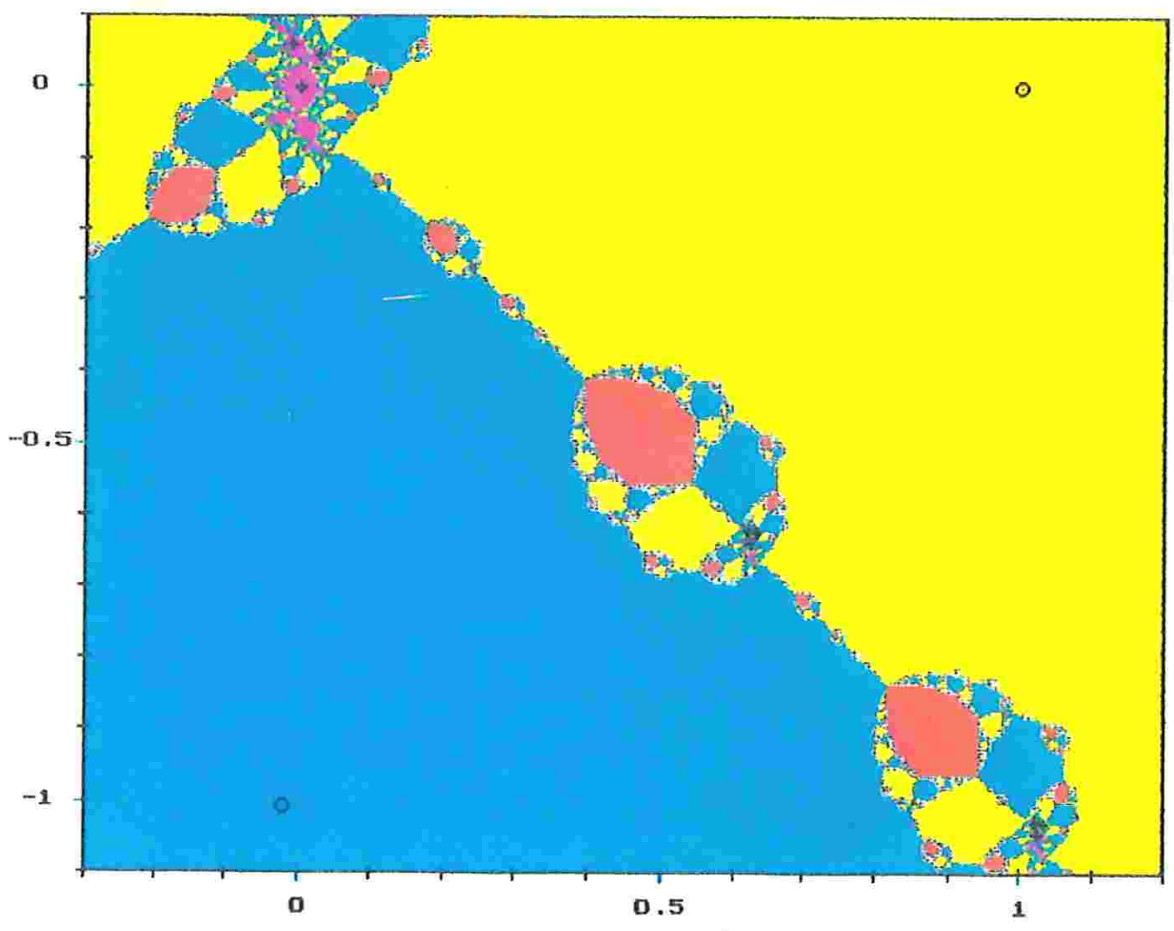

Figura 13 - Bacias de convergência e valores iniciais para os quais o método de Newton falha, para o polinômio $p_{a}$, com $\mathrm{a}=1.0324+0.9688 \mathrm{i}$. 


\section{4 - Método de Newton para polinômio de grau 4}

B. Barna ${ }^{4}$, em 1953 e 1956, considerou a transformação associada ao método de Newton de um polinômio $p$ com zeros apenas reais. Ele verificou que se o grau de $p$ é maior ou igual a 4, então o conjunto de valores iniciais para os quais o método de Newton falha, é um conjunto de Cantor de medida nula. Isto não ocorre necessariamente se o polinômio possui alguma raiz complexa. Através de uma análise semelhante à da seção anterior, identificaremos polinômios do quarto grau para os quais existem bacias de não convergência do método de Newton.

Sem a pretensão de esgotar a análise dos polinômios do quarto grau, consideremos $p(z)=\mu(z-\alpha)(z-\beta)(z-\gamma)(z-\xi)$ com pelo menos dois zeros distintos. De forma análoga ao caso do polinômio cúbico, para determinarmos $T^{\prime}(z)=A z+B$ tal que $p \circ T=p_{b}, \operatorname{com} p_{b}(z)=z^{4}+(b-1) z-b$ para algum $b$, obtemos o sistema de equações

$$
\left\{\begin{array}{l}
4 B-(\alpha+\beta+\gamma+\xi)=0 \\
6 B^{2}-3 B(\alpha+\beta+\gamma+\xi)+\alpha \beta+\alpha \gamma+\alpha \xi+\beta \gamma+\beta \xi+\gamma \xi=0 \\
r=A^{3}(b-1) \\
s=-A^{4} b
\end{array}\right.
$$

Observamos que a segunda equação impõe uma condição aos zeros do polinômio $p$, restringindo, assim, nossa análise. Resolvendo o sistema desconsiderando a segunda equação, obtemos quatro valores para $A$,

$$
\begin{gathered}
A_{1}=d+f, \quad A_{2}=d-f, \quad A_{3}=-d+g, \quad A_{4}=-d-g, \\
B=\frac{\alpha+\beta+\gamma+\xi}{4}
\end{gathered}
$$

onde

$$
d=\frac{m}{48^{1 / 3} n^{1 / 6}}, \quad f=i \frac{\left(12 g n^{1 / 2}+q m+2^{1 / 3} n^{2 / 3} m^{1 / 2}\right)^{1 / 2}}{48^{1 / 3} n^{1 / 6} m^{1 / 2}}
$$

${ }^{4}$ B. Barna, Uber die Divergenzpunkte des Newtonschen Verfahren zur Bestimmany von Wurzeln Algebraischer Gleichungen. Publ. Math. , Debrecen, 3, 109-118, (1953); Publ. Math., Debrecen, 4. 384-397. (1956). 


$$
\begin{array}{cc}
g=\frac{\left(12 g n^{1 / 2}-q m-2^{1 / 3} n^{2 / 3} m^{1 / 2}\right)^{1 / 2}}{48^{1 / 3} n^{1}{ }^{1 / 2} m^{1 / 2}}, & m=\left(q+2^{1 / 3} n^{2 / 3}\right)^{1 / 2}, \\
n=9 r^{2}+3^{1 / 2}\left(27 r^{4}-256 s^{3}\right)^{1 / 2}, & q=83^{1 / 3} s .
\end{array}
$$

Se $T_{i}(z)=A_{i}(z)+B$, então $p \circ T_{i}(z)=p_{b_{i}}(z)(i=1,2,3,4)$ com $b_{i}=-\frac{s}{A_{i}^{4}}$.

A expressão $p_{b}(z)=z^{4}+(b-1) z-b$ representa uma família, a um parâmetro $b$, de polinômios mônicos com uma das raizes unitária. A transformação associada ao método de Newton de $p$, pelo lema 2.1.6, é conjugada a

$$
N_{p_{b}}(z)=\frac{3 z^{4}+b}{4 z^{3}+b-1}
$$

Proposição 2.4.1. () único ponto critico não fixo da transformação $N_{p_{b}} \dot{e}$ a origem.

Prova: Como a derivada de (2.4.1) é:

$$
N_{p_{b}}^{\prime}(z)=\frac{p_{b}(z) p_{b}^{\prime \prime}(z)}{\left(p^{\prime}(z)_{b}\right)^{2}}=\frac{\left(z^{4}+(b-1) z-b\right) 12 z^{2}}{\left(4 z^{3}+b-1\right)^{2}}
$$

os pontos críticos de $N_{p_{b}}$ são os zeros de $p_{b}$ e a origem $z=0$. Pela proposição 2.1.1, os zeros de $p_{b}$ são pontos fixos (super) atratores de $N_{p_{b}}$. Como $N_{p_{b}}(0) \neq 0$, temos o resultado.

\subsection{1 - Morfologia no plano do parâmetro $b$}

A morfologia no plano do parâmetro $b$ permite visualizar os valores de $b$ para os quais a transformação do método de Newton $N_{p_{b}}$ pode possuir bacias de não convergência. Para a construção dessa figura elaboramos um programa computacional em linguagem $\mathrm{C}++$. O algoritmo do programa é análogo ao descrito na subseção 2.3.1 para a morfologia no plano do parâmetro $a$. Como a diferença básica reside na mudança do parâmetro considerado e das transformações correspondentes, não vemos necessidade de repetí-lo. 
A figura 14 fornece uma visão geral do comportamento da órbita do ponto crítico da transformação do método de Newton $N_{p_{b}}$. Foi obtida considerando -5.4, 3.4, -3.3, 3.3, como os limites de variação da parte real e imaginária , pmin, pmax, qmin, qmax, respectivamente. Na região em cinza as iteradas do ponto crítico convergem para a raiz real unitária. Nas regiões brancas, convergem para algum dos outros três zeros do polinômio $p_{b}$. Finalmente, nas regiões pretas, nas quais se focaliza o nosso maior interesse, a órbita da origem não converge para os pontos fixos da transformação $N_{p_{b}}$.

As graduações horizontal e vertical nas margens das figuras desta subseção representam, respectivamente, a parte real e imaginária do parâmetro $b$.

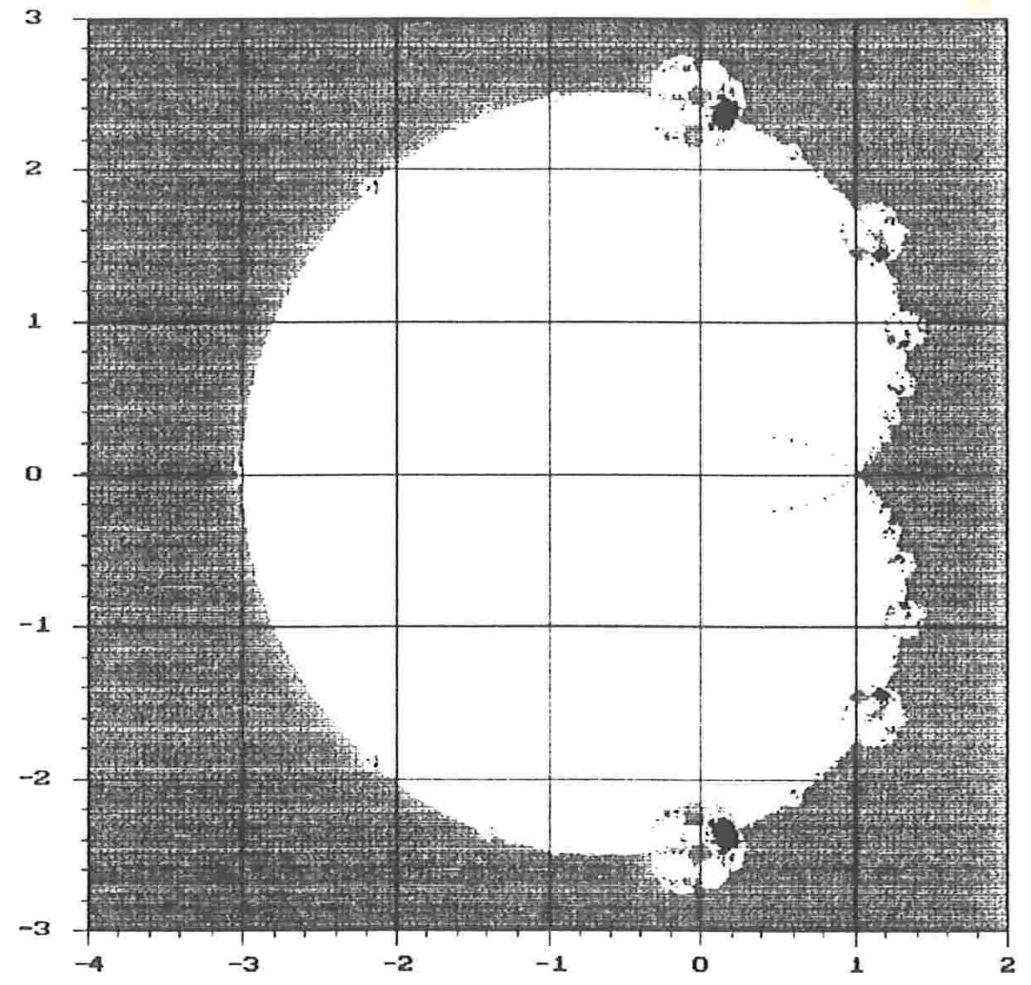

Figura 14 - Morfologia no plano do parâmetro b 
Restringindo as coordenadas, ampliamos regiões e podemos observar com mais detalhes, por exemplo, a " ilha " que se encontra na parte superior da figura 14.

Para construir a figura 15 atribuímos os valores -0.7 e 0.5 para os limites de variação da parte real, 2.0 e 2.9 da parte imaginária do parâmetro $b$. Da figura 15 selecionamos alguns valores do parâmetro $b$. Para as transformações $N_{p_{b}}$ correspondentes a estes valores, calculamos a órbita da origem. Verificamos o período do ciclo para o qual a órbita converge. Depois calculamos o módulo do autovalor do ciclo. Na tabela 2 foram listados estes valores do parâmetro $b$, com o respectivo período e módulo do autovalor do ciclo para o qual a órbita da origem pela $N_{p_{b}}$ converge.

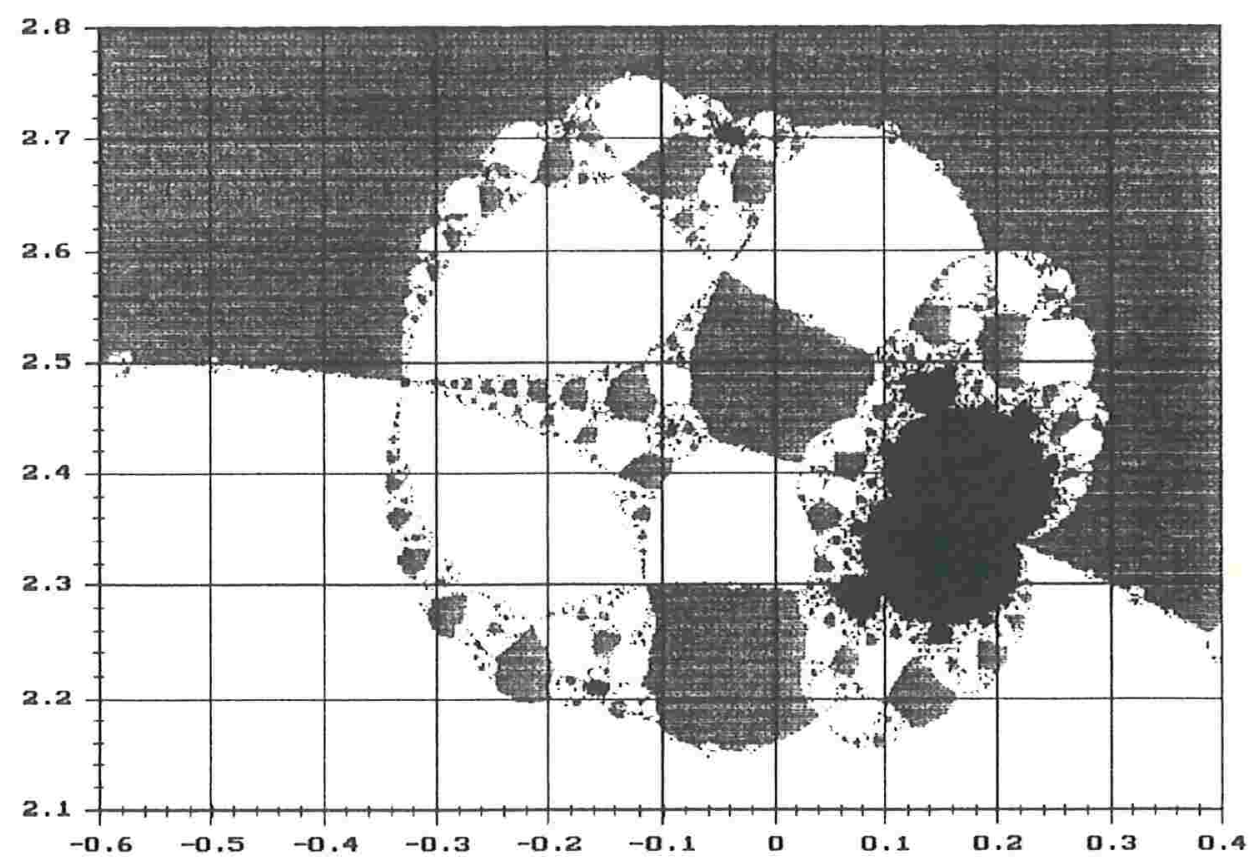

Figura 15 - Ampliação da " ilha " na parte superior da figura 14. 
Tabela 2

\begin{tabular}{|c|c|c|c|}
\hline \multicolumn{2}{|c|}{ Parâmetro $\quad b$} & \multicolumn{2}{|c|}{ Ciclo evidenciado pela origem } \\
\hline Parte real & Parte imaginária & Período & Autovalor \\
\hline-0.2 & 2.6 & 1 & 0.0000 \\
\hline 0.2 & 2.4 & 2 & 0.4869 \\
\hline 0.14 & 2.47 & 4 & 0.1843 \\
\hline 0.223 & 2.450 & 6 & 0.1699 \\
\hline 0.247 & 2.408 & 8 & 0.1969 \\
\hline
\end{tabular}

Para alguns dos valores do parâmetro $b$ da tabela 2 visualizaremos o conjunto dos valores iniciais para os quais o correspondente método de Newton falha.

\subsection{2 - Valores iniciais para os quais o método de Newton fallha}

Como vimos anteriormente, os pontos no conjunto de Julia $J\left(N_{p_{b}}\right)$ são valores iniciais para os quais o método de Newton não converge para os zeros de $p_{t}$. É possivel obtermos uma boa aproximação de $J\left(N_{p_{b}}\right)$ determinando a órbita regressiva de um ponto do conjunto

Proposição 2.4.2. O infinito pertence ao conjunto de Julia $J\left(N_{p_{b}}\right)$.

Prova: Seja

$$
h(z)=\left\{\begin{array}{lll}
\frac{1}{z} & \text { se } & z \neq 0 \\
\infty & \text { se } & z=0
\end{array}\right.
$$

então, 


$$
\phi(w)=h \circ N_{p_{b}} \circ h^{-1}(w)=\frac{(b-1) w^{4}+4 w}{b w^{4}+3} \quad \Rightarrow \quad \phi(0)=0 \Rightarrow N_{p_{c}}(\infty)=\propto
$$

e

$$
\phi^{\prime}(w)=\frac{12\left(-b w^{4}+(b-1) w^{3}+1\right)}{\left(b w^{4}+3\right)^{2}} \quad \Rightarrow \quad \phi^{\prime}(0)=\frac{1}{N_{p_{b}}^{\prime}(\infty)}=\lambda=\frac{4}{3}>1 .
$$

Portanto, pelo teorema 1.3.7, o infinito pertence ao conjunto de Julia $J\left(N_{p_{b}}\right)$.

Além do próprio infinito, suas pré-imagens pela $N_{p_{b}}$ são os pontos críticos de $p_{b}$ : as três raízes cúbicas de $(1-b) / 4$, que pela invariância do conjunto de Julia, estão em $J\left(N_{p_{b}}\right)$.

Como no caso do polinômio cúbico, para traçar a órbita regressiva convém encontrar a expressão das pré-imagens pela transformação $N_{p_{b}}$ de um ponto $w$ em $\mathrm{C}$; em outras palavras, os valores de $z$ que satisfazem a igualdade

$$
\frac{3 z^{4}+b}{4 z^{3}+b-1}=w
$$

As expressões dos valores de $z$ foram determinadas com o auxilio do software Mathematica. Assim, as pré-imagens de um ponto w em C são dadas por:

$$
\begin{aligned}
& z_{1}=\frac{w}{3}+\frac{t}{3 \sqrt{2} s^{1 / 6}}+\frac{u}{3 \sqrt{2} s^{1 / 6} t^{1 / 2}} \\
& z_{2}=\frac{w}{3}+\frac{t}{3 \sqrt{2} s^{1 / 6}}-\frac{u}{3 \sqrt{2} s^{1 / 6} t^{1 / 2}} \\
& z_{3}=\frac{w}{3}-\frac{t}{3 \sqrt{2} s^{1 / 6}}+\frac{v}{3 \sqrt{2} s^{1 / 6} t^{1 / 2}}
\end{aligned}
$$




$$
z_{4}=\frac{w}{3}-\frac{t}{3 \sqrt{2} s^{1 / 6}}-\frac{v}{3 \sqrt{2} s^{1 / 6} t^{1 / 2}}
$$

onde:

$$
\begin{gathered}
r=\sqrt{-a^{3}-3 a^{2}(1-a) w-3 a(1-a)^{2} w^{2}-(1-a)^{3} w^{3}+a^{2} w^{4}+2 a(1-a) w^{5}+(1-a)^{2} w^{6}} \\
s=a w^{2}+w^{3}-a w^{3}+r \\
t=\sqrt{3 a+3 w-3 a w+2 w^{2} s^{1 / 3}+3 s^{2 / 3}} \\
u=\sqrt{(2)^{5 / 2} w^{3} s^{1 / 2}-3 a t-3 w t+3 a w t+4 w^{2} s^{1 / 3} t-3 s^{2 / 3} t} \\
v=\sqrt{-(2)^{5} w^{3} s^{1 / 2}-3 a t-3 w t+3 a w t+4 w^{2} s^{1 / 3} t-3 s^{2 / 3} t}
\end{gathered}
$$

Com base no algoritmo proposto na seção 1.5 , implementamos um programa computacional para o traçado do conjunto de Julia $J\left(N_{p_{b}}\right)$, para um dado valor do parâmetro $b$. O programa foi elaborado em $C++$ e sua listagem completa é apresentada no apêndice. Os dados de entrada são o valor do parâmetro $b$ e os limites de variação da parte real ( $x \min$ e $x \max$ ) e imaginária ( ymin e ymax ) da variável $z$.

Para o traçado do conjunto de Julia das figuras relacionadas nesta subseção, adotamos como nivel máximo de recorrência, nvmax, igual a 9. Como em cada nível intermediário são marcados graficamente $4^{k}$ pontos, ao final do processo são plotados 349.524 pontos do conjunto de Julia.

A figura 16 mostra uma aproximação do conjunto de Julia para a transformação $N_{p_{b}}$, correspondente ao valor de $b=-0.2+2.6$ i. Foi obtida pelo programa citado acima, considerando os valores $-2.9,2.7,-2.3$ e 1.9 para $x \min , x \max , y \min$ e ymax, respectivamente. Como a órbita da origem converge para um dos zeros de $p_{b}$, o conjunto de Fatou de $N_{p_{b}}$ não possui domínios de Sullivan além das bacias de atração dos pontos fixos. Dessa maneira, esta figura representa o conjunto dos pontos para os quais o método de Newton falha para $p_{b}$. 


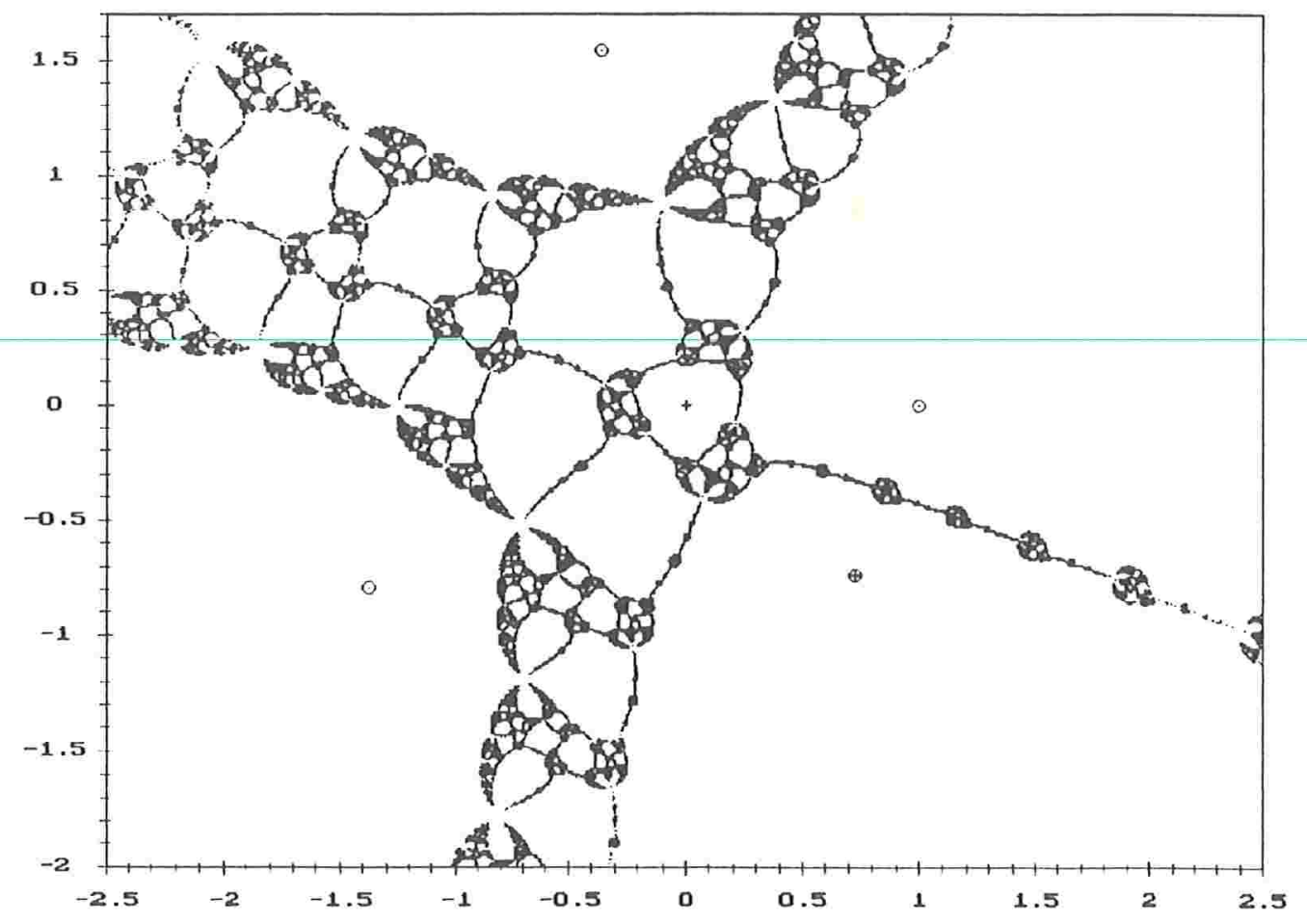

Figura 16 - Conjunto de Julia de $N_{p_{b}}$, para $b=-0.2+2.6 \mathrm{i}$.

Os zeros do polinômio estão indicados por um círculo com um ponto no interior; a origem e o ciclo para o qual sua órbita converge são representados por cruzetas. As graduações horizontal e vertical nas margens das figuras desta subseção, representam a parte real e imaginária da variável $z$.

Como na subseção 2.3.2, para os valores do parâmetro $b$ contidos nas regiões pretas das figuras 14 e 15, conjecturamos que as correspondentes transformações do método de Newton $N_{p_{b}}$ possuem ciclos não repulsores, além dos pontos fixos. Esses ciclos implicam na existência de domínios eventualmente periódicos de não convergência do método de Newton. Para visualizar estes domínios como também as bacias de atração dos pontos fixos, quando são de interesse, implementamos uma rotina computacional análoga à descrita naquela subseção. Como a diferença básica reside na mudança do parâmetro considerado e das transformações correspondentes, não vemos necessidade de repetí-la. Apenas, cabe salientar que agora são necessárias quatro cores distintas entre si, uma para cada bacia dos quatro zeros do polinômio $p_{b}$; e ainda distintas das cores selecionadas para o conjunto dos valores iniciais para os quais o método de Newton falha. 


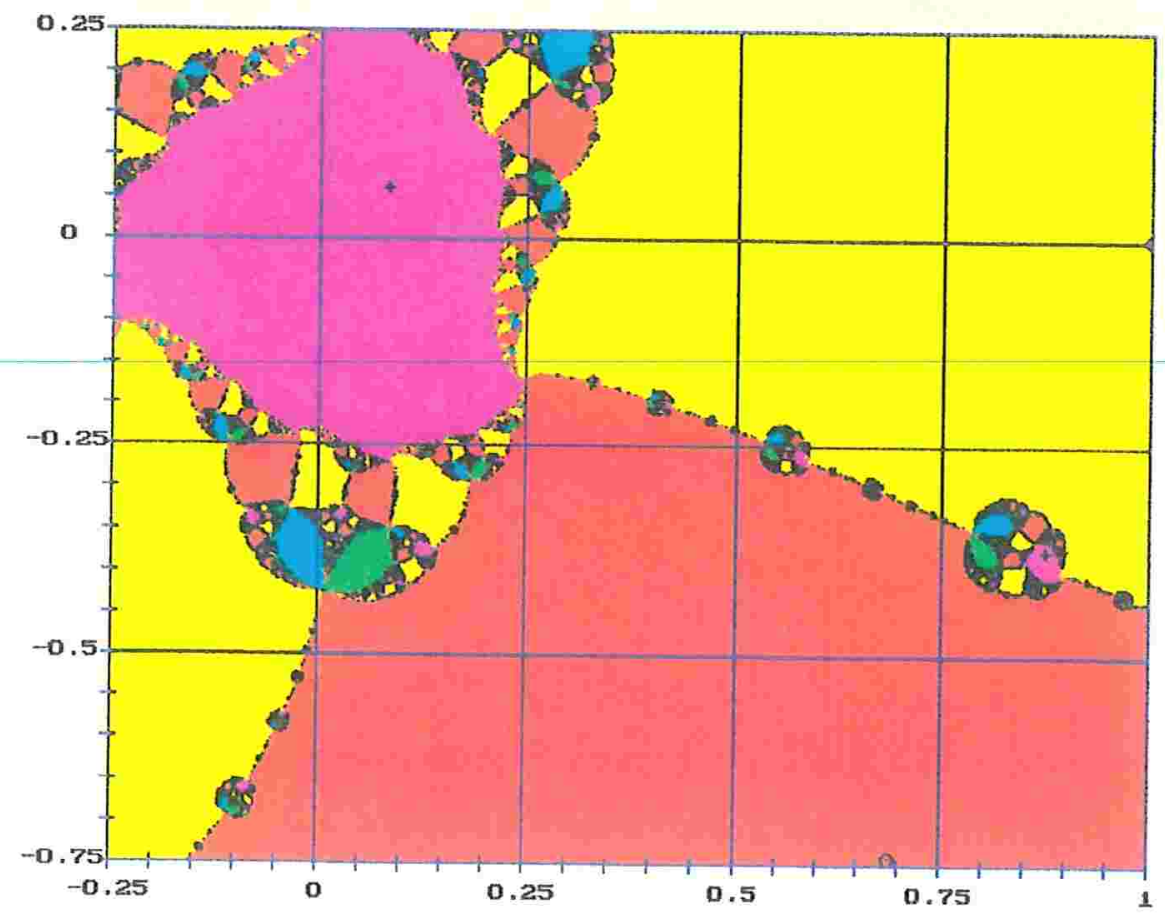

Figura 17 - Bacias dos zeros e valores iniciais para os quais o método de Newton falha, para o polinômio $p_{b}, \operatorname{com} b=0.2+2.4 \mathrm{i}$.

$\mathrm{O}$ valor do parâmetro $b$, na figura 17 , é $0.2+2.4$ i. Para a construção dessa figura, foram fornecidos os valores $-0.4,1.2,-0.8$ e 0.4 para $x$ min, xmax, ymin e ymax, respectivamente. O programa percorre cada uma das 640 colunas e verifica se o ponto $z_{0}$ da grade satisfaz a condição

$$
\left|N_{P_{h}}^{k}\left(z_{0}\right)-N_{P_{s}}^{k-1}\left(z_{0}\right)\right|>10^{-6}
$$

para todo $k$ entre 1 e o número máximo de iterações, $n m a x$. No caso afirmativo, o pixel correspondente a $z_{0}$ é assinalado em magenta. Esses pontos representam a bacia de atração do ciclo atrator de período 2 , evidenciado pela órbita da origem, observando que um dos pontos do ciclo atrator está situado muito próximo da origem. No caso contrário, ou seja, se $z_{0}$ satisfizer a condição

$$
\left|N_{P_{h}}^{k}\left(z_{0}\right)-N_{P_{A}}^{k-1}\left(z_{0}\right)\right| \leq 10^{-6}
$$


para algum $k$ entre 1 e $n m a x$, o pixel correspondente é assinalado em amarelo, verde, vermelho ou ciano, dependendo do zero do polinômio $p_{b}$ para o qual a órbita de $z_{0}$ converge. Finalizado este processo, é traçado o conjunto de Julia, em cinza.

Os zeros do polinômio $p_{b}=z^{4}+(b-1) z-b$ são:

$$
\begin{aligned}
& z_{1}=1 \\
& z_{2}=-\frac{1}{3}-\frac{2^{4 / 3}}{3 \alpha}+\frac{\alpha}{3.2^{1 / 3}} \\
& z_{3}=-\frac{1}{3}-\frac{1}{6}\left(\frac{-2^{4}}{\alpha}+\frac{\alpha}{2^{1 / 3}}\right)+i \frac{\sqrt{3}}{6}\left(\frac{2^{4 / 3}}{\alpha}+\frac{\alpha}{2^{1 / 3}}\right) \\
& z_{4}=-\frac{1}{3}-\frac{1}{6}\left(\frac{-2^{4}{ }^{4}}{\alpha}+\frac{\alpha}{2^{1 / 3}}\right)-i \frac{\sqrt{3}}{6}\left(\frac{2^{4}{ }^{4}}{\alpha}+\frac{\alpha}{2^{1 / 3}}\right)
\end{aligned}
$$

com:

$$
\alpha=\left(7-27 b+3^{3 / 2} \sqrt{3-14 b+27 b^{2}}\right)^{1 / 3}
$$

Observamos, inicialmente, que $\alpha$ nunca se anula, qualquer que seja $b$ em $\bar{C}$. Para identificar para qual dos zeros de $p_{b}$ a órbita de $z_{0}$ converge, basta verificar se converge para um valor unitário, ou com parte real menor ou igual a $-1 / 3$, ou nenhum destes casos. Em qualquer uma das situações, exceto a do valor unitário, devemos analisar se a parte imaginária é positiva, negativa ou nula. Cabe observar que, se $b=7 / 27$, os zeros $z_{2}, z_{3}$ e $z_{4}$ possuem parte real igual a $-1 / 3$, e diferem no sinal da parte imaginária. Se $b=-3$, então $z_{1}=z_{2}$. Se

$$
b=\frac{14 \pm 2^{7} i}{54}
$$

então $z_{3}=z_{4}$ 
As figuras 16 e 17 foram obtidas com o mesmo programa. Para a figura 16 escolhemos a opção de não traçar as bacias dos pontos fixos (super) atratores, enquanto para a figura 17, optamos em traçar as referidas bacias. 


\section{Apêndice}

\section{Listagens dos programas computacionais}

Apresentamos, neste apêndice, as listagens completas dos programas computacionais citados no capítulo 2. Esses programas foram escritos em linguagem $\mathrm{C}++$. Na forma que são aqui apresentados, os programas foram compilados no sistema Borland $\mathrm{C}++$, versão 3.1. Os programas executáveis produzidos com o mencionado compilador, podem ser rodados em microcomputadores usuais da linha $\mathrm{PC}$, equipados com DOS, versão 5.0 ou posterior, adaptador gráfico VGA e coprocessador matemático. A ausência do coprocessador pode tornar a velocidade do processamento inaceitavelmente lenta.

A primeira é a listagem do programa MORFZ3 e refere-se à construção da morfologia no plano do parâmetro $a$, da transformação associada ao método de Newton

$$
N_{p_{a}}=\frac{2 z^{3}+a}{3 z^{2}+a-1}
$$

do polinômio cúbico

$$
p_{a}(z)=z^{3}+(a-1) z-a .
$$


A segunda listagem diz respeito ao programa JULNWZ3, que traça o conjunto de Julia, as bacias de não convergência do método de Newton, e as bacias (super) atratoras dos pontos fixos da transformação $N_{p_{a}}$.

A terceira concerne ao programa MORFZ4, que constrói a figura da morfologia no plano do parâmetro $b$, da transformação associada ao método de Newton

$$
N_{p_{b}}(z)=\frac{3 z^{4}+b}{4 z^{3}+b-1}
$$

do polinômio de grau 4

$$
p_{b}(z)=z^{4}+(b-1) z-b .
$$

A última listagem é a do programa JULNWZ4 e refere-se ao traçado do conjunto dos pontos onde o método de Newton falha, e das bacias (super)atratoras dos pontos fixos da transformação $N_{p_{h}}$.

O leitor interessado poderá solicitar os quatro programas executáveis à autora deste trabalho, remetendo uma mensagem para:

Universidade Federal do Paraná

Centro Politécnico - Jardim das Américas

A/C Elizabeth Wegner Karas

Caixa Postal 19081

Curitiba - PR, 81531 - 970

ou E-mail para:

\section{EWK@BRUFPR.BITNET.}




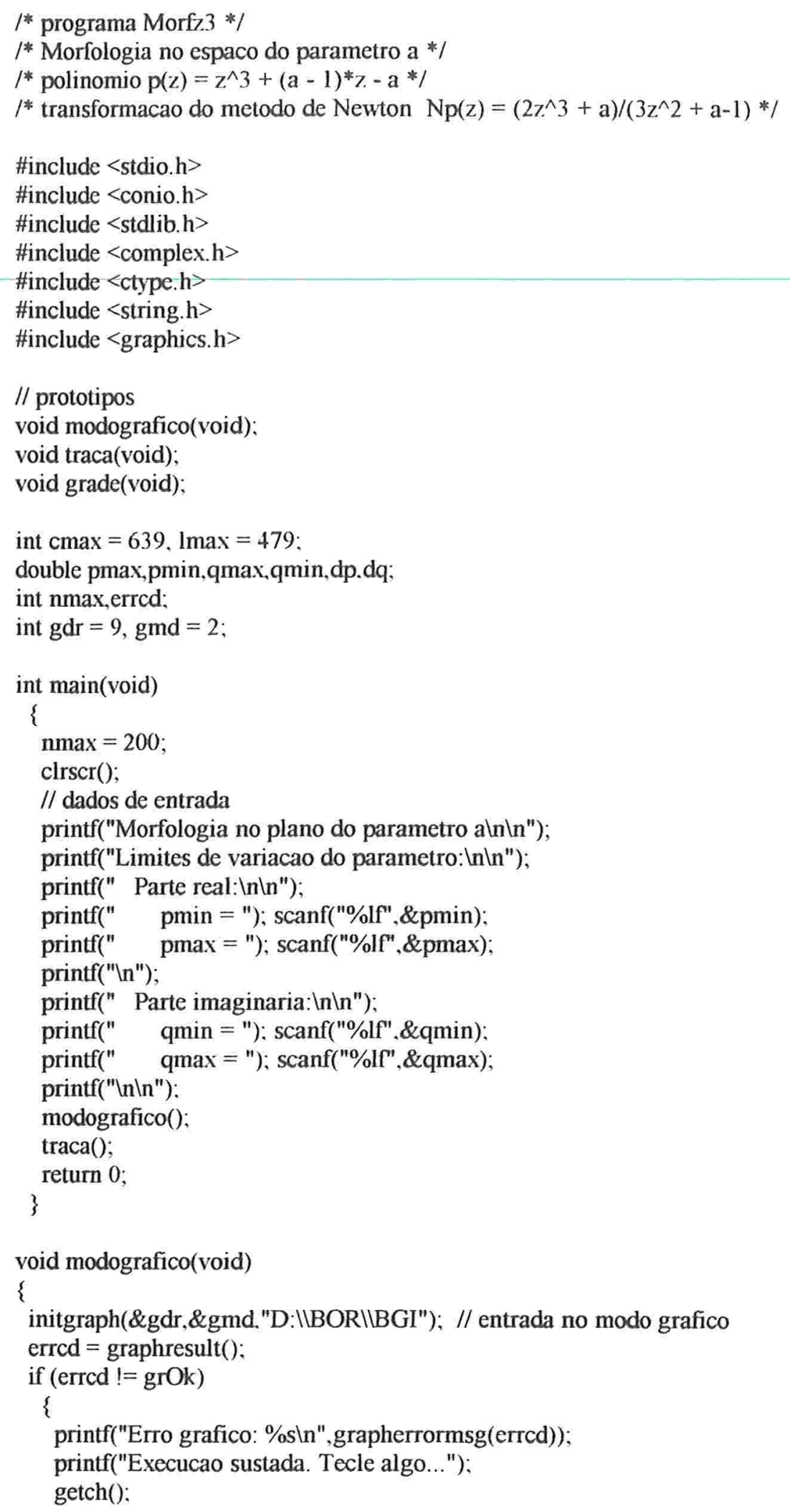




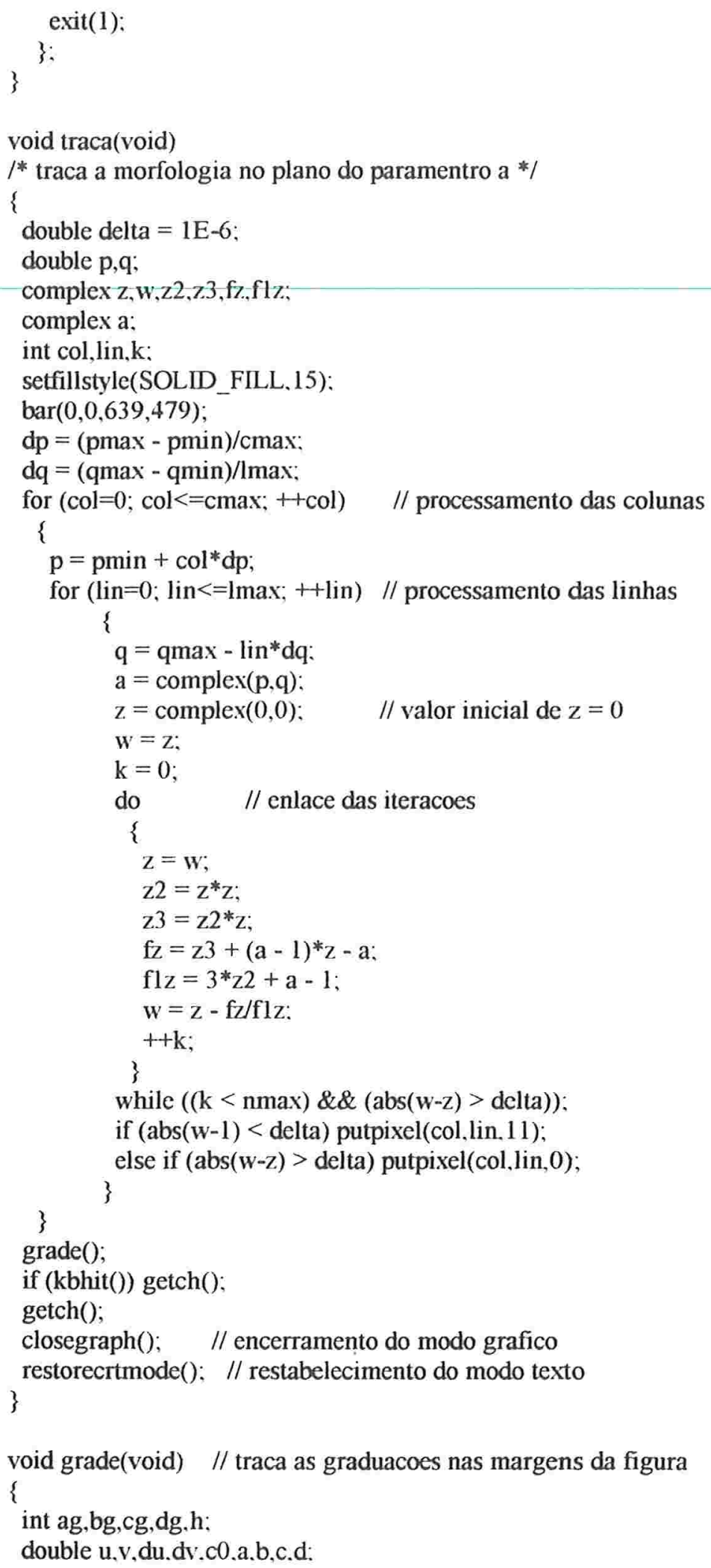


double wp,lp.hp.wq.lq.hq:

char snum[6]:

$\mathrm{wp}=$ pmax $-\mathrm{pmin}$ :

$\mathrm{wq}=\mathrm{qmax}-\mathrm{qmin}$ :

if $(w p>6.0)$

\{

$\mathrm{c}=\operatorname{ceil}(\mathrm{pmin}+0.1)$;

$\mathrm{d}=$ floor $($ pmax -0.1$)$;

$\mathrm{du}=1.0$

\}

else if $(w p>3.0)$

\{

$\mathrm{c}=\operatorname{ceil}(2 * \operatorname{pmin}+0.1) / 2.0$;

$\mathrm{d}=$ floor $(2 * \operatorname{pmax}-0.1) / 2.0$;

$\mathrm{du}=0.5$

\}

else if $(w p>1.5)$

\{

$\mathrm{c}=\operatorname{ceil}\left(4^{*} \operatorname{pmin}+0.1\right) / 4.0$;

$\mathrm{d}=$ floor $\left(4^{*} \operatorname{pmax}-0.1\right) / 4.0$;

$\mathrm{du}=0.25$;

\}

else if $(w p>0.5)$

\{

$\mathrm{c}=\operatorname{ceil}\left(10^{*} \operatorname{pmin}+0.1\right) / 10.0$;

$\mathrm{d}=$ floor $\left(10^{*} \operatorname{pmax}-0.1\right) / 10.0$;

$\mathrm{du}=0.1$;

\}

else if $(w p>0.06)$

\{

$\mathrm{c}=\operatorname{ceil}\left(100^{*} \operatorname{pmin}+0.1\right) / 100.0$;

$\mathrm{d}=$ floor $\left(100^{*} \operatorname{pmax}-0.1\right) / 100.0$;

$\mathrm{du}=0.01$;

\}

else

\{

$\mathrm{c}=\operatorname{ceil}(1000 * \mathrm{pmin}+2.6) / 1000.0$;

$\mathrm{d}=$ floor $\left(1000^{*}\right.$ pmax -2.6$) / 1000.0$ :

$\mathrm{du}=0.003$;

\}

if $(w q>4.5)$

\{

$\mathrm{b}=\operatorname{ceil}($ qmin +0.1$)$;

$\mathrm{a}=$ floor $($ qmax -0.1$)$;

$\mathrm{dv}=1.0$;

\}

else if $(w q>2.2)$

\{

$\mathrm{b}=\operatorname{ceil}(2 * \mathrm{qmin}+0.1) / 2.0$;

$\mathrm{a}=$ floor $(2 *$ qmax -0.1$) / 2.0$.

$\mathrm{dv}=0.5$ : 


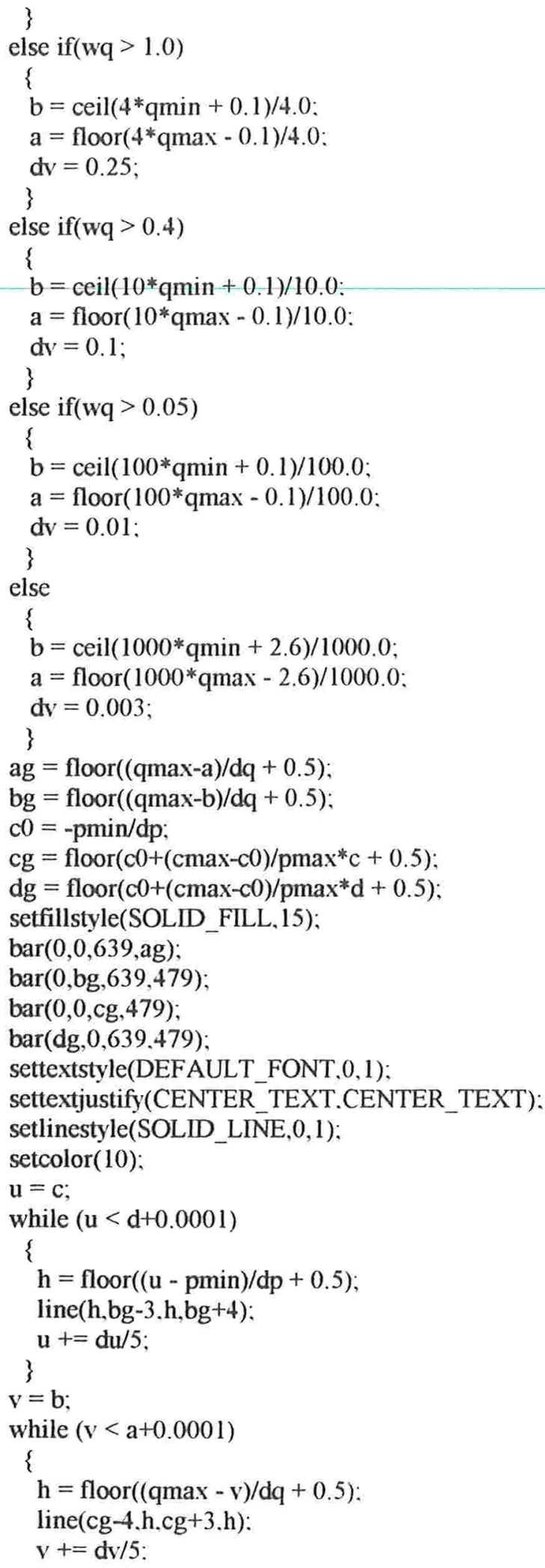




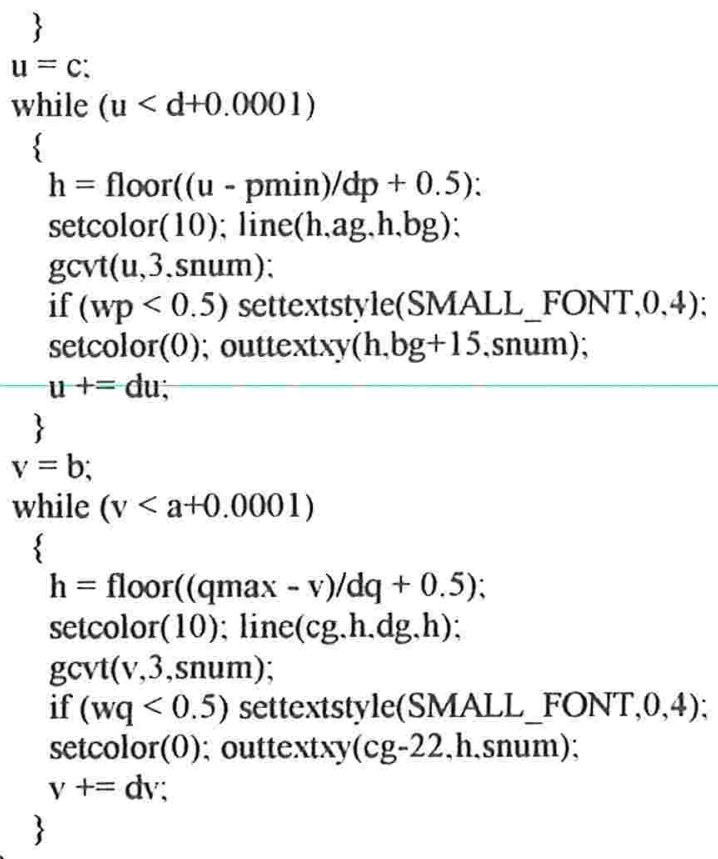


/* Programa JulNwz3 */

1* Constroi o conjunto para o qual o metodo de Newton falha e bacias de atracao dos pontos fixos

de $N f(z)=\left(2 z^{\wedge} 3+a\right) /\left(3 z^{\wedge} 2+a-1\right) * /$

\#include $<$ stdio. $\mathrm{h}>$

\#include <stdlib.h $>$

\#include $<$ conio. $\mathrm{h}>$

\#include $<$ ctype. $\mathrm{h}>$

\#include $<$ complex.h $>$

\#include <math.h $>$

\#include <graphics.h>

\#define PLMAX 32

struct pontoz

\{

complex pz:

int pnivel:

;

/* prototipos */

void marque(complex zk):

void marque2(complex zk);

void marque 3 (complex zk);

void guarde(struct pontoz $\mathrm{pz}$ );

void grade(void);

struct pontoz resgate(void);

struct pontoz pl[PLMAX]: // a pilha

struct pontoz regc; // registro auxiliar

complex $\mathrm{z}, \mathrm{w}, \mathrm{a}$;

double xmax, xmin,ymax,ymin, $d x, d y$;

int $\operatorname{cmax}=639$;

int $1 \max =479$;

int $n v m a x=11$;

int col,lin,coluna.linha,topo;

int cor;

int main(void)

\{

int $n \max =200$;

double delta $=1 \mathrm{E}-6$;

double p.q,x,y;

int $\mathrm{gdr}=9$;

int gmd $=2$;

int errcd,nivel.k:

int $\mathrm{m}=0$;

complex z1,z2,z3,z4,za,zb,zc.c2,cz,f,g.h;

complex fz,flz:

char ch; 
clrscr():

printf("Conjunto de pontos para os quais o metodo de Newton falhaln");

printf("Polinomio $\left.\mathrm{p}(\mathrm{z})=\mathrm{z}^{\wedge} 3+(\mathrm{a}-1) \mathrm{z}-\mathrm{a} \backslash \mathrm{n} \backslash \mathrm{n} "\right)$ :

printf("Valor do parametro a: $\ln \backslash n ")$;

printf(" Parte real: "); scanf("\%lf".\&p):

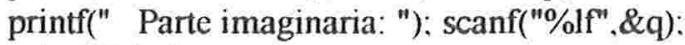

printf("lnไn");

printf("Limites de variacao da variavel $z: \ln \backslash n$ "):

printf(" Parte real: $\ln \mid n ")$ :

printf(" $\quad$ xmin $=") ; \operatorname{scanf}\left({ }^{" \%} \% l f^{\prime \prime}, \& \times m i n\right) ;$

printf(" $\quad$ xmax $=")$ : scanf("\%lf".\&xmax);

printf("In");

printf(" Parte imaginaria: $\ln \backslash n ")$;

printf(" $\quad$ ymin = "); $\operatorname{scanf}\left(" \% \mathrm{lf}^{\prime \prime}, \& \mathrm{ymin}\right)$;

printf(" $\quad$ ymax $=$ "); scanf("\%lf",\&ymax);

printf("'nın");

printf("Traca as bacias dos pontos fixos superatratores ? (s/n) ");

$\mathrm{ch}=\operatorname{getch}()$;

$\mathrm{a}=$ complex(p,q):

$\mathrm{dx}=(\mathrm{xmax}-\mathrm{xmin}) / \mathrm{cmax}$ :

$d y=(y \max -y \min ) / \mathrm{lmax}$ :

initgraph(\&gdr.\&gmd. "D:ILBORILBGI"):

errcd = graphresult () :

if (errcd != grOk)

\{

printf("Erro grafico: \%sln",grapherrormsg(errcd));

printf("Tecle algo... In!n");

getch();

exit(1);

\}

setfillstyle(SOLID_FILL, 15);

$\operatorname{bar}(0,0,639,479)$;

$\mathrm{w}=$ complex $(0,0) ; \quad$ // Verifica se a orbita da origem

$\mathrm{k}=0 ; \quad$ // converge para alguma raiz

do // Inicio do enlace das iteracoes

$\mathrm{z}=\mathrm{w}$;

$\mathrm{z} 2=\mathrm{z} * \mathrm{z}$

$\mathrm{z} 3=\mathrm{z} 2 * \mathrm{z}$

$\mathrm{fz}=\mathrm{z} 3+(\mathrm{a}-1)^{*} \mathrm{z}-\mathrm{a}$;

$\mathrm{flz}=3 * \mathrm{z} 2 \mathrm{2}+\mathrm{a}-1$;

if $(\operatorname{abs}(\mathrm{flz})<1 \mathrm{E}-20)$ break;

$\mathrm{w}=\mathrm{z}-\mathrm{fz} / \mathrm{fl} \mathrm{z}$;

$\mathrm{k}++$;

\}

while $((\mathrm{k}<\mathrm{nmax}) \& \&(\mathrm{abs}(\mathrm{w}-\mathrm{z})>$ delta $))$;

if $((\operatorname{abs}(\mathrm{w}-\mathrm{z})<$ delta) \& \& (toupper(ch) ! ' 'S')) cmax = 6:

// Traca bacias: de nao convergencia e/ou dos pontos fixos

for $(\mathrm{col}=0$; $\mathrm{col}<=\mathrm{cmax}$; $++\mathrm{col}$ ) // processamento das colunas

\{

$\mathrm{x}=\mathrm{xmin}+\mathrm{col}^{*} \mathrm{dx}$ 


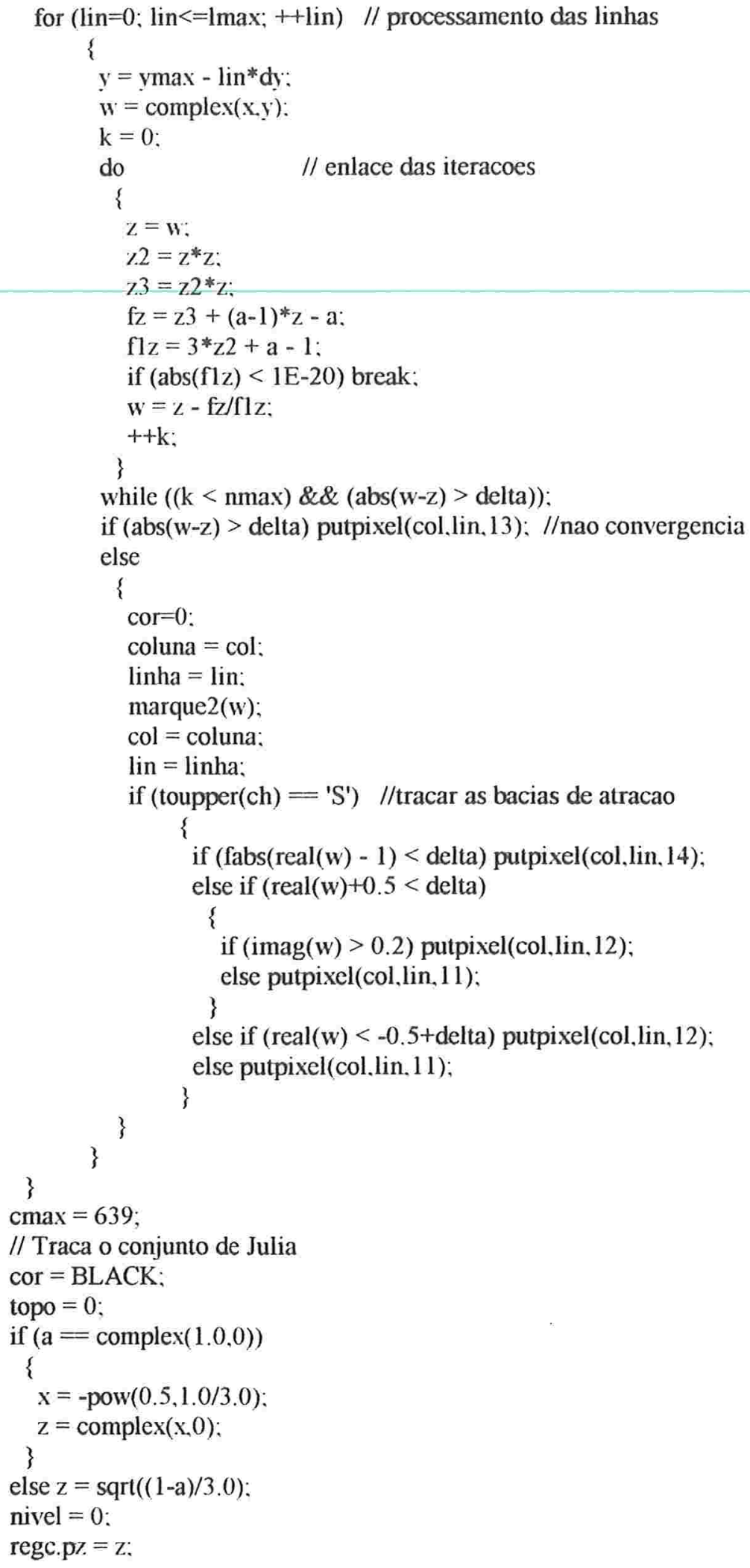




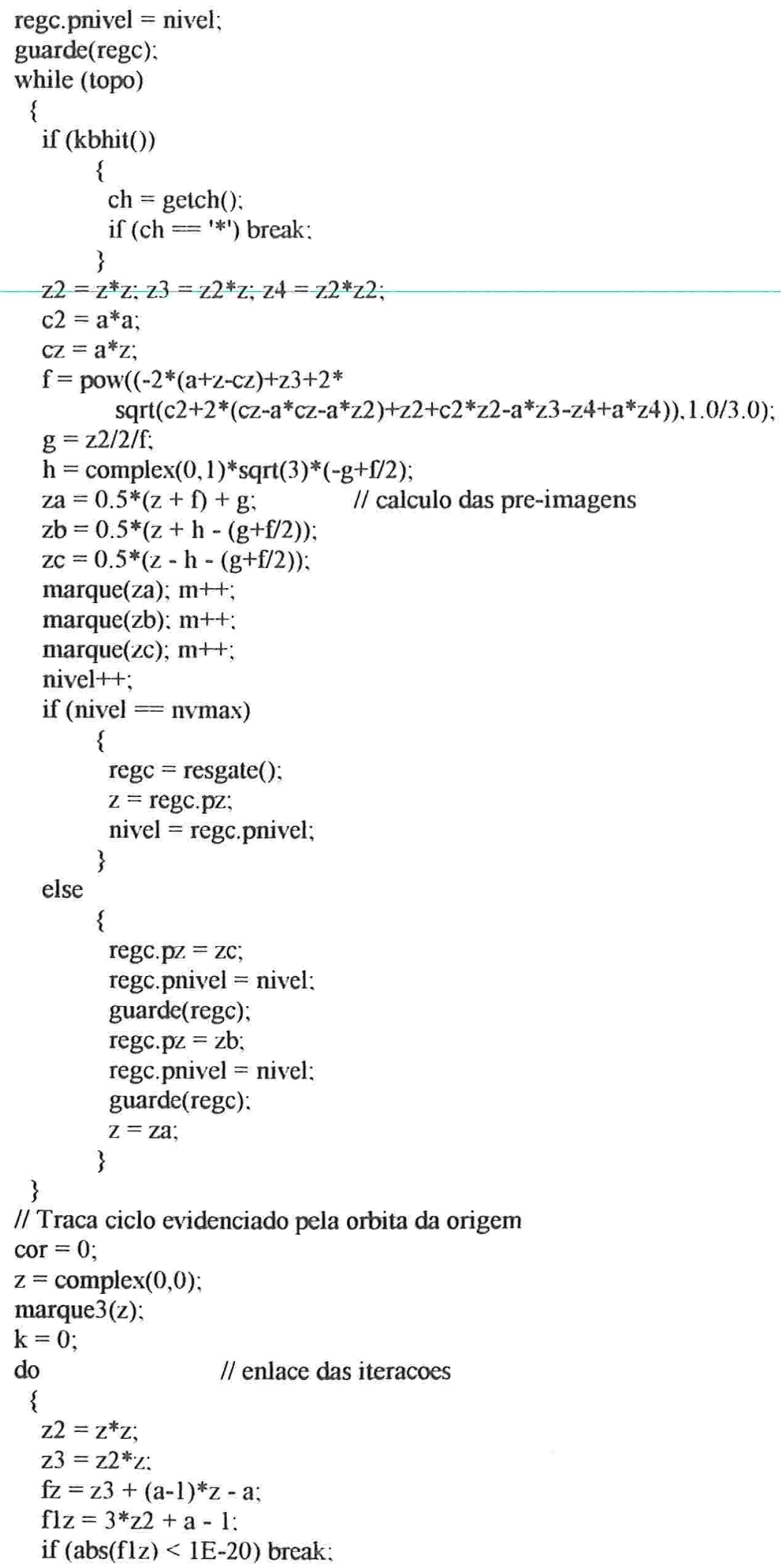




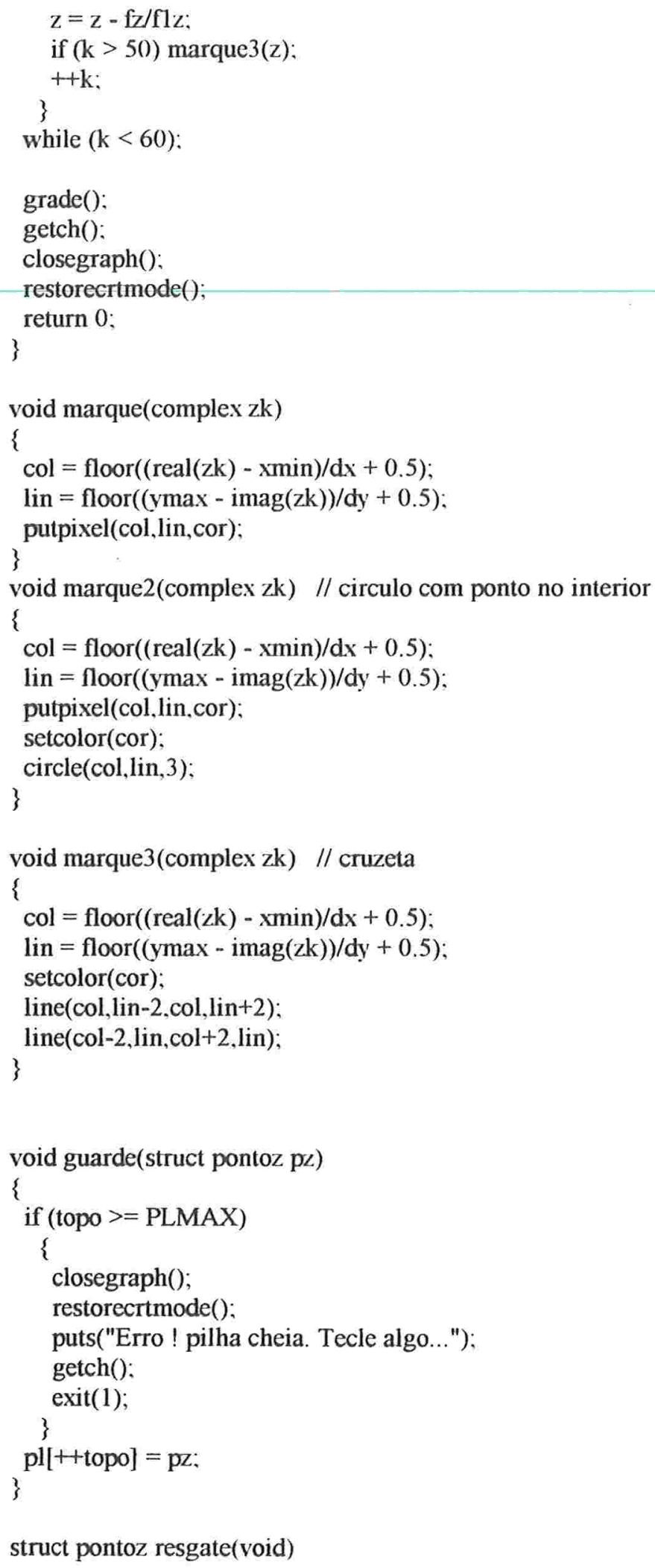




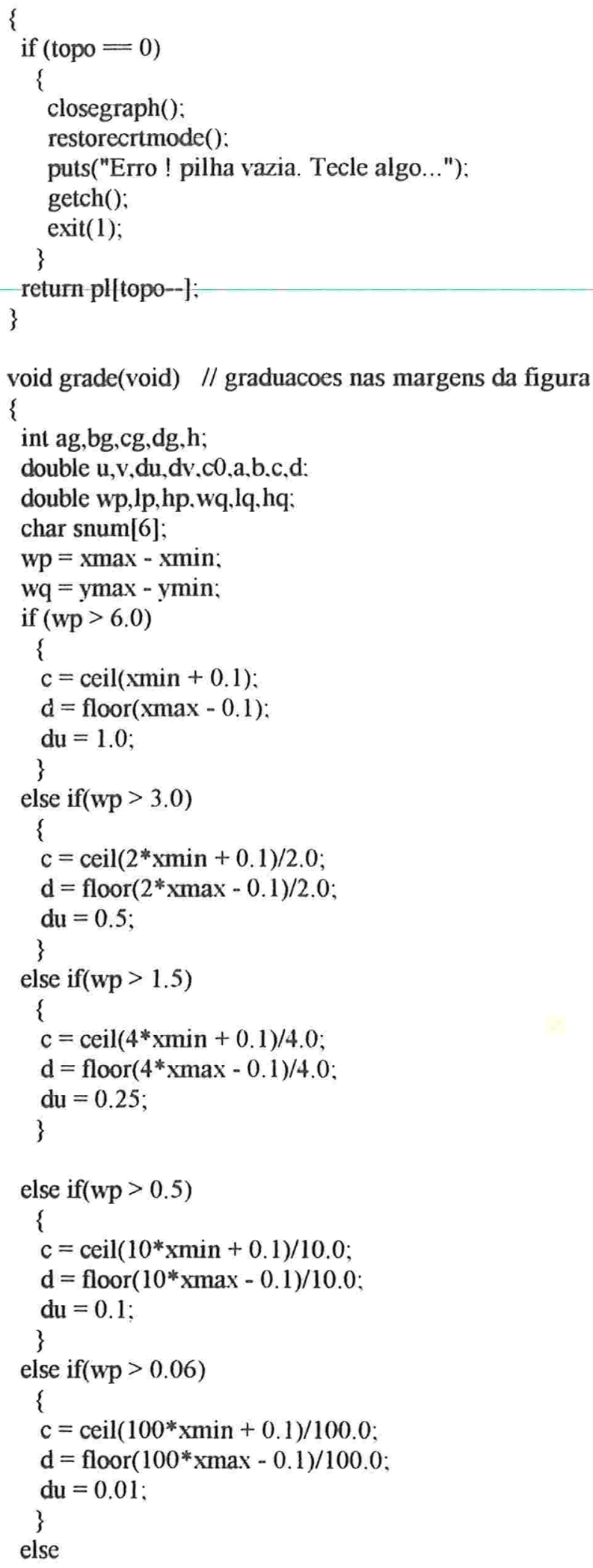




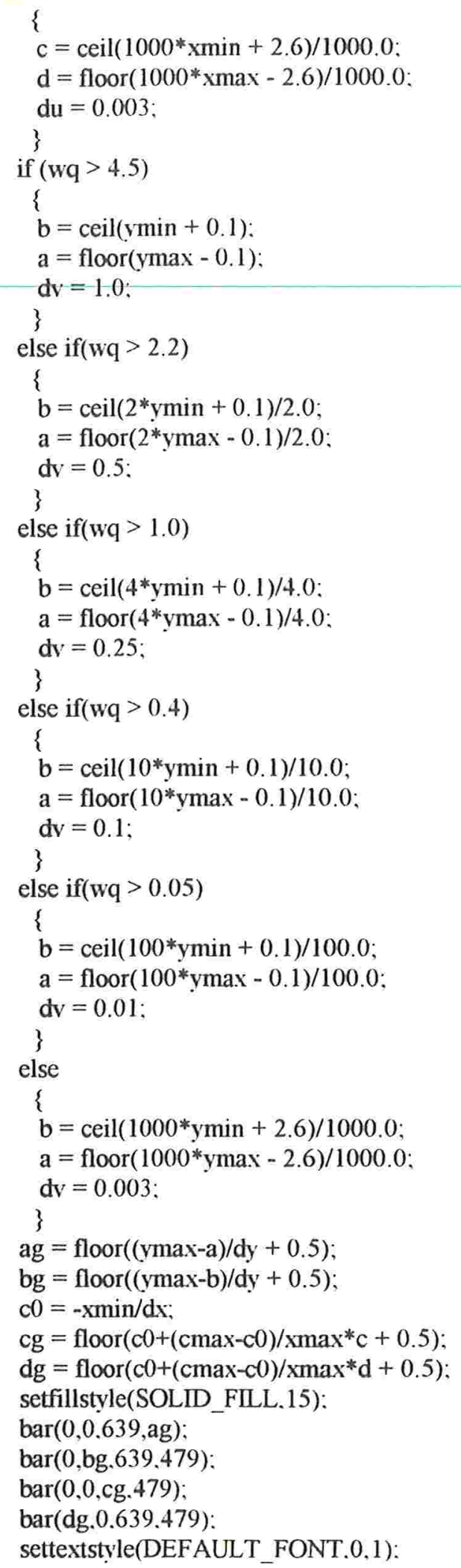




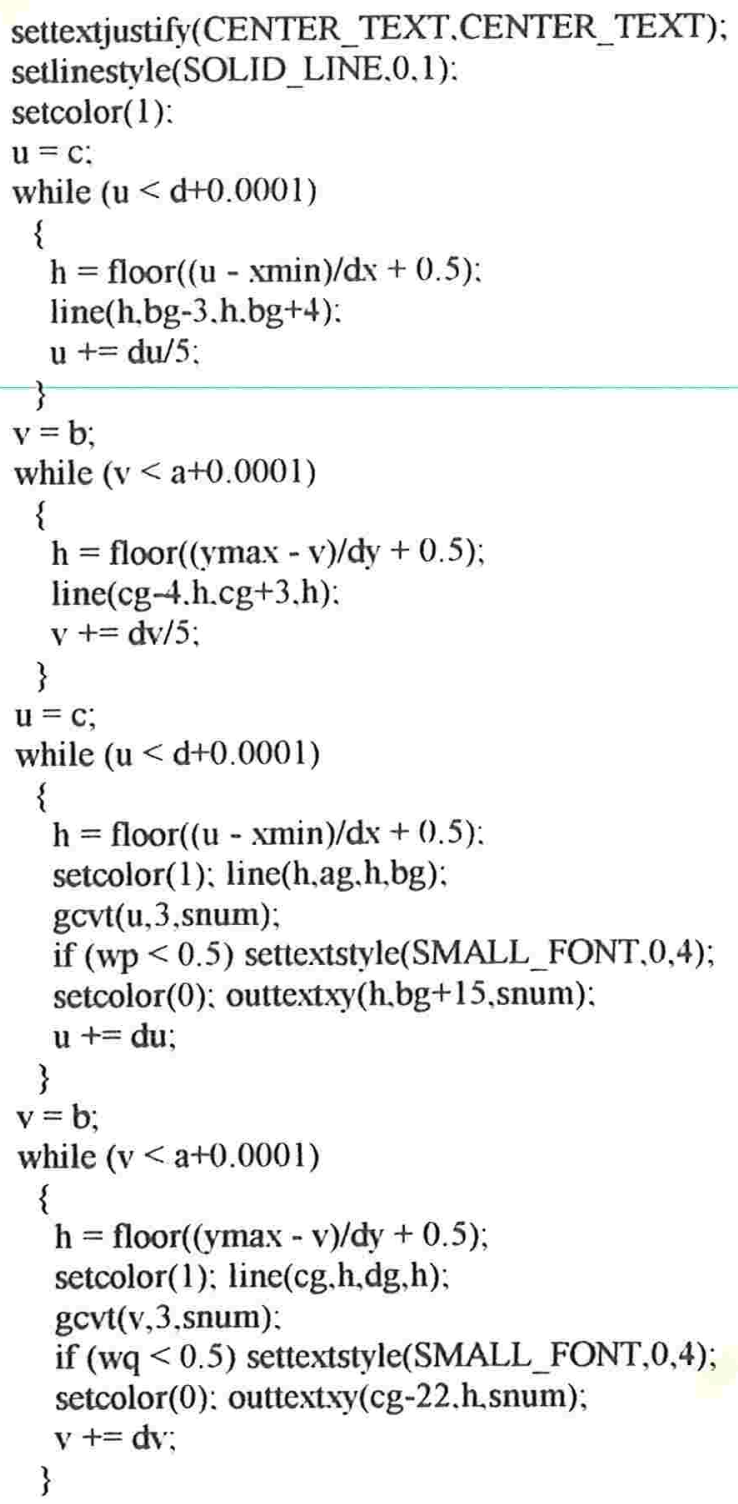




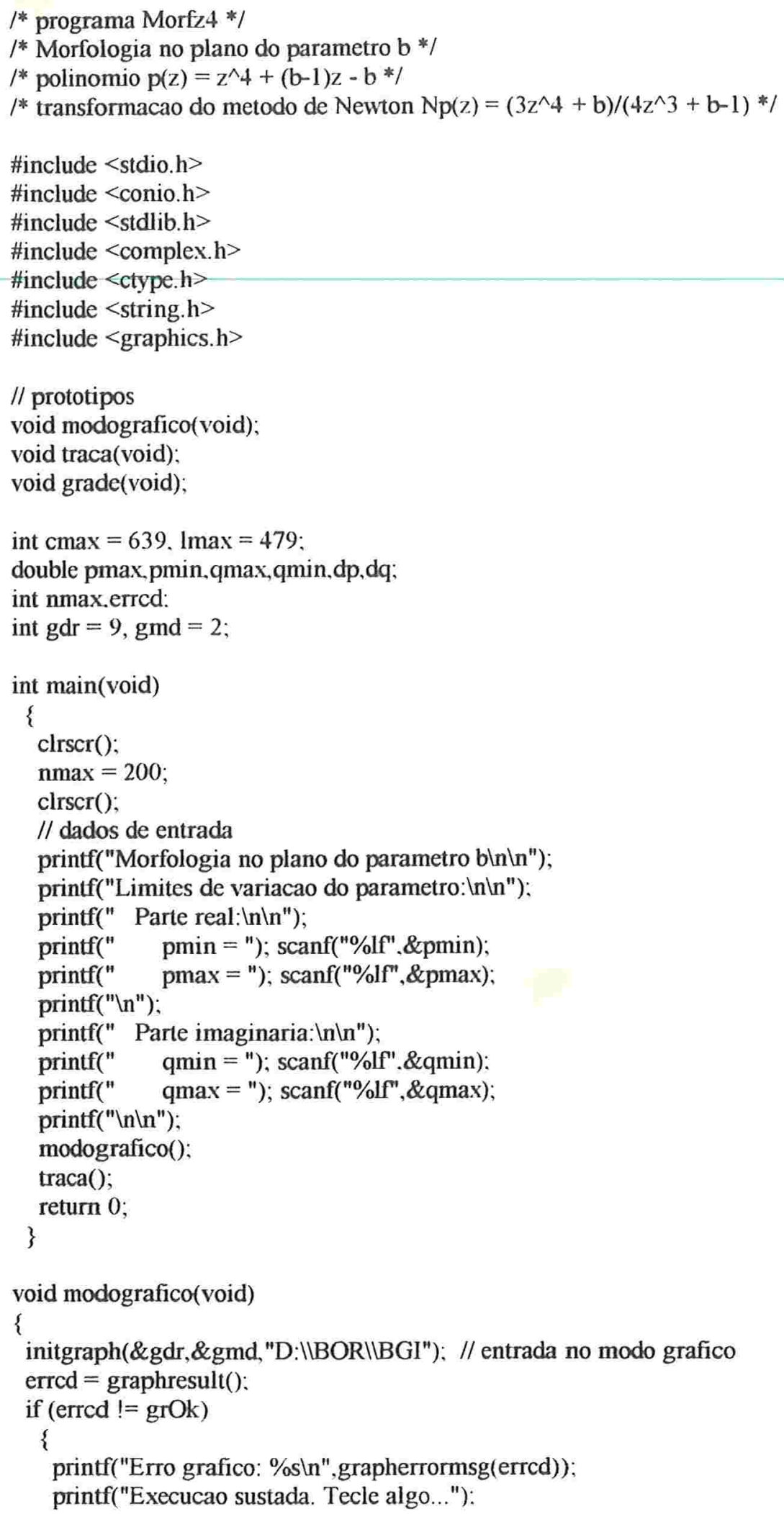




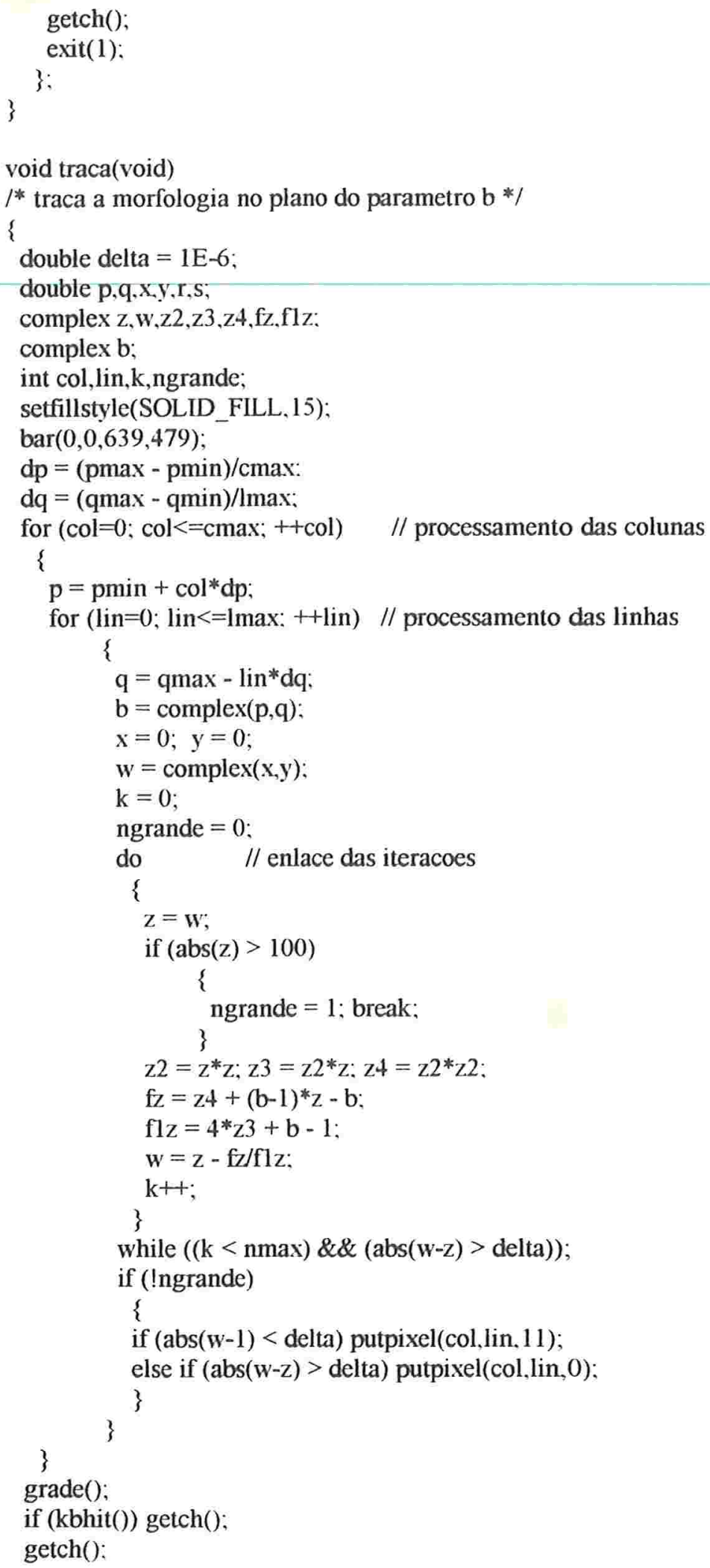




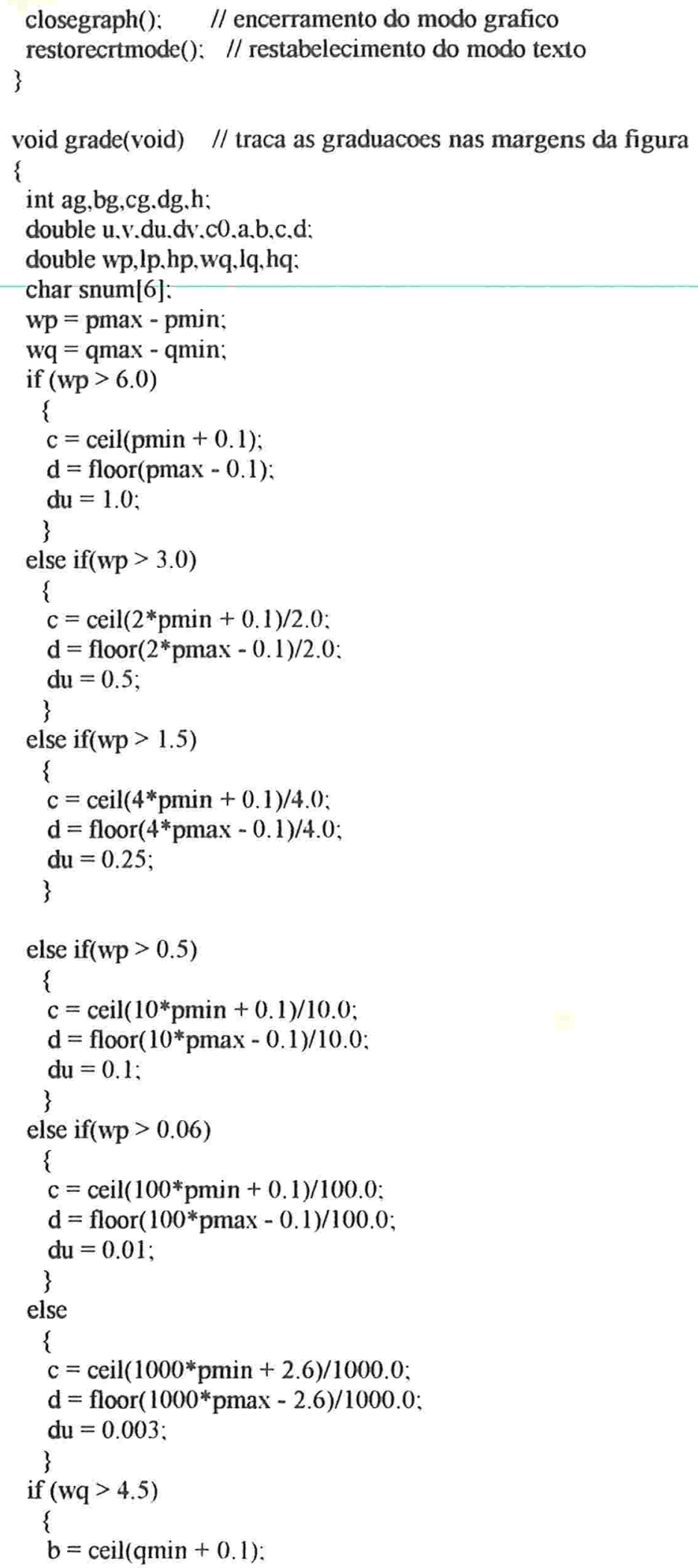




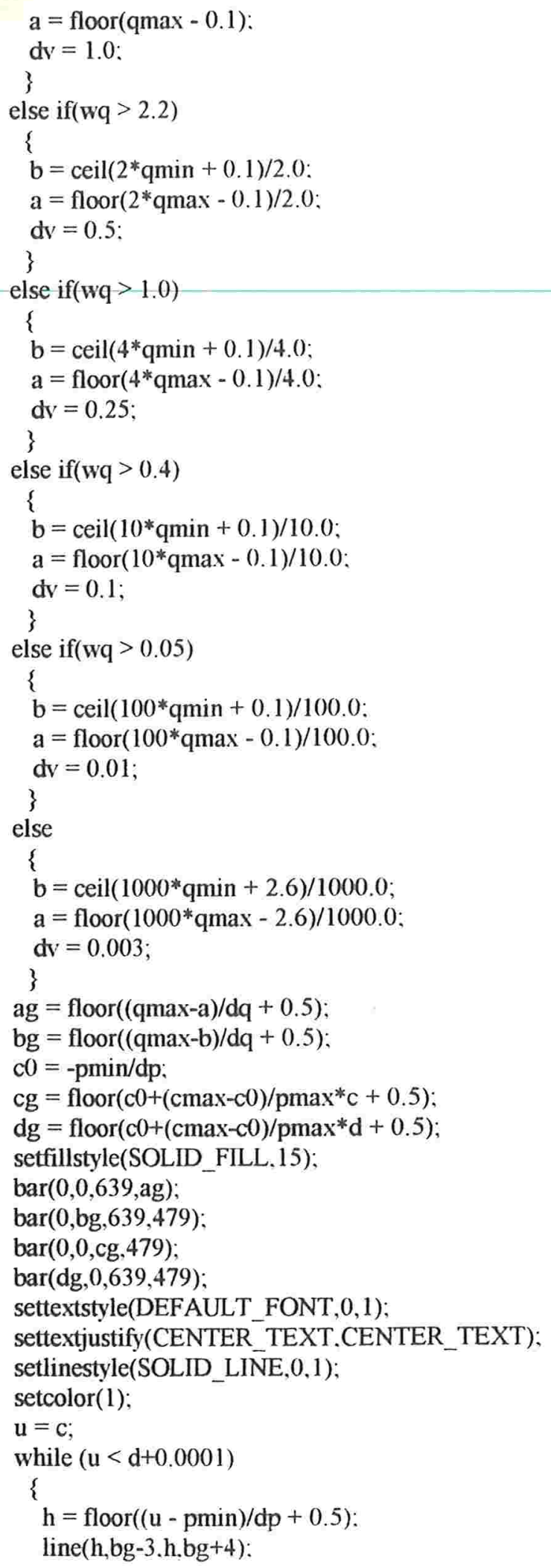




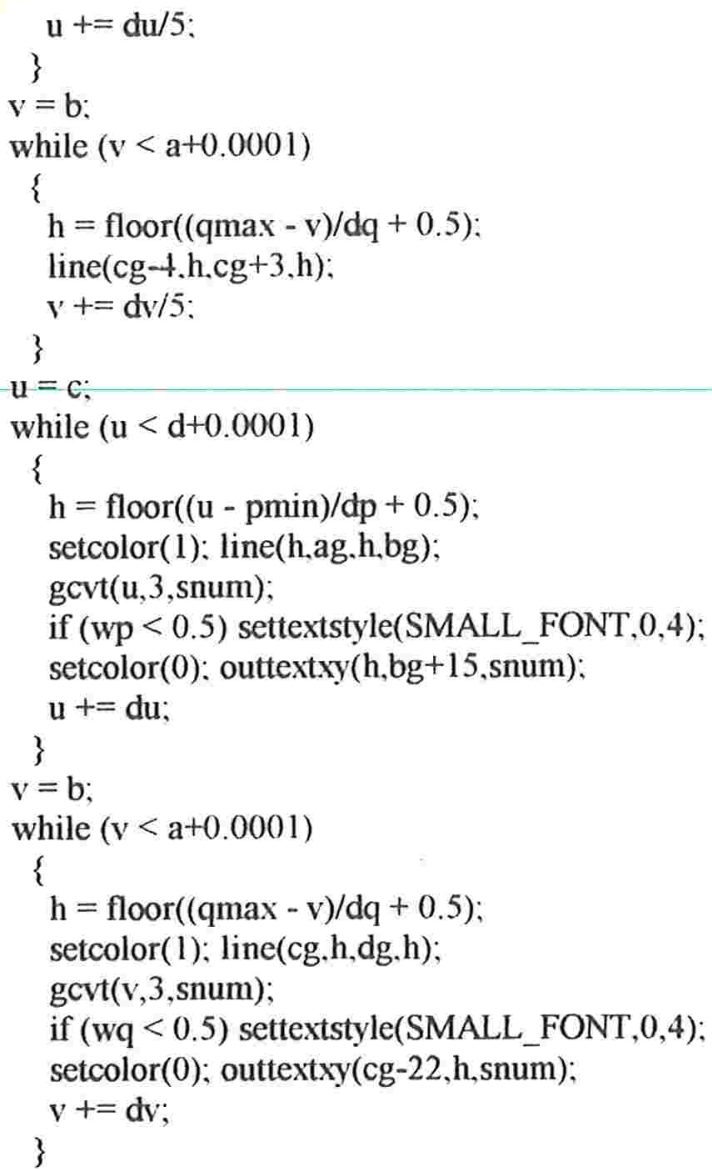




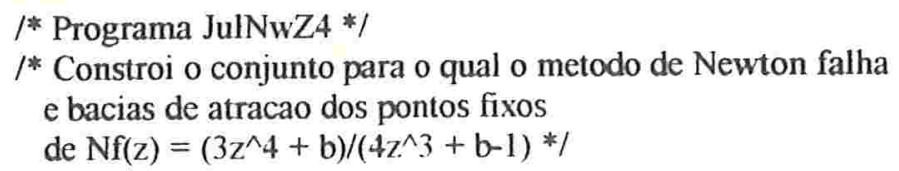


complex w2,w3,w4,w5,w6;

char ch:

$\operatorname{clrscr}()$;

printf("Conjunto de pontos para os quais o metodo de Newton falhaln"):

printf("Polinomio $\mathrm{p}(\mathrm{z})=\mathrm{z}^{\wedge} 4+(\mathrm{b}-1) \mathrm{z}-$ bln $\backslash n$ "):

printf("Valor do parametro b: $\ln \backslash n$ ");

printf(" Parte real: "); scanf("\%lf",\&p):

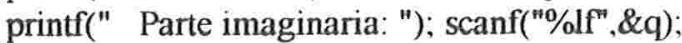

printf("In\n");

printf("Limites de variacao da variavel $z: \ln l n ")$;

printf(" Parte real: $\ln \backslash n ")$;

printf(" $\quad$ xmin = "); $\operatorname{scanf("\% lf",\& xmin);~}$

printf(" $\quad$ xmax = "); scanf("\%lf",\&xmax);

printf("'n");

printf(" Parte imaginaria: $\ln \backslash n$ "):

printf(" ymin = "); scanf("\%lf",\&ymin);

printf(" $\quad$ ymax = "); scanf("\%lf",\&ymax);

printf("Inln");

printf("Traca as bacias dos pontos fixos superatratores ? (s/n) "):

$\mathrm{ch}=\operatorname{getch}()$ :

$\mathrm{b}=$ complex $(\mathrm{p}, \mathrm{q})$;

$\mathrm{dx}=(\mathrm{xmax}-\mathrm{xmin}) / \mathrm{cmax}$;

$\mathrm{dy}=(\mathrm{ymax}-\mathrm{ymin}) / \mathrm{lmax}$;

initgraph(\&gdr,\&gmd, "D:IVBORIIBGI");

errcd = graphresult();

if (errcd != grOk)

\{

printf("Erro grafico: \%s\n",grapherrormsg(errcd));

printf("Tecle algo... $\ln \backslash n$ ");

getch():

exit(1);

\}

setfillstyle(SOLID_FILL, 15);

$\operatorname{bar}(0,0.639,479)$;

$\mathrm{w}=$ complex $(0,0) ; \quad$ // Verifica se a orbita da origem

$\mathrm{k}=0$; $\quad$ // converge para alguma raiz.

do // Inicio do enlace das iteracoes

\{

$\mathrm{Z}=\mathrm{W}$;

$\mathrm{z} 2=\mathrm{z}^{*} \mathrm{z} ; \mathrm{z} 3=\mathrm{z} 2 * \mathrm{z} ; \mathrm{z} 4=\mathrm{z} 2 * \mathrm{z} 2$

$\mathrm{fz}=\mathrm{z} 4+(\mathrm{b}-1) * \mathrm{z}-\mathrm{b}$;

$\mathrm{flz}=4 * \mathrm{z} 3+\mathrm{b}-1$

if $(\operatorname{abs}(\mathrm{flz})<1 \mathrm{E}-20)$ break:

$\mathrm{w}=\mathrm{z}-\mathrm{fz} / \mathrm{fl} \mathrm{z}$;

$\mathrm{k}++$;

\}

while $((\mathrm{k}<\mathrm{nmax}) \& \&(\operatorname{abs}(\mathrm{w}-\mathrm{z})>$ delta $))$;

if $((\operatorname{abs}(w-z)<$ delta) \&\& (toupper $(\mathrm{ch}) !=$ 'S')) $\mathrm{cmax}=10$ :

// Traca bacias: de nao convergencia e/ou dos pontos fixos

for $(\mathrm{col}=0$ ) $\mathrm{col}<=\mathrm{cmax}$; $+\mathrm{col}) \quad / /$ processamento das colunas

\{ 


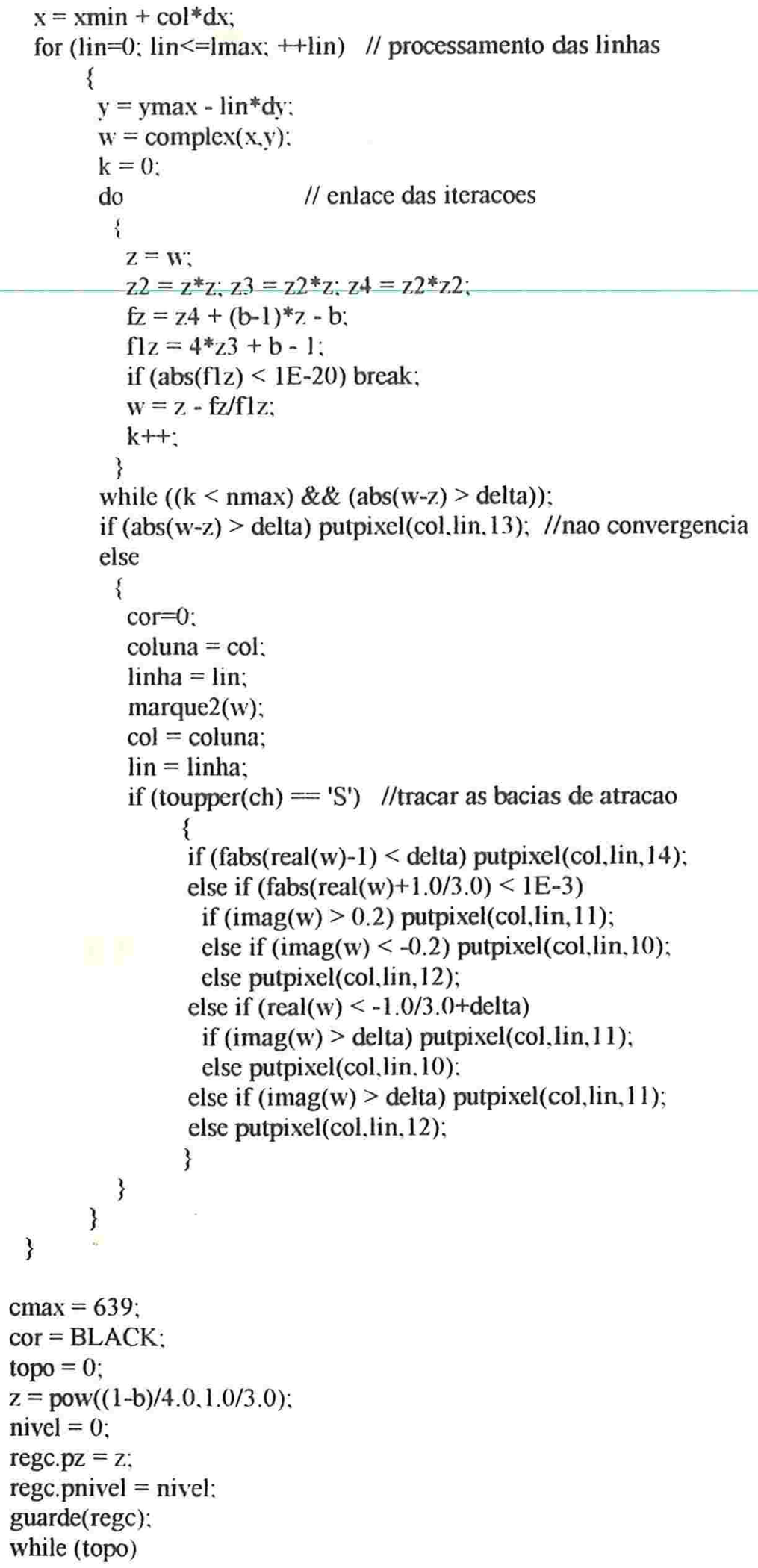




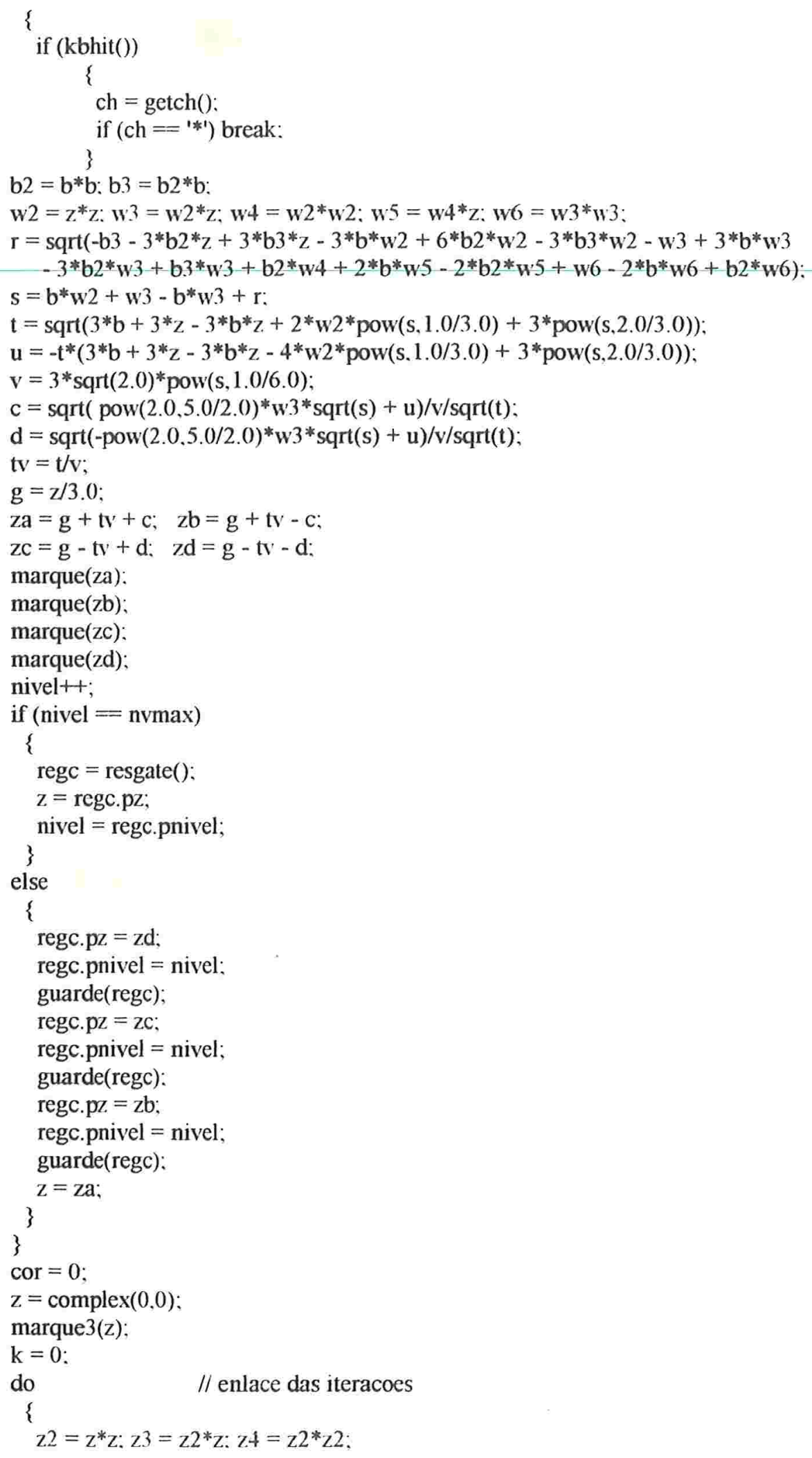




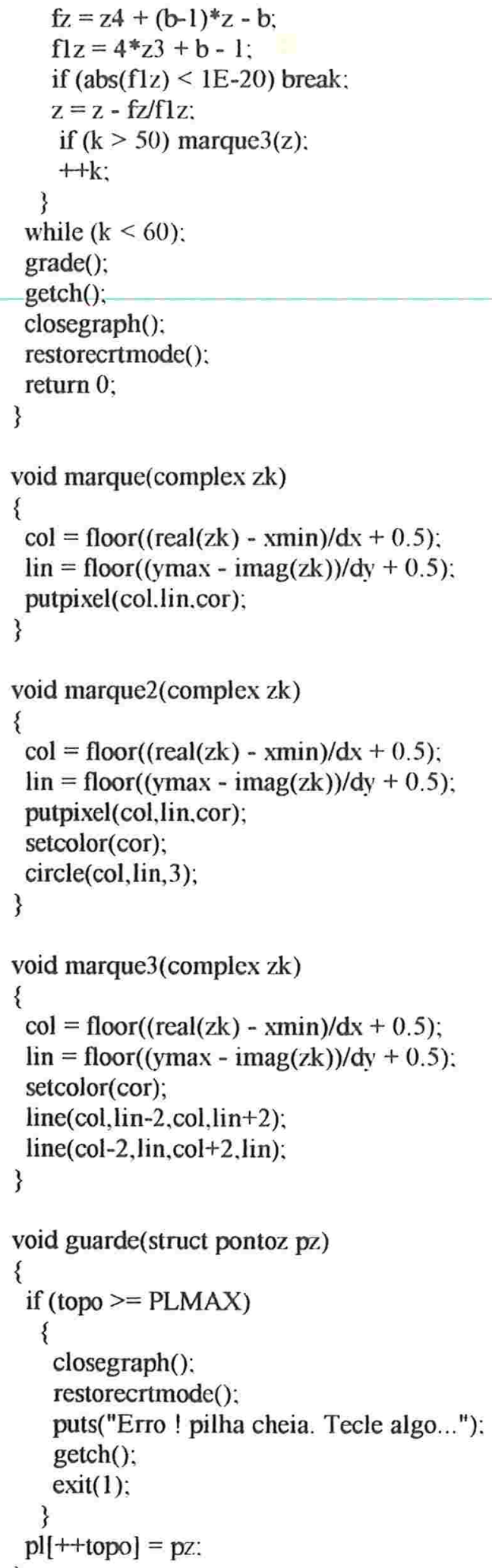




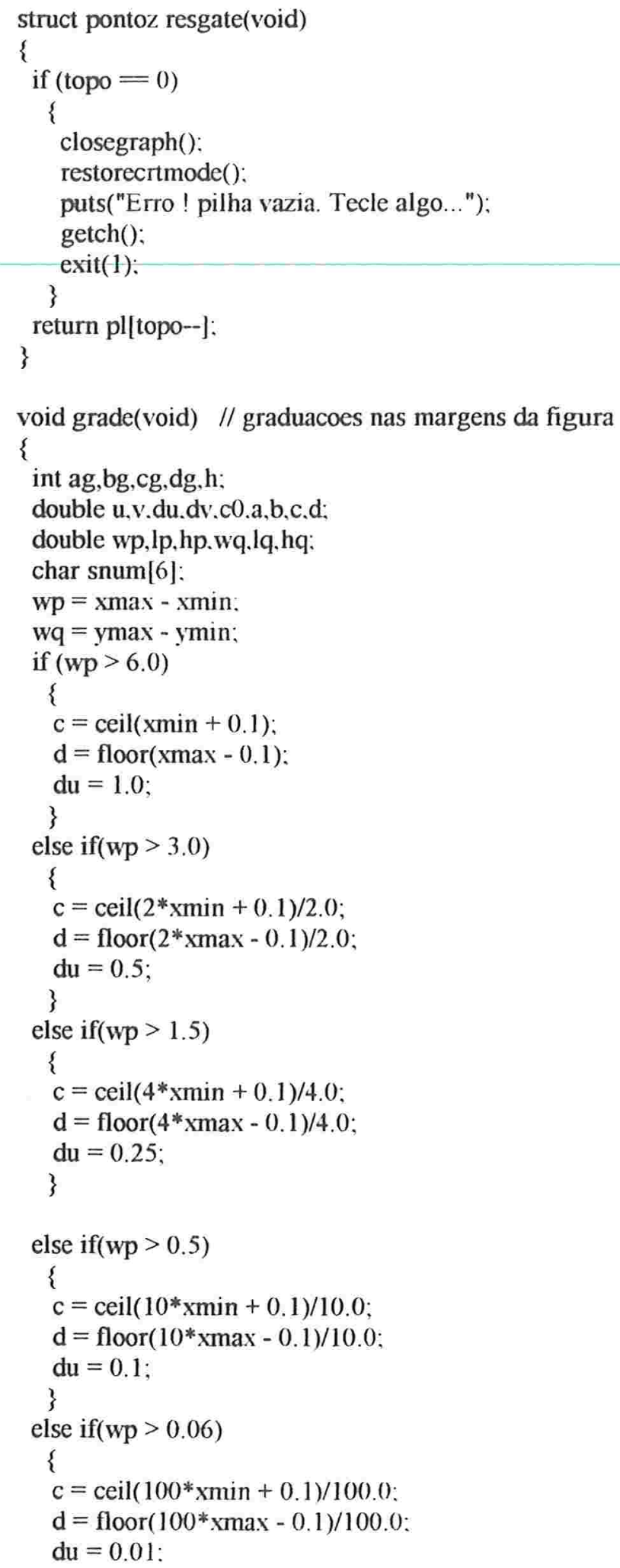




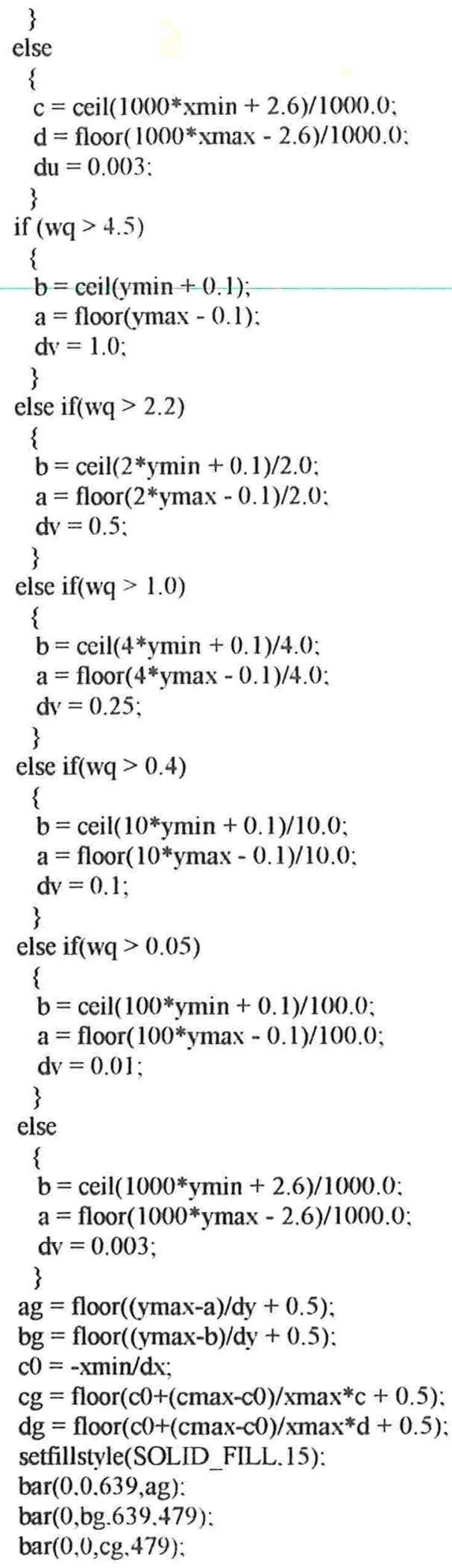




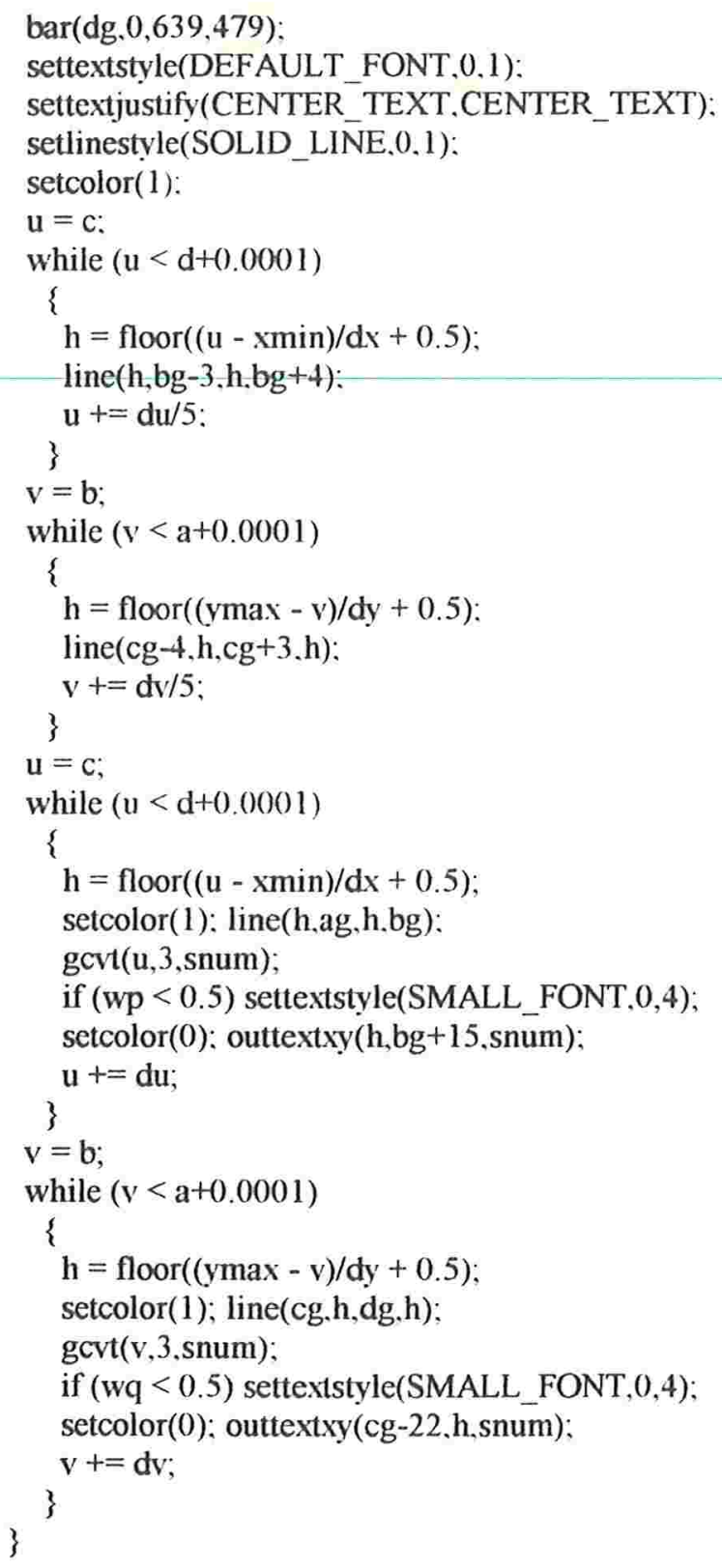




\section{Relação do material ilustrativo}

\section{Relação de figuras}

Número Figura Pág.

1 Órbitas parciais da transformação $z \mapsto z\left(1+z^{3}\right) \quad 19$

2 Algoritmo do traçado do conjunto de Julia de uma transformação $R \quad 28$

3 Direções para o caso em que existem três ciclos indiferentes e $\ell=1 \quad 32$

4 Morfologia no plano do parâmetro $a \quad 46$

$5 \quad$ Ampliação da "ilha" na parte superior da figura 2

6 Ampliacão de outra "ilha" da figura $2 \quad 48$

7 Uma das regiões onde o método de Newton exibe comportamento 49 periódico

8 Outra das regiões onde o método de Newton exibe comportamento 50 periódico

$9 \quad$ Conjunto de Julia de $N_{p_{a}}$, para $a=1.75 \mathrm{i}$

10 Valores iniciais para os quais o método de Newton falha para $p_{a}, \quad 56$ $\operatorname{com} a=0.3+1.65 \mathrm{i}$

11 Bacias de convergência e valores iniciais para os quais o método de 58 Newton falha, para o polinômio $p_{a}$, com $a=0.27+1.65 \mathrm{i}$ 
12 Bacias de convergência e valores iniciais para os quais o método de Newton falha, para o polinômio $p_{a}$, com $a=1.02+0.96 \mathrm{i}$

13 Bacias de convergência e valores iniciais para os quais o método de 60 Newton falha, para o polinômio $p_{a}, \operatorname{com} a=1.0324+0.9688 \mathrm{i}$

14 Morfologia no plano do parâmetro $b$

15 Ampliação da "ilha" na parte superior da figura 12

16 Conjunto de Julia de $N_{p_{b}}$, para $b=-0.2+2.6 \mathrm{i}$

17 Bacias de convergência e valores iniciais para os quais o método de 69 Newton falha, para o polinômio $p_{b}, \operatorname{com} b=0.27+1.65 \mathrm{i}$

\section{Relação de tabelas}

\section{Número Conteúdo}

1 Parâmetro a e ciclo evidenciado pela órbita da origem pela transformação $N_{p_{a}}$

2 Parâmetro $b$ e ciclo evidenciado pela órbita da origem pela transformação $N_{p_{b}}$ 


\section{Bibliografia}

[1] L. V. Ahlfors, Complex Analysis, Mc Graw Hill, (1979).

[2] A. F. Beardon, Iteration of rational functions, Graduate Texts in Mathematics, vol. 132, Springer Verlag, (1991).

[3] P. Blanchard, Complex Analytic dynamics on the Riemann sphere, Bull. AMS, 11, 85-141, (1984).

[4] J. H. Curry, L. Garnett, D. Sullivan, On the iteration of a rational functions: Computer experiments with Newton's Method, Comm. Math. Phys., 91, 267-277, (1983).

[5] J. H. Curry, C. E.Wayne, On the nonpathelogical behavior of Newton's Method, Cont. Math., 28, 407 - 417, (1984).

[6] R. L. Devaney, An Introduction to Chaotic Dynamical Systems, Addison Wesley, (1986).

[7] H. M. Farkas, I. Kra, Riemann Surfaces, Graduate Texts in Mathematics, vol 71, Springer Verlag, (1980).

[8] E. Hille, Analytic Function Theory, Ginn and Company,vol. 2, (1962).

[9] G. A. Jones, D. Singermann, Complex functions: An algebraic and geometric view point, Cambridge University Press, (1987).

[10] J. Milnor, Dynamics in one complex variables: Introductory lectures, Preprint SUNY Stony Brook, Institute for Mathematical Sciences, (1990). 